Kansas State University Libraries

New Prairie Press

Academic Chairpersons Conference

34th Academic Chairpersons Conference, New

Proceedings

\title{
Change Leadership in Higher Education
}

Jeff Buller

Florida Atlantic University, jeffbuller@mac.com

Follow this and additional works at: https://newprairiepress.org/accp

Part of the Educational Leadership Commons, and the Higher Education Administration Commons

(c) $(1) \Theta \Theta$

This work is licensed under a Creative Commons Attribution-Noncommercial-No Derivative Works 3.0 License.

\section{Recommended Citation}

Buller, Jeff (2017). "Change Leadership in Higher Education," Academic Chairpersons Conference Proceedings. https://newprairiepress.org/accp/2017/Trends/13

This Event is brought to you for free and open access by the Conferences at New Prairie Press. It has been accepted for inclusion in Academic Chairpersons Conference Proceedings by an authorized administrator of New Prairie Press. For more information, please contact cads@k-state.edu. 


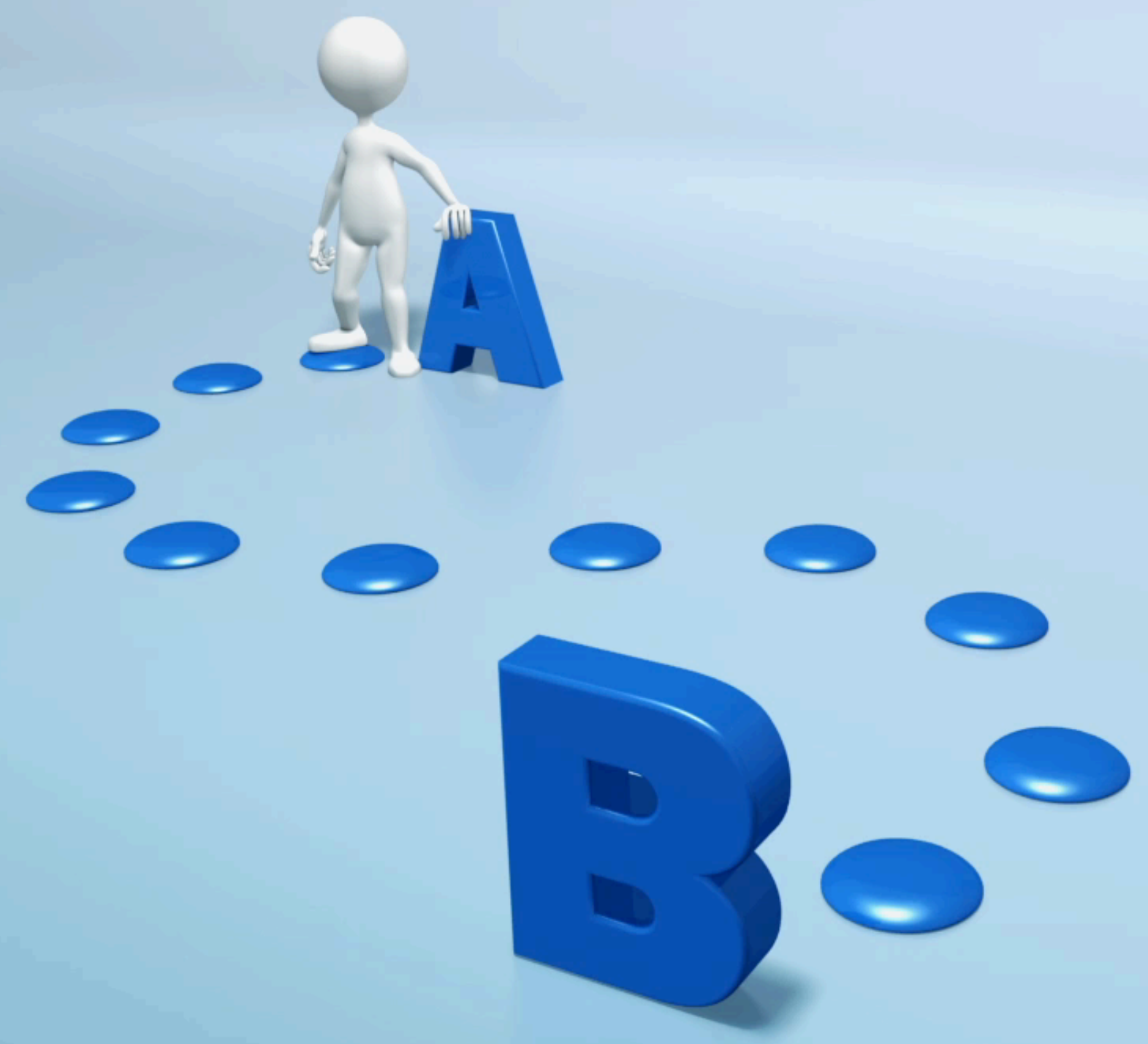

Change Leadership in Higher Education A Workshop for Academic Leaders 


\section{Our Goals for This Workshop}

- To better understand what change really is and why it can be so difficult

- To understand the impediments that often prevent us from meeting our change goals

- To develop more successful strategies for pursuing change ... even those changes that are imposed on us 


\section{Exercise \#1}

- In order to make our discussion as

practical and realistic as possible,

let's think of some changes that

affect you personally.

- Turn to Exercise \#1 in your

workbook, and identify three current

or prospective changes:

1. A change that you'd like to occur in your area.

2. A change that you're being forced to make in your area or at your institution whether you like it or not.

3. A change that you'd like to make in your personal life but that you're finding difficult to make. 


\section{Exercise \#1}

We'll take two minutes for this exercise. 


\section{Exercise \#1}

- Now keep those changes in mind as we explore what works and what doesn't work in terms of change leadership.

- We'll refer to them several times

during this workshop.

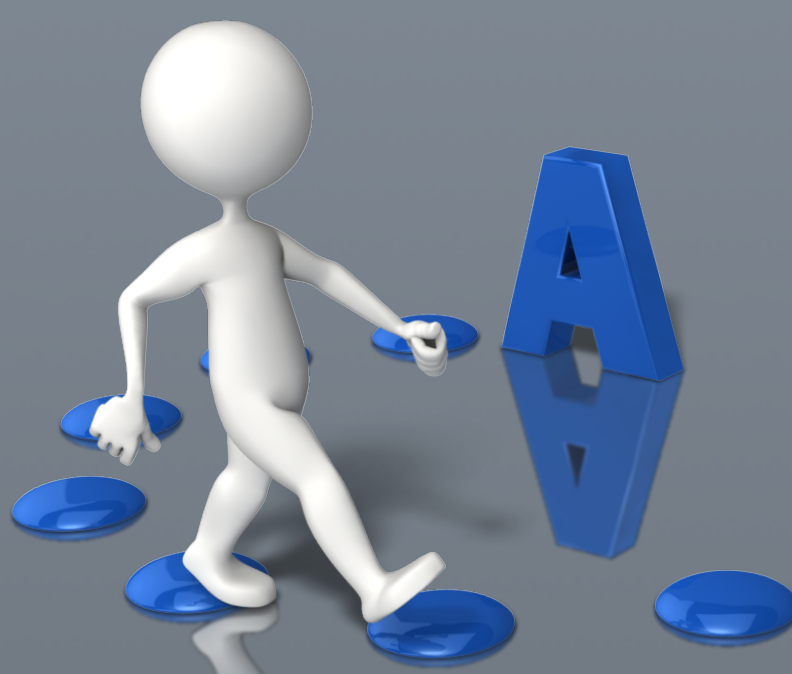




\section{Major Sources}

\section{SWITCH a}

HOW TO CHANGE THINGS

WHEN CHANGE IS HARD

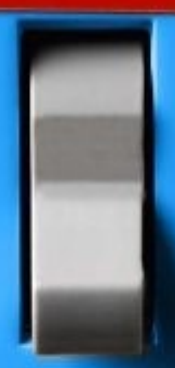

CHIP HEATH \& DAN HEATH THE BESTSELLING AUTHORS OP MADE TO STICK
JEFFREY L. BULLER

Change Leadership in HIGHER EDUCATION

A Practical Guide to Academic Transformation

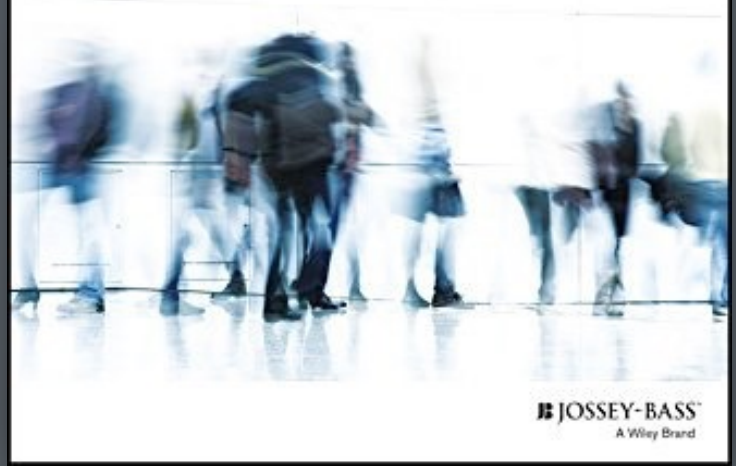

Rethinking Positive Thinking INSIDE THE NEW SCIENCE OF MOTIVATION

$$
\text { OO }
$$

Gabriele Oettingen 


\section{The Paradox}

- We work in a field in which we constantly develop new ideas, solutions, and practices within our own fields. Basically we're in the progress business.

- But we and our colleagues often find it hard to change our own ideas, solutions, and practices within our own fields. Basically we're in the progress-resistance business.

THE

SLUE BUTTON

IS TRUE
THE ED BUTTON IS FALSE 


\section{So, Why Is Change So Hard?}

Change in higher education is particularly hard (and frequently unsuccessful) because:

- PSYCHOLOGY: We try to implement change without understanding people's mindset about change.

- SOCIOLOGY: We try to import mechanisms for change that don't fit our organizational culture.

- PHILOSOPHY: We try to change things for the wrong reasons.

If we want to lead effectively for change, we need to explore three factors individually. 


$$
\begin{gathered}
\text { The Psychology of } \\
\text { Change }
\end{gathered}
$$

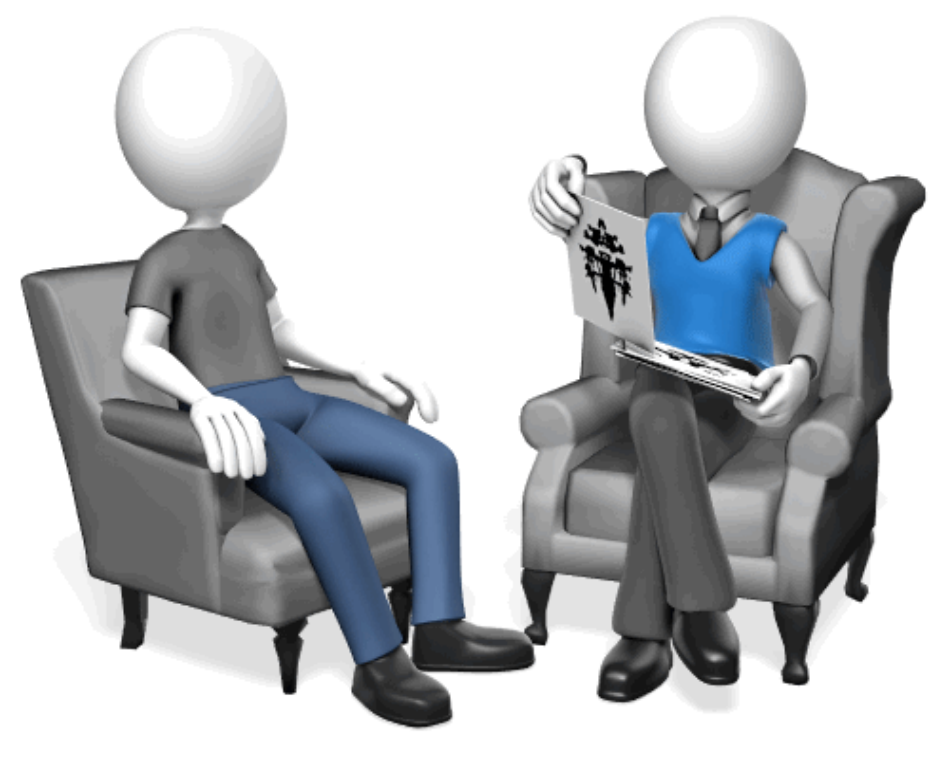




\section{The Meaning of Change}

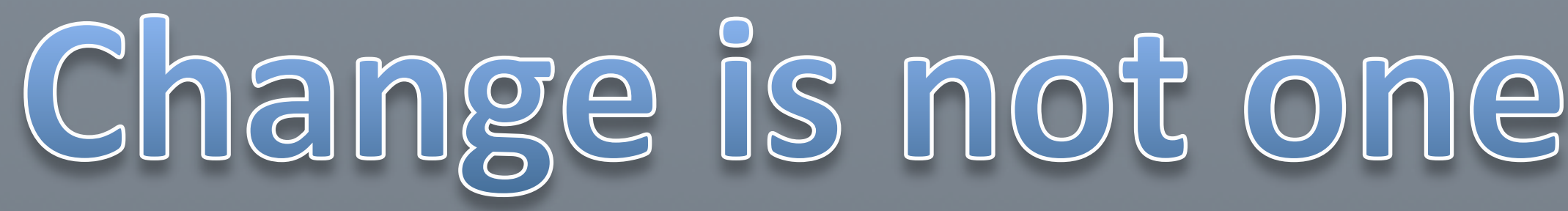

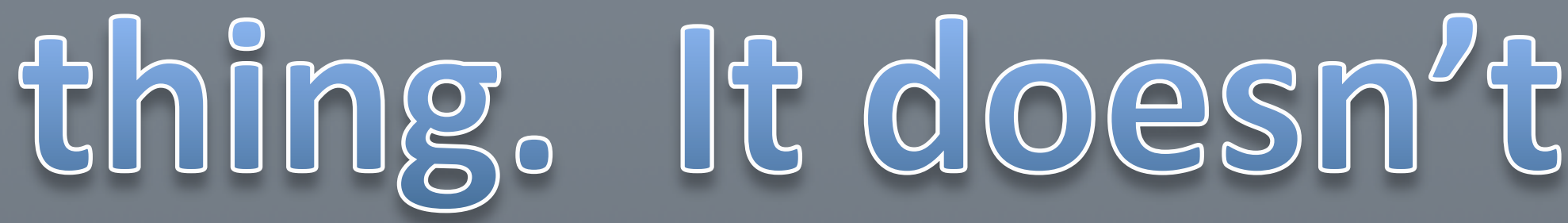

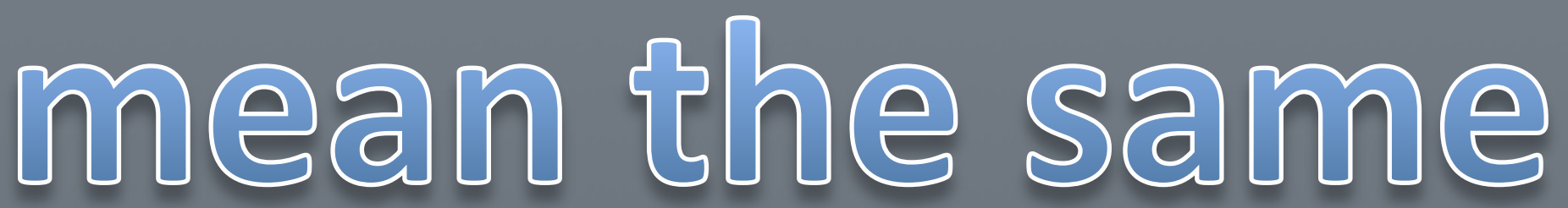

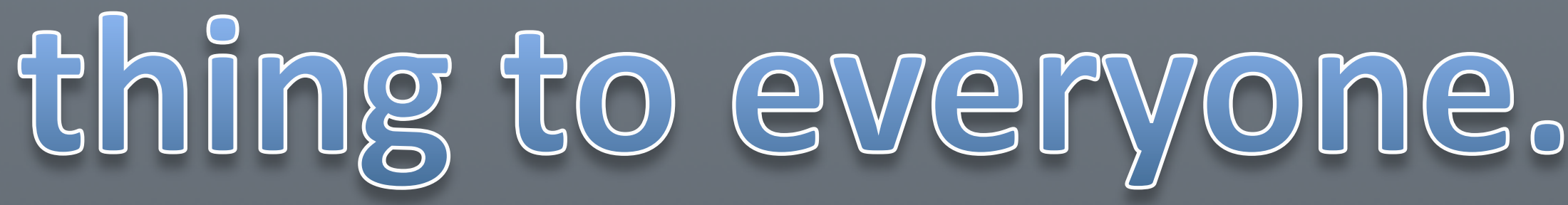




\section{The Meaning of Change}

\section{Why?}
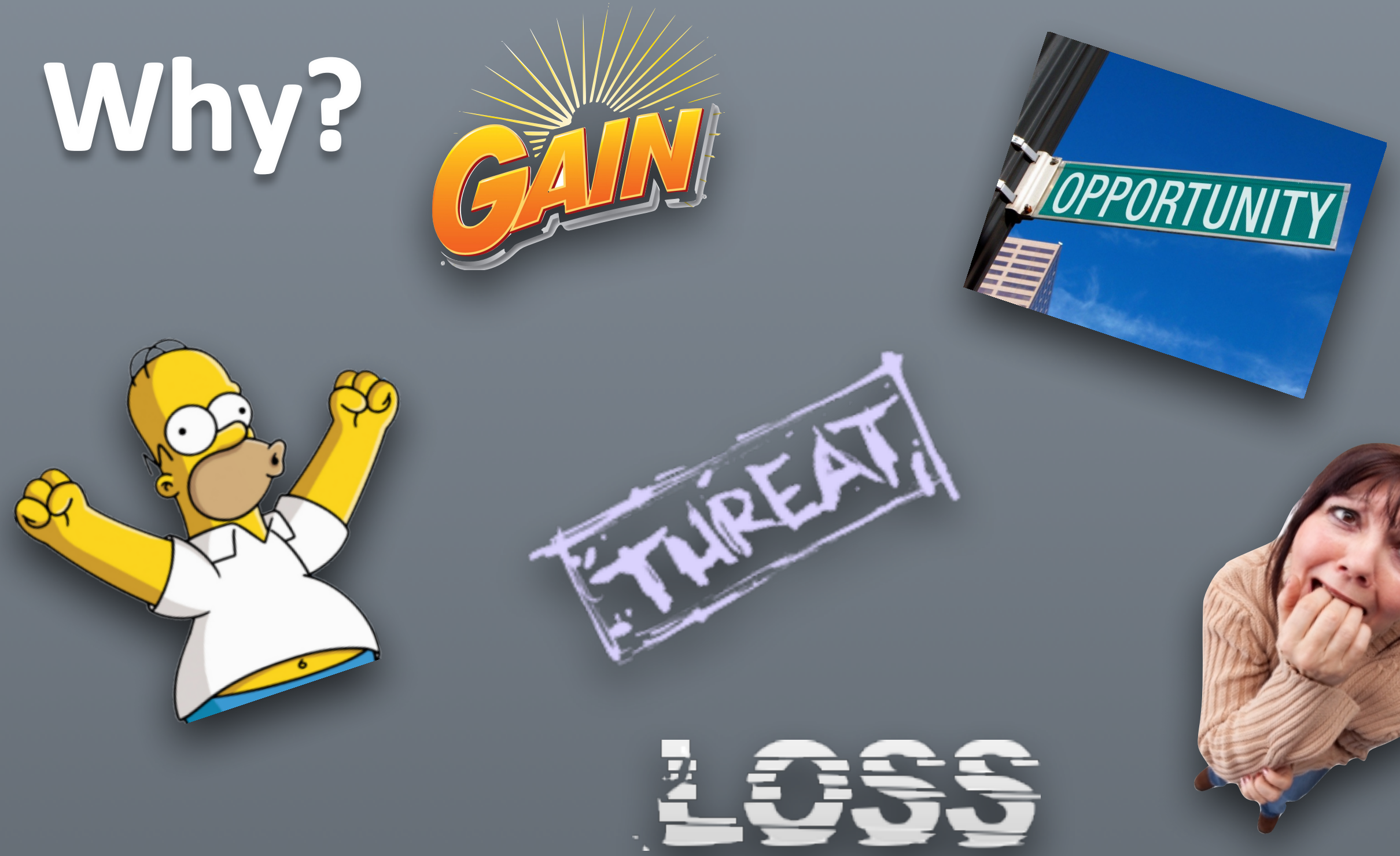
There Are Many Meanings of "Change"

We'll examine three very common meanings:

- replacement

improvement

the change journey

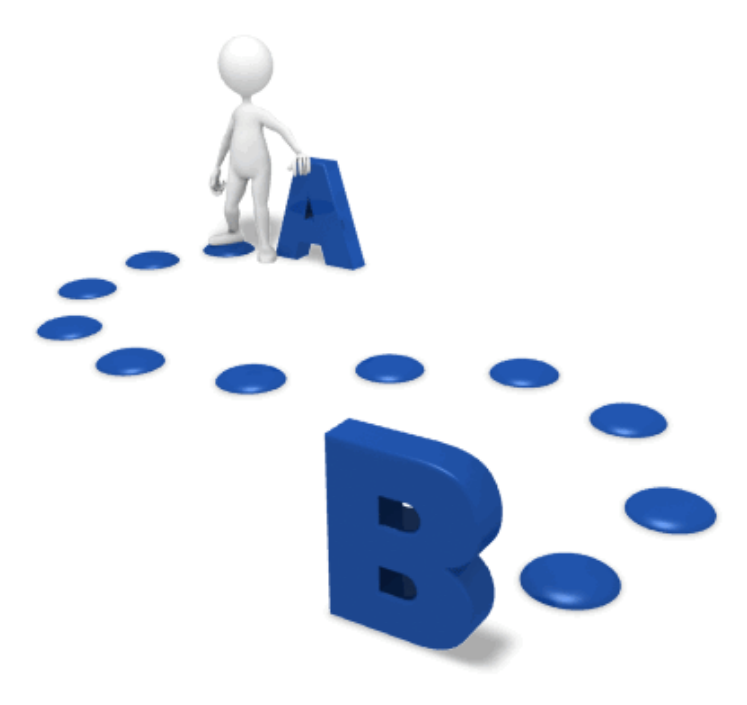




\section{The Replacement View of Change}

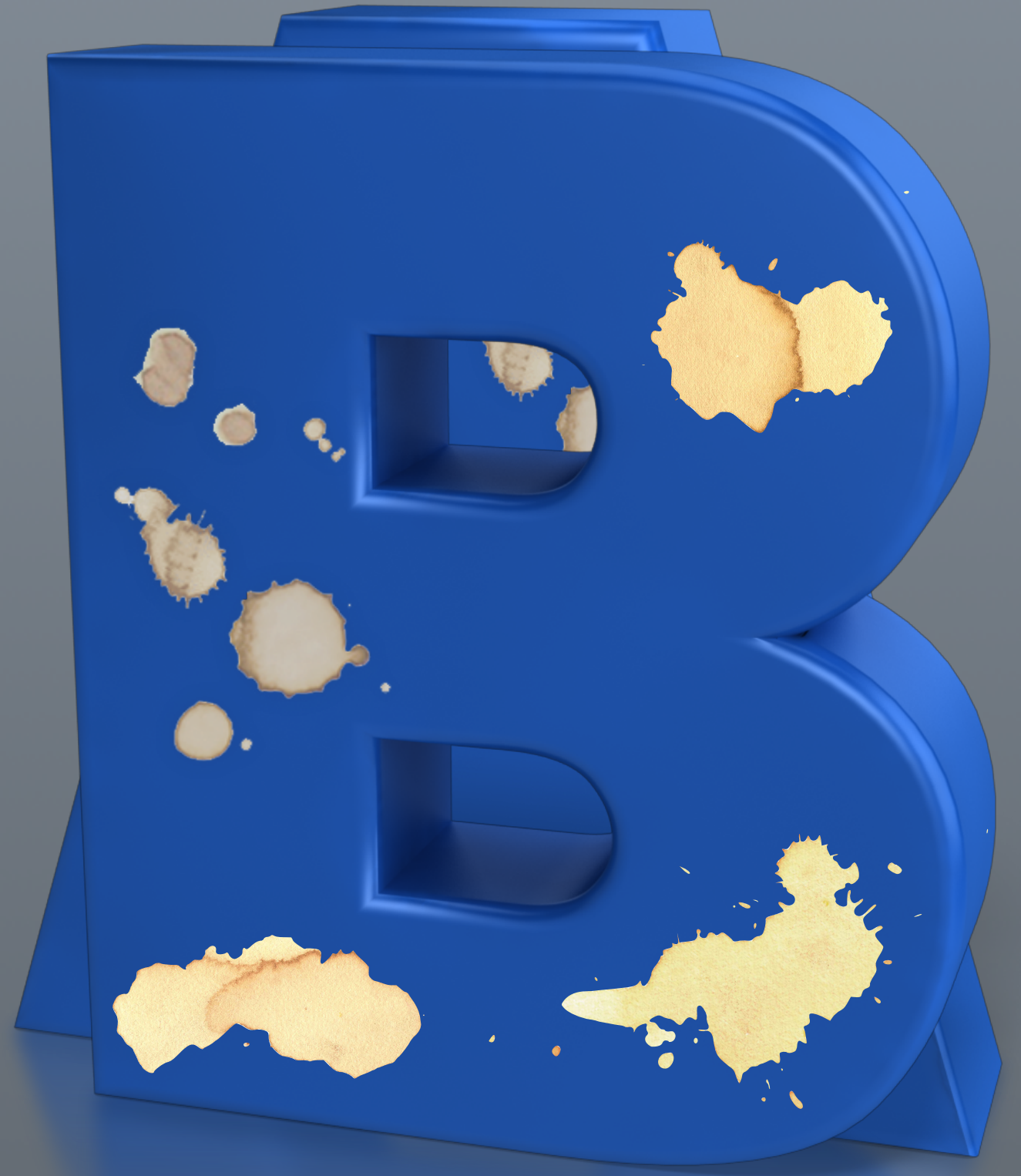

IOSS 


\section{The Improvement View of Change}

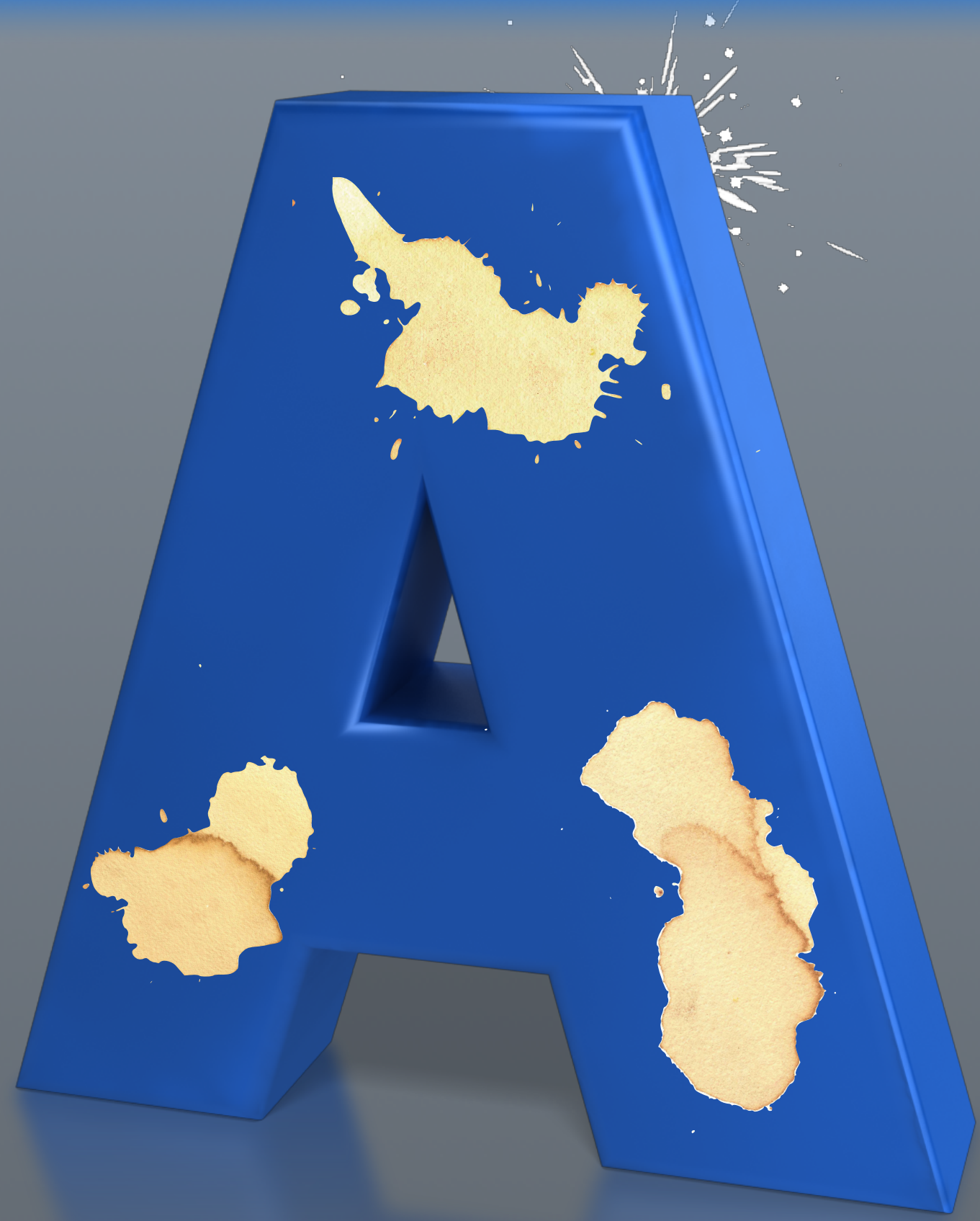




\section{The Impact of These Views}

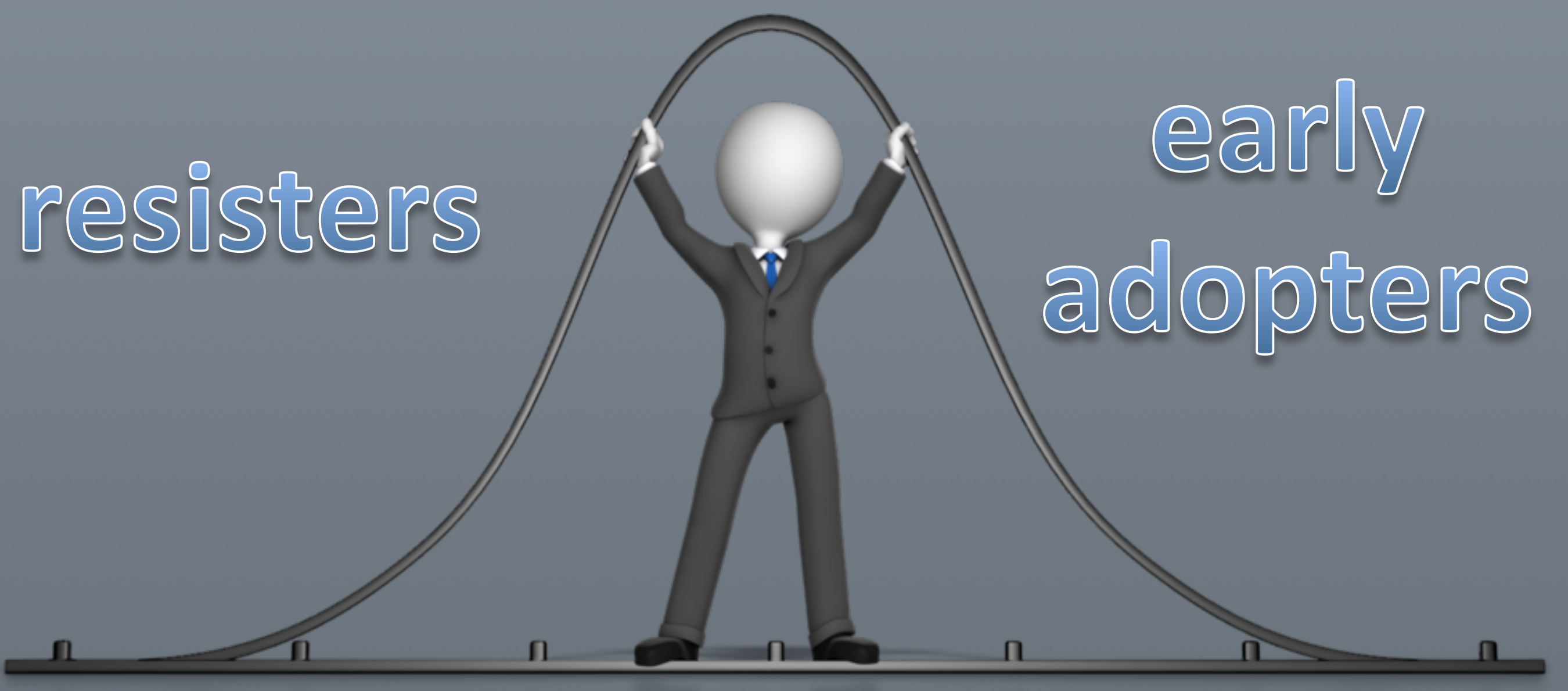

replacement

journey improvement

What kind of journey? 


\section{The Heath Model}

How @@ we

[e@@ nost

efifectively,

given the

psychology of

$$
\text { change? }
$$

\section{SWITCH d.}

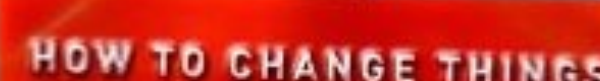

HOW TO CHANGE THINGS

WHEN CHANGE IS HARD

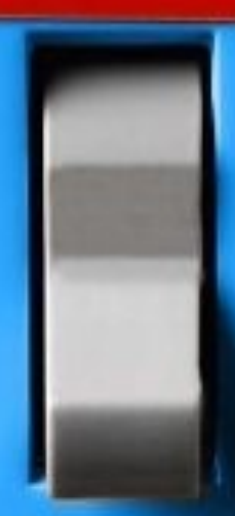

CHIP HEATH \& DAN HEATH THE Bestseling AUTHORS or MADE TO STICK 


\section{The Heath Model}

Three components of the psychology of change

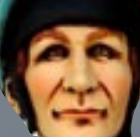

The Rider

our rational,

intellectual side

iii)

4.9

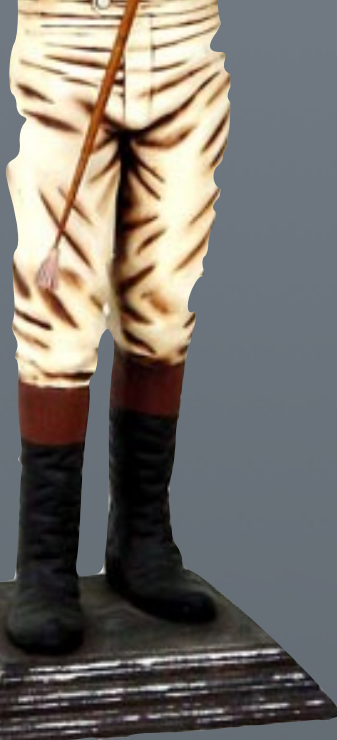
change may be necessary."

\section{SWITCH} (1)

\section{HOW TO CHANGE THINGS}

WHEN CHANGE IS HARD

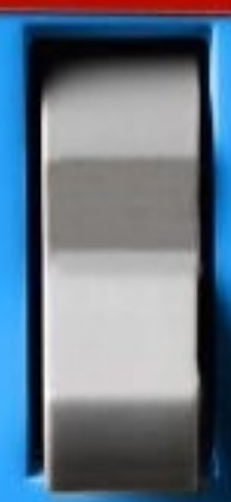

CHIP HEATH \& DAN HEATH 


\section{The Heath Model}

Three components of the psychology of change

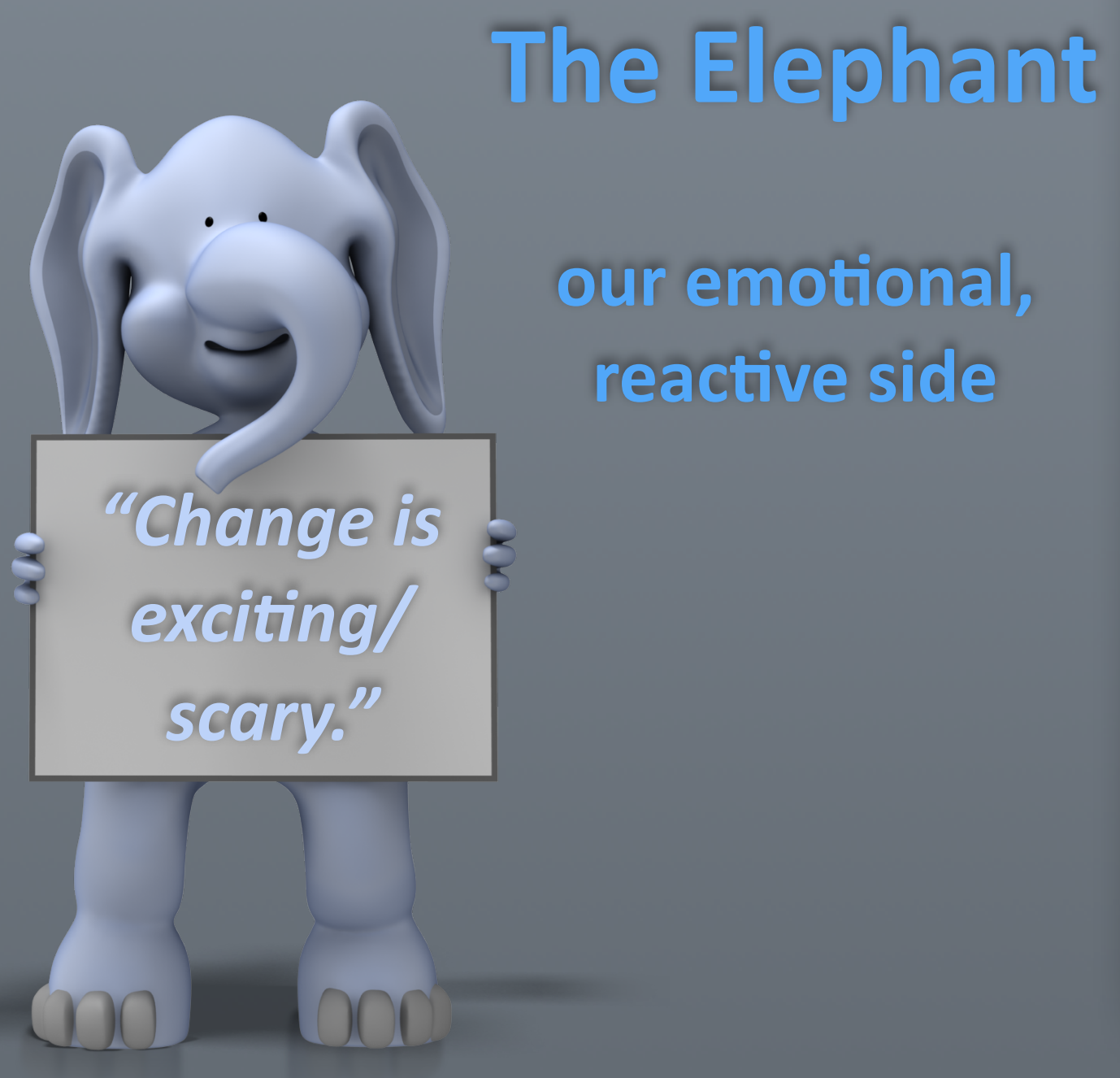

\section{SWITCH (1)}

HOW TO CHANGE THINGS

WHEN CHANGE IS HARD

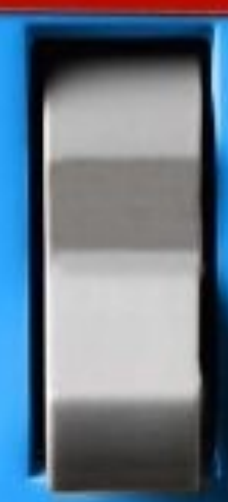

CHIP HEATH \& DAN HEATH THE BESTSELLING AUTHORS OF MADE TO STICK 


\section{The Heath Model}

Three components of the psychology of change

"I think

we're headed this

\section{The Path} way."

our perception of

where we're going

\section{SWITCH} (1)

HOW TO CHANGE THINGS

WHEN CHANGE IS HARD

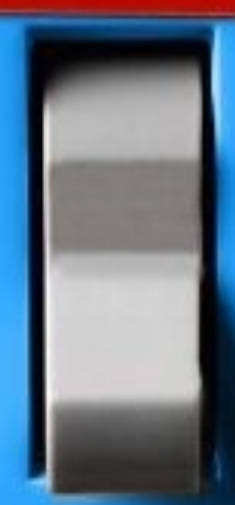

CHIP HEATH \& DAN HEATH THE BEsTSELLING AUTHORS Or MADE TO STICK 


\section{The Heath Model}

\section{Engaging the Rider}

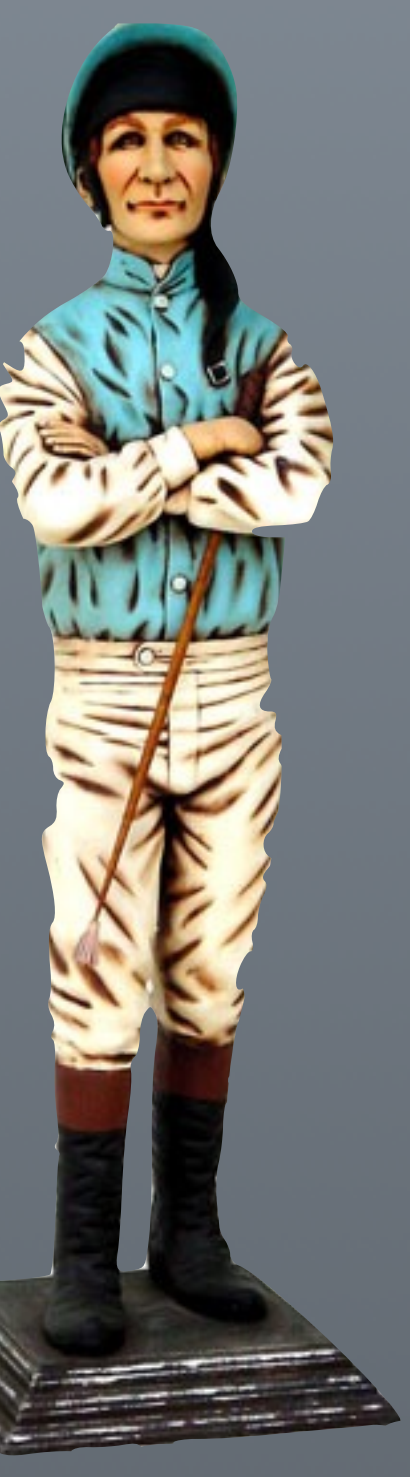

1. Follow the bright spots

$\checkmark$ Appreciative Inquiry

$\checkmark$ What's working well?

$\checkmark$ Use that as a model

$\checkmark$ Do more of it

2. Script the critical moves

$\checkmark$ Resist urge to overthink

$\checkmark$ Set specific, achievable goals

$\checkmark$ Note progress

3. Point to the destination

$\checkmark$ Place specific goals within long-term context

$\checkmark$ Keep eyes on the prize

$\checkmark$ Explain the benefits 


\section{The Heath Model}

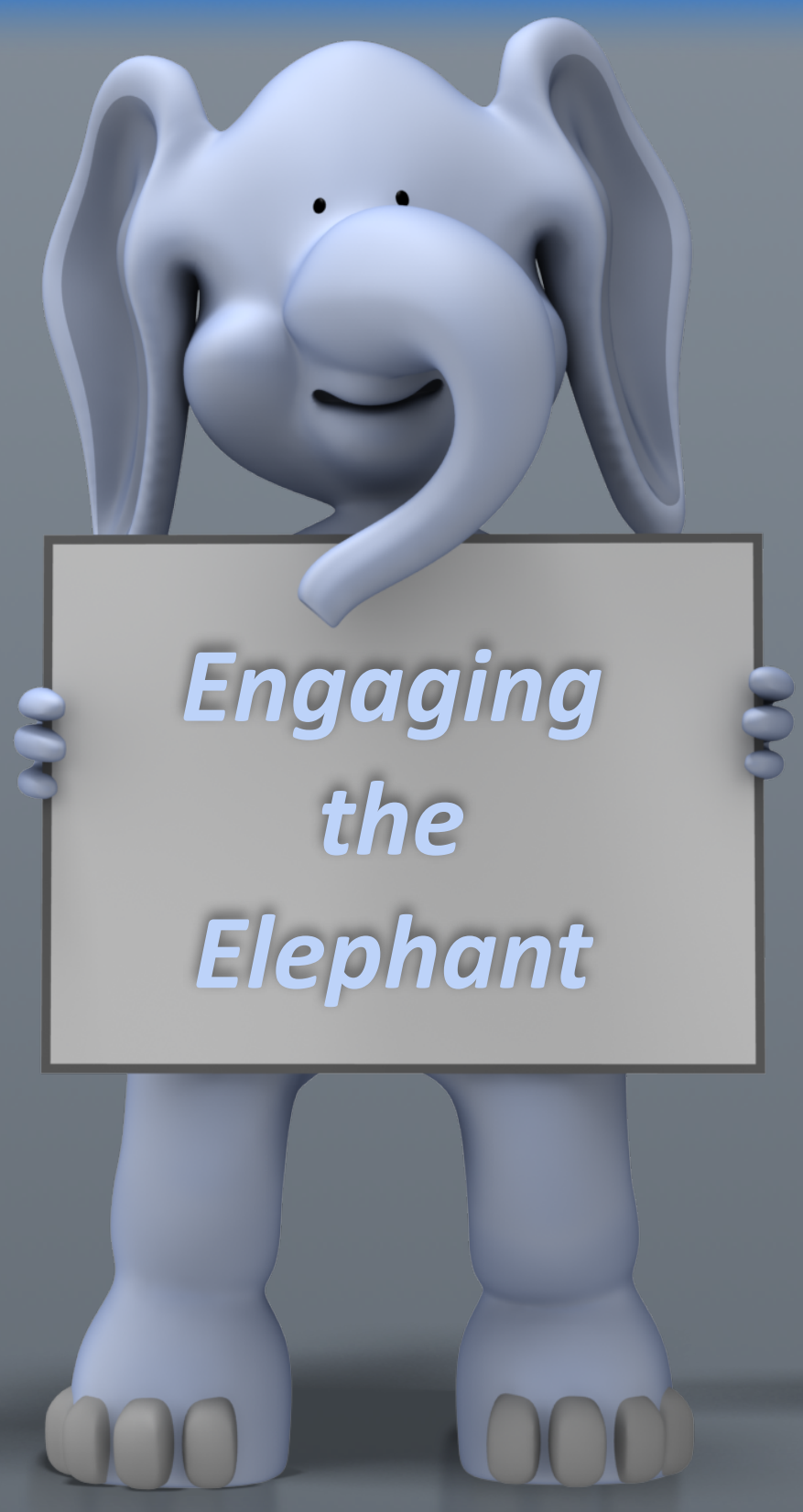

1. Find the feeling: What is the dominant emotion?

2. Shrink the change: How can the change look less imposing, more manageable?

3. Appeal to identity: How does the change relate to who we are, our core values?

4. Grow your people: How can our community become more creative, entrepreneurial, inventive? 


\section{Exercise \#2}

Unspiraling a death spiral.

- In this hypothetical case study,

you're asked to advise a colleague about how to pursue a change that's resisted even by those whom the change would help.

- Use the Heath Brothers Model to advise your colleague.

- Discuss this case in small groups for ten minutes.

- Then we'll see what ideas you have. 


\section{Exercise \#2}

We'll take ten minutes for this exercise.

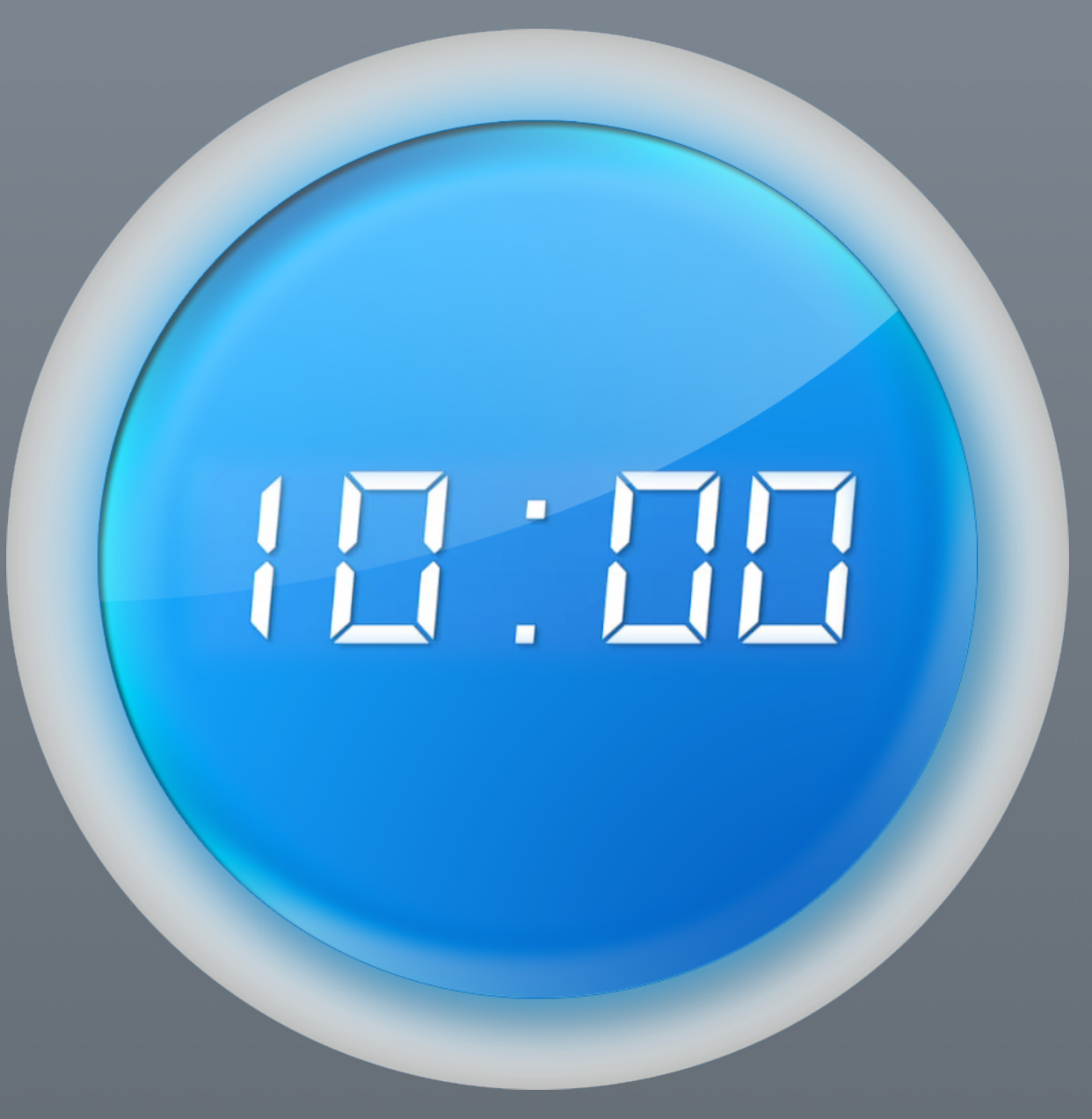




\section{Exercise \#2}

- Unspiraling a death spiral.

- In this hypothetical case study,

you're asked to advise a colleague about how to pursue a change that's resisted even by those whom the change would help.

- Use the Heath Brothers Model to advise your colleague.

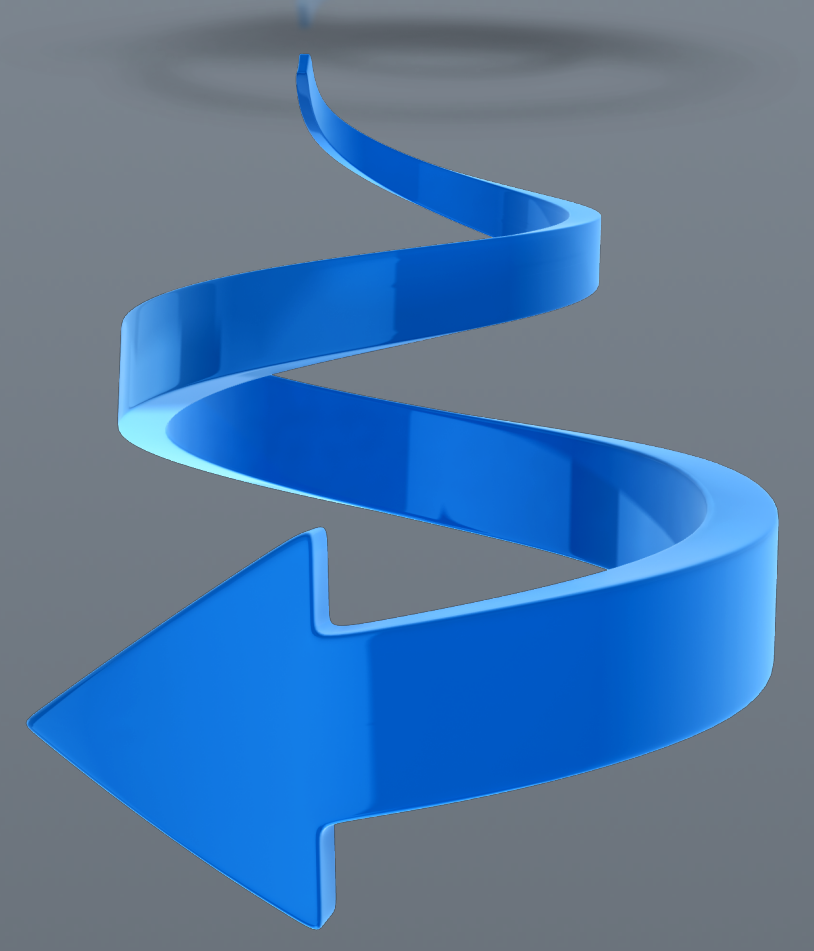

What ideas did you have? 


\section{Exercise \#3}

- Now let's make these insights practical for you by examining the important changes that you identified earlier.

(1) You've got questions about the rider, elephant, and path involved in each of your changes.

- Spend ten minutes answering these questions.

- If you finish early, talk with others about how easy or difficult you found this process. 


\section{Exercise \#3}

We'll take ten minutes for this exercise.

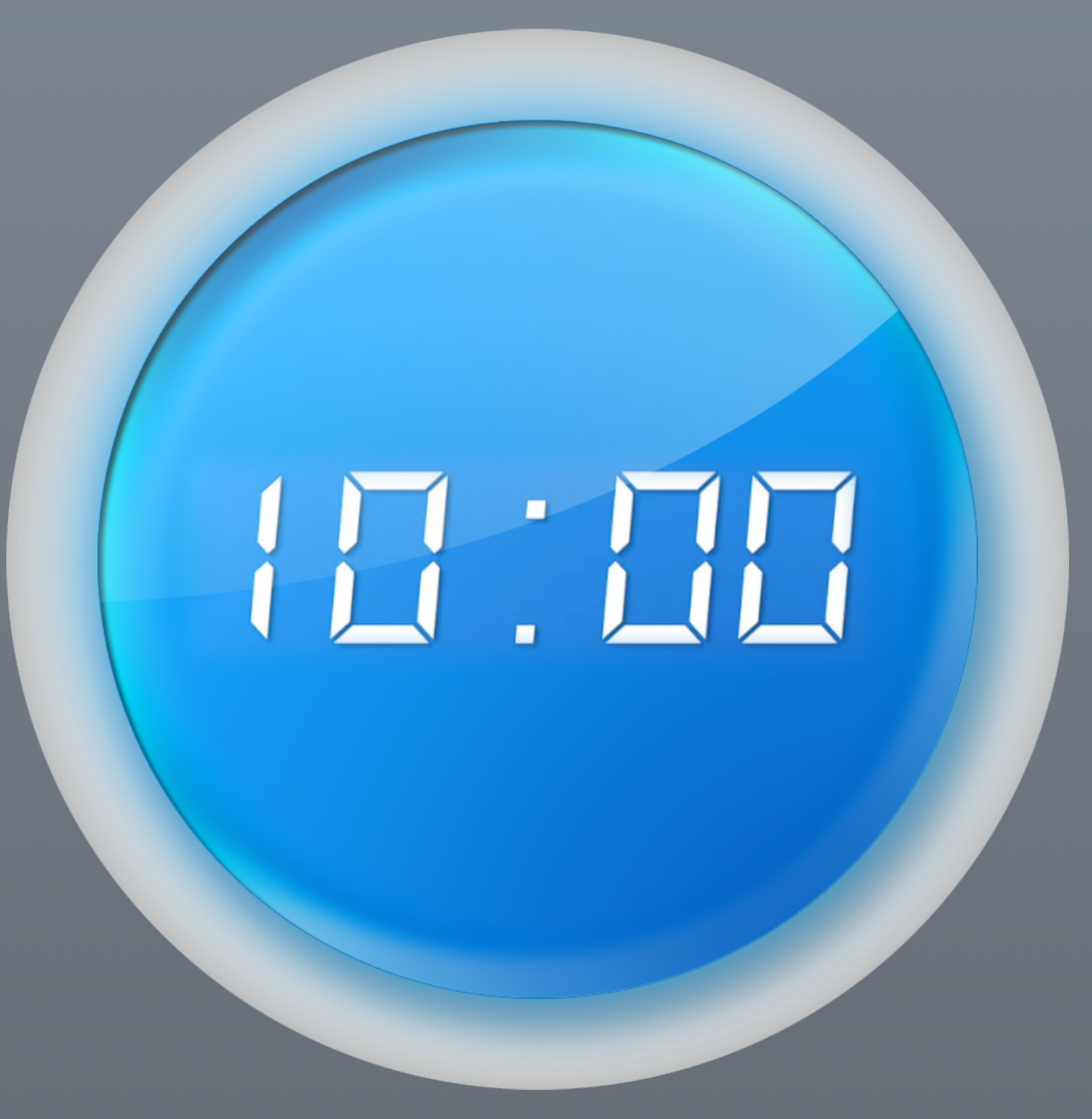




\section{Exercise \#3}

- How easy or difficult did you find this process?

- For any of your changes do you have clearer sense of what to do next?

What are the challenges that you're still facing with respect to these changes? 


$$
\begin{gathered}
\text { The Sociology of } \\
\text { Change }
\end{gathered}
$$

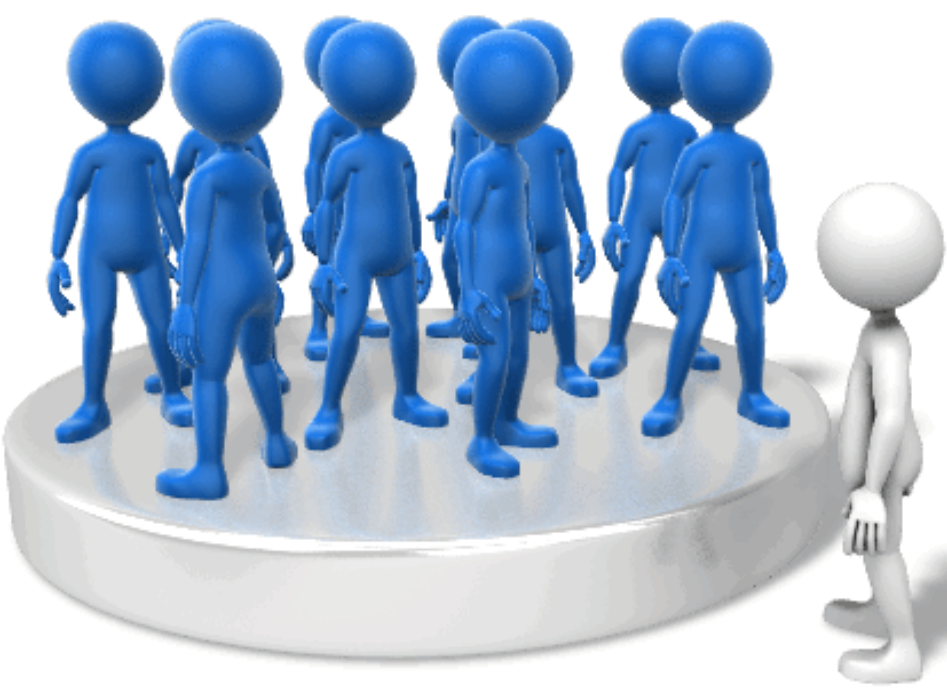




\section{The Sociology of Change}

Change @oesñ iccur within a vacuum. lit @LWays occurs wirhin a systen. 


\section{The Sociology of Change}

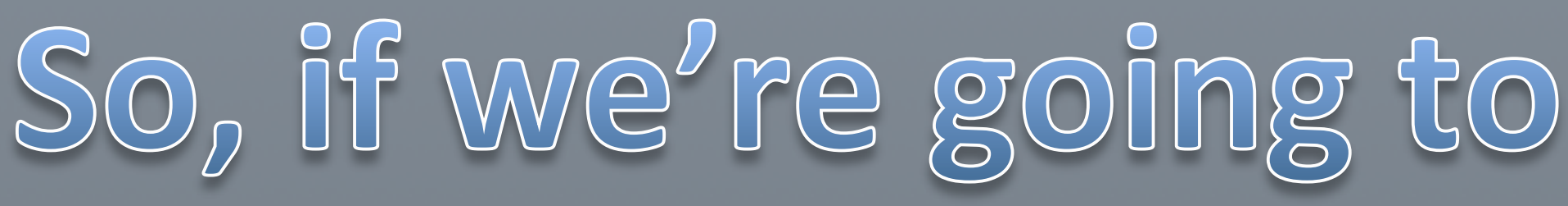

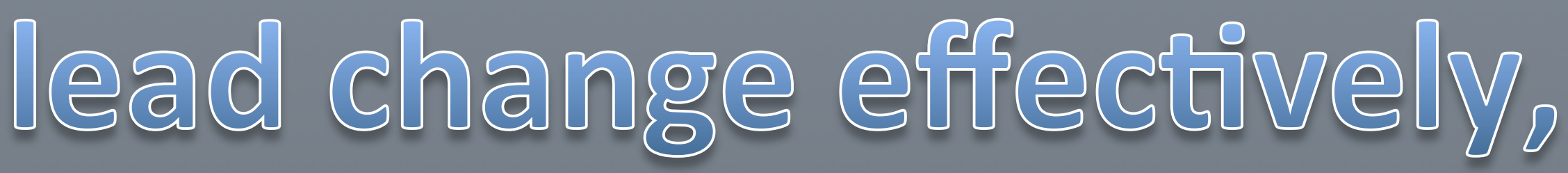

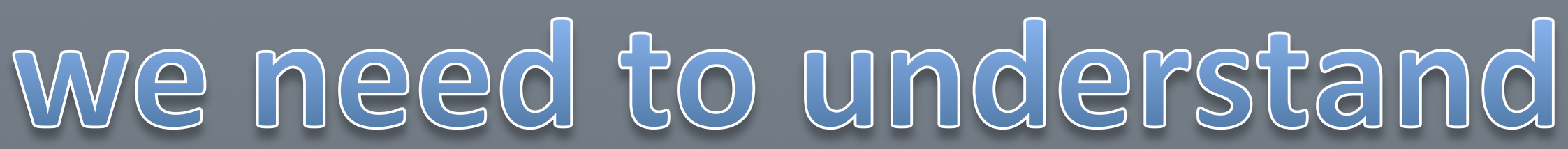

the system in which it

OCGUIS. 


\section{The Sociology of Change}

A systems

approach to

change

leadership.

JEFFREY L. B ULLER

Change Leadership in HIGHER EDUCATION

A Practical Guide to Academic Transformation

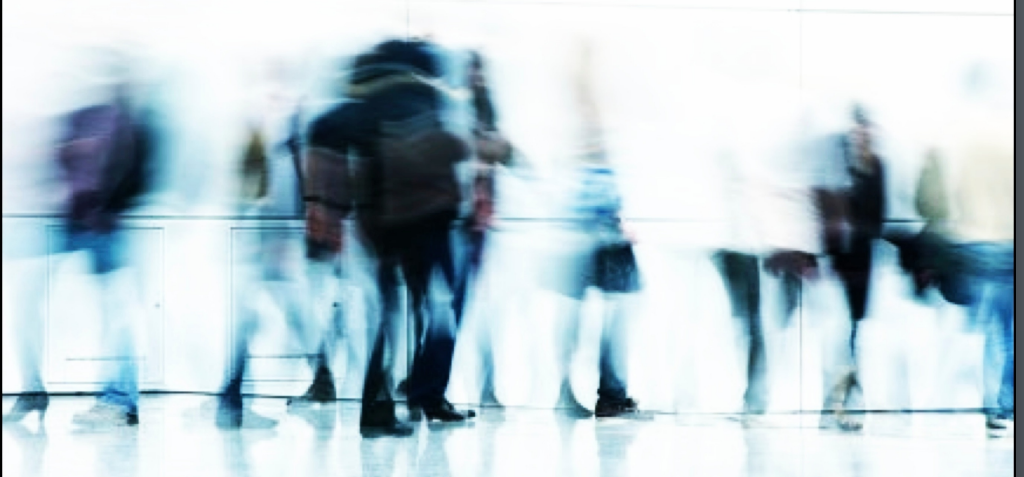




\section{Hierarchical Organizations}
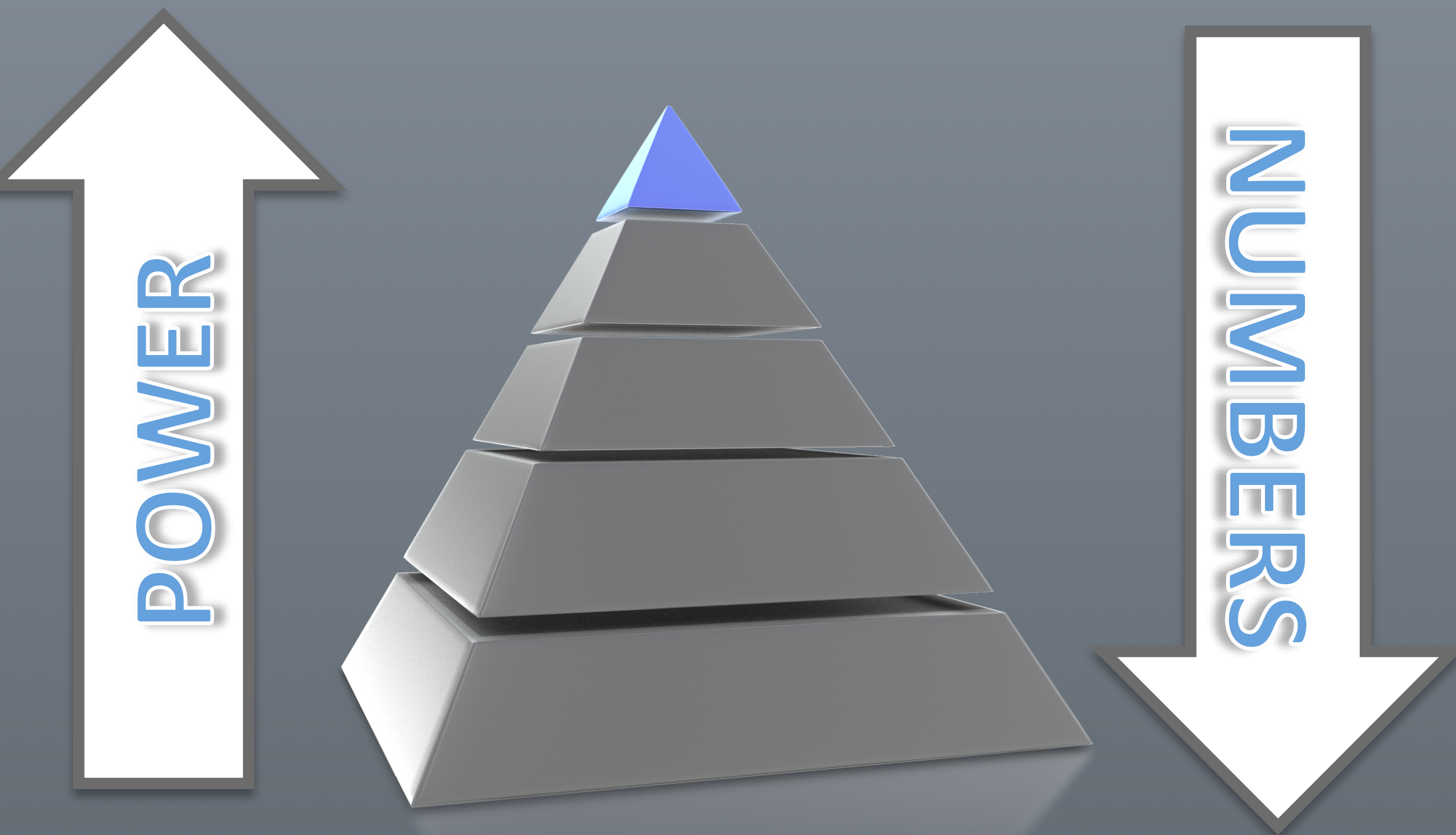


\section{Hierarchical Organizations}

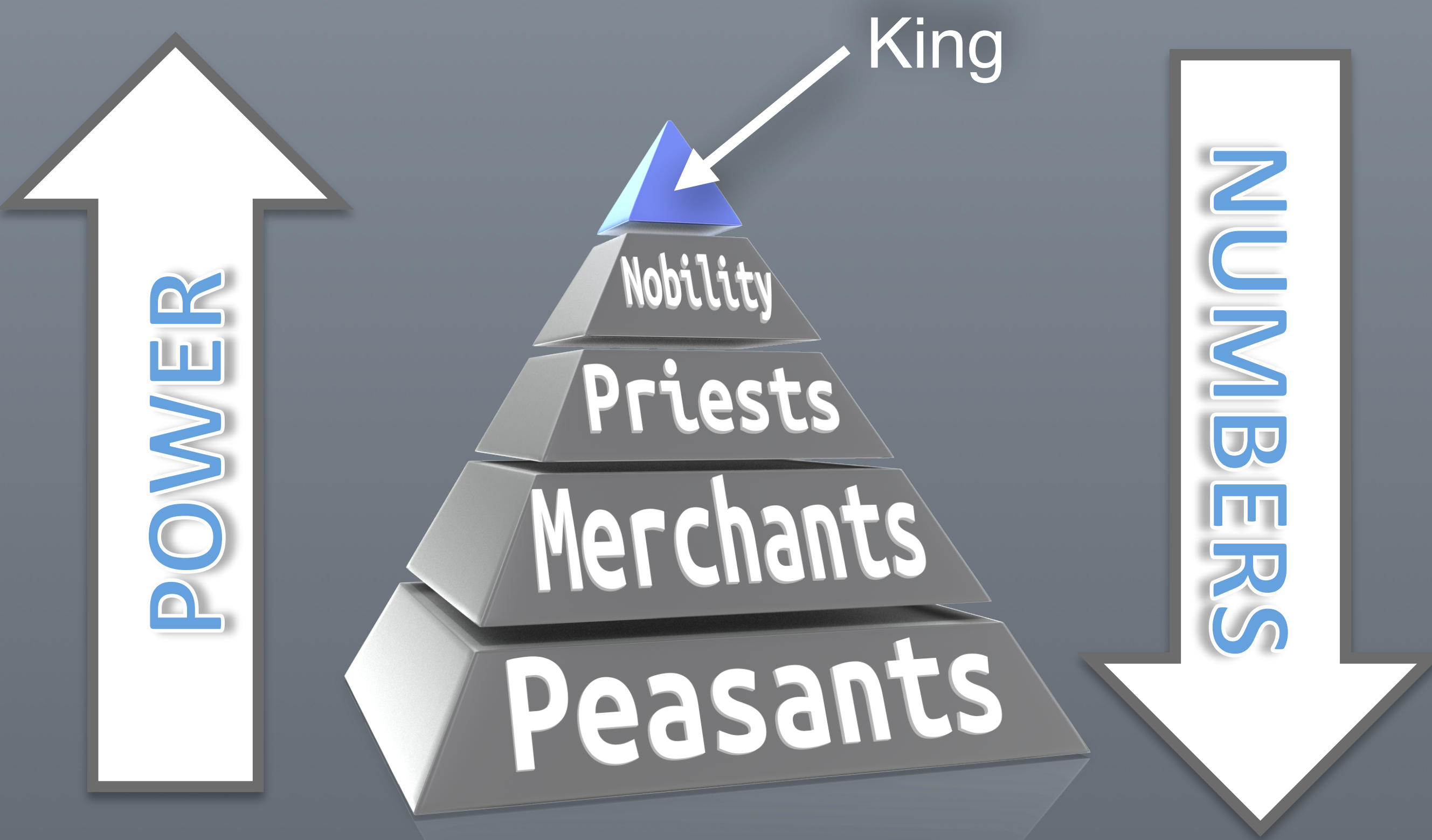




\section{Hierarchical Organizations}

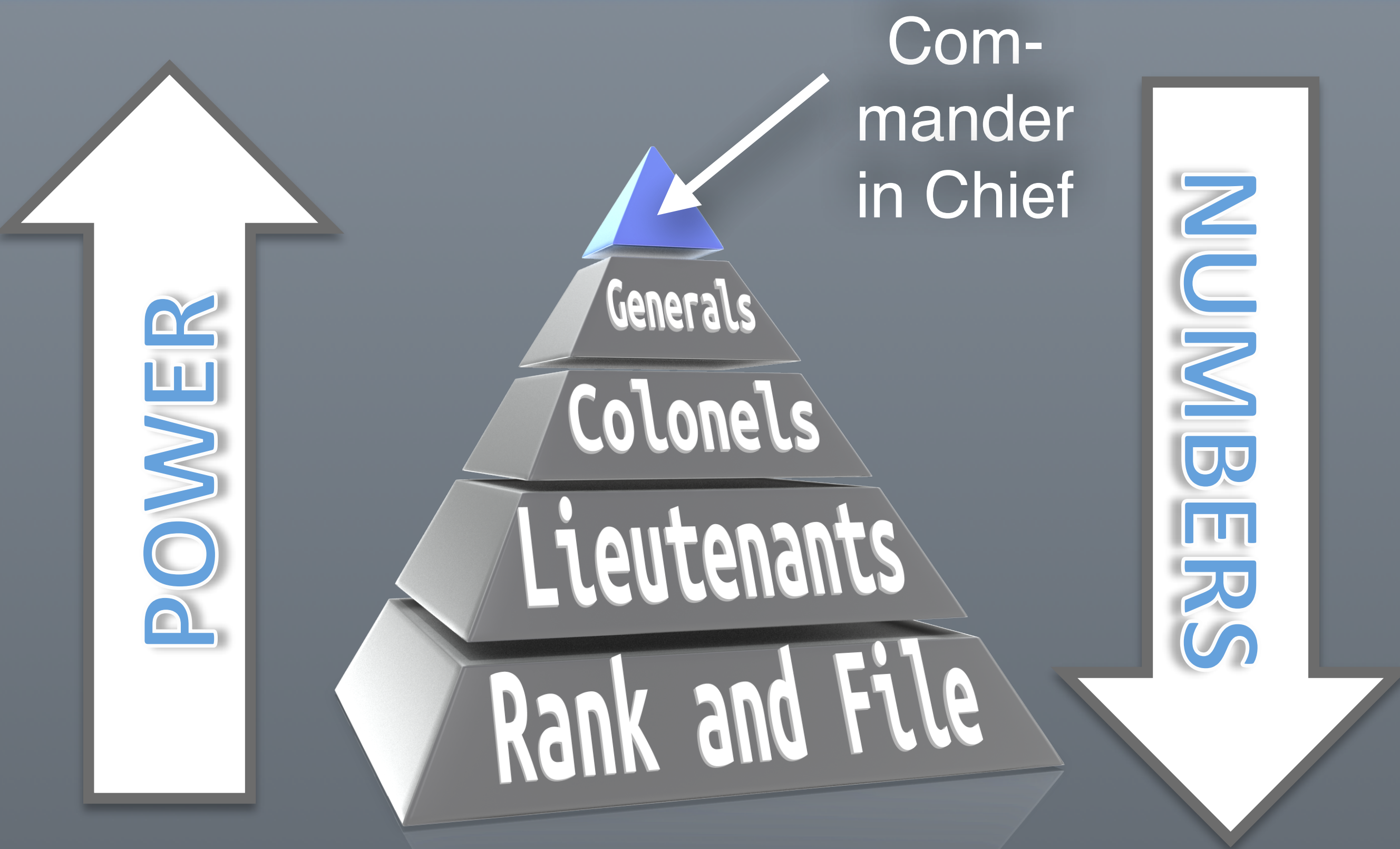




\section{Hierarchical Organizations}

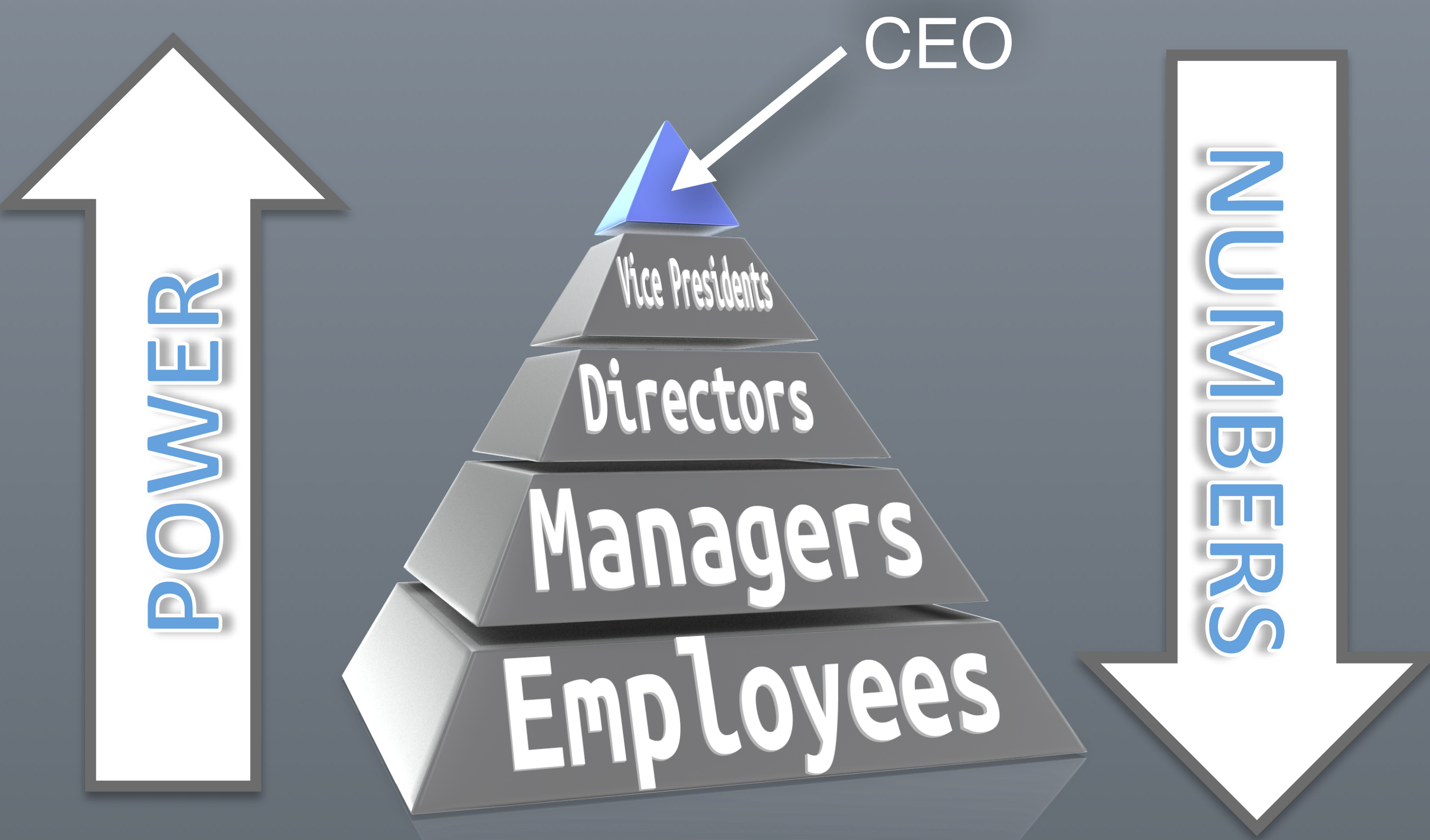




\section{Hierarchical Organizations}

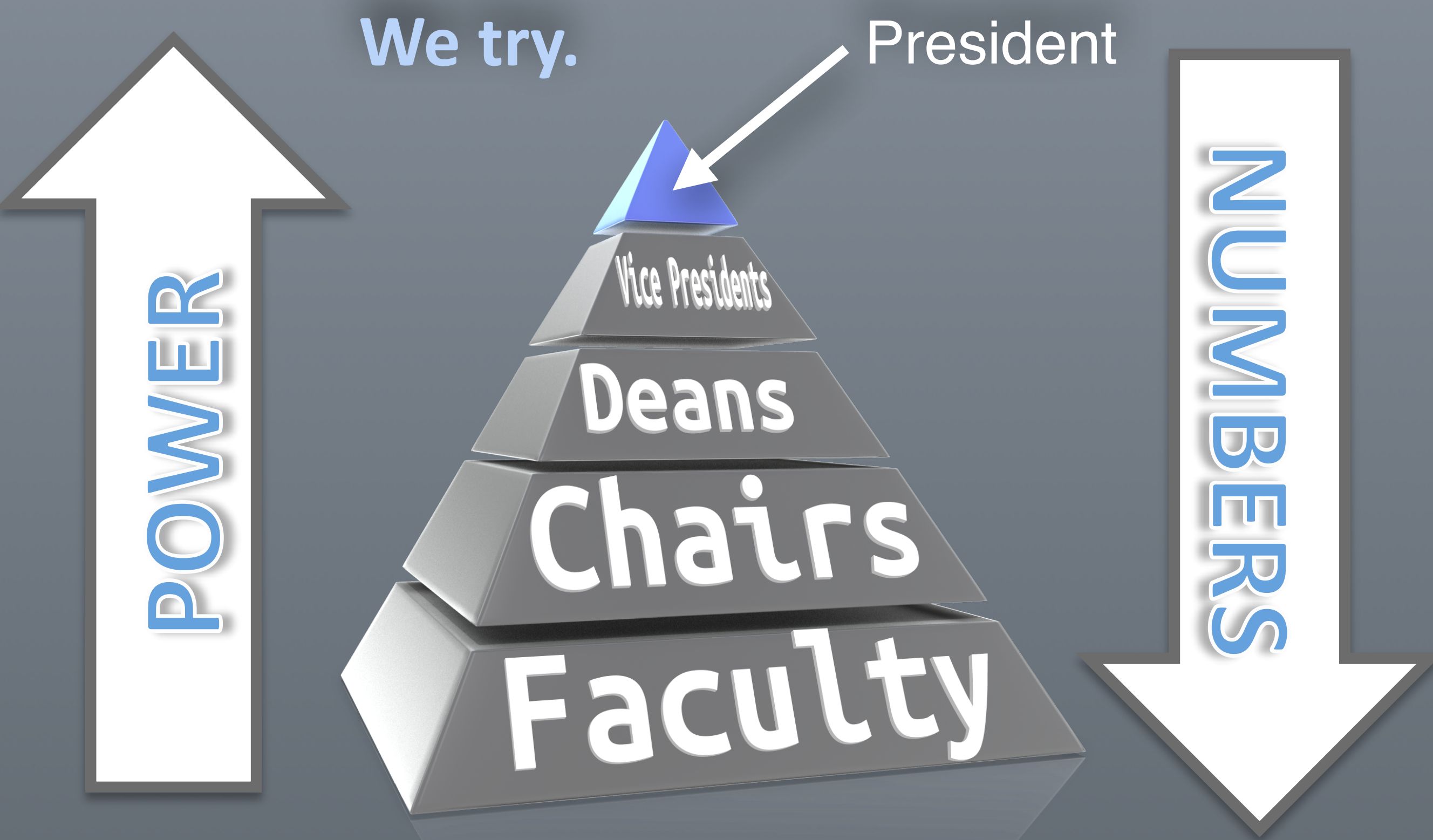




\section{Decision Making and Strategy}

Commander in

Chief

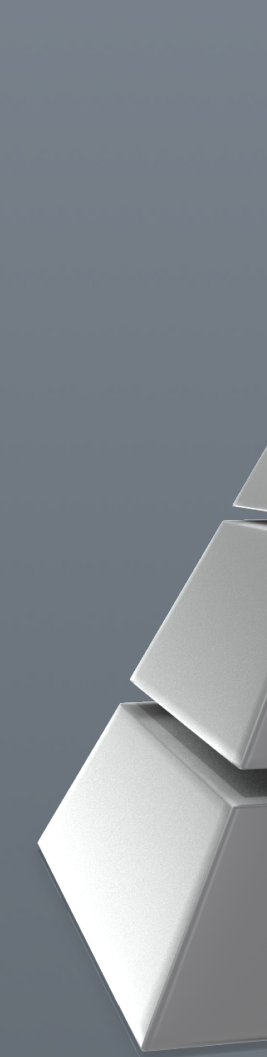

\section{Lieutenants}

Rank and Fle

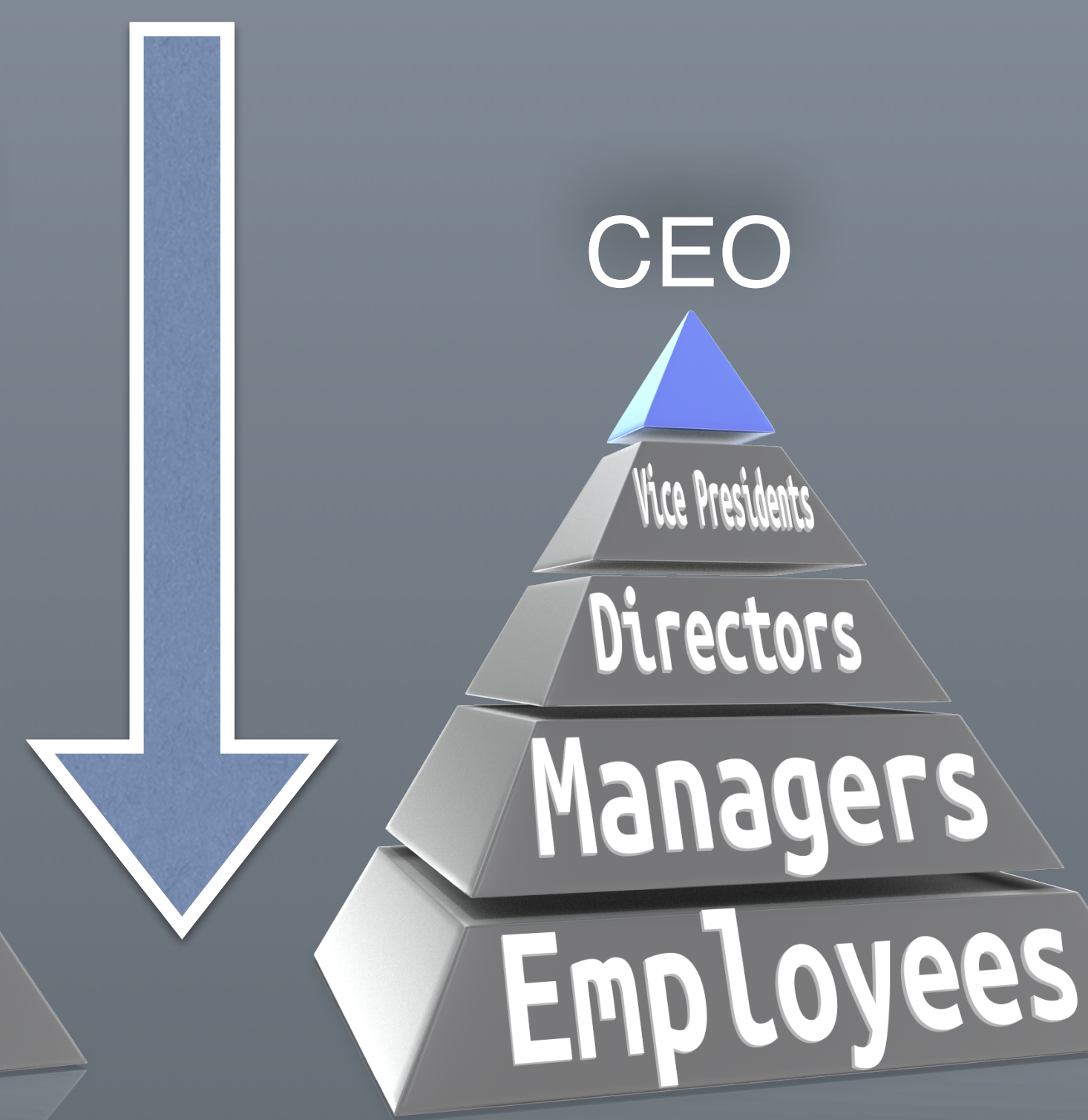




\section{Curricular Decisions}

\section{President}
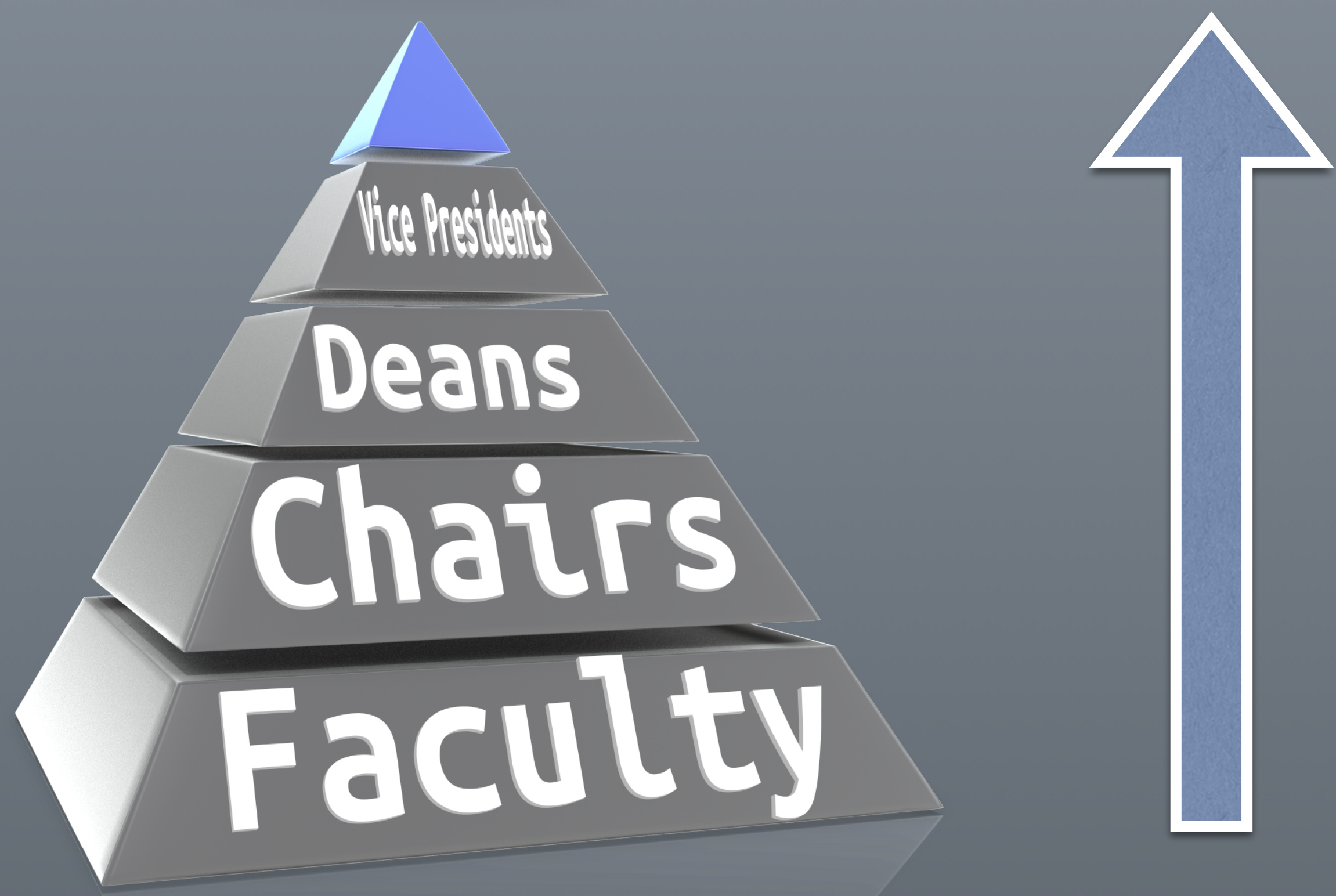


\section{Matrix Organization}

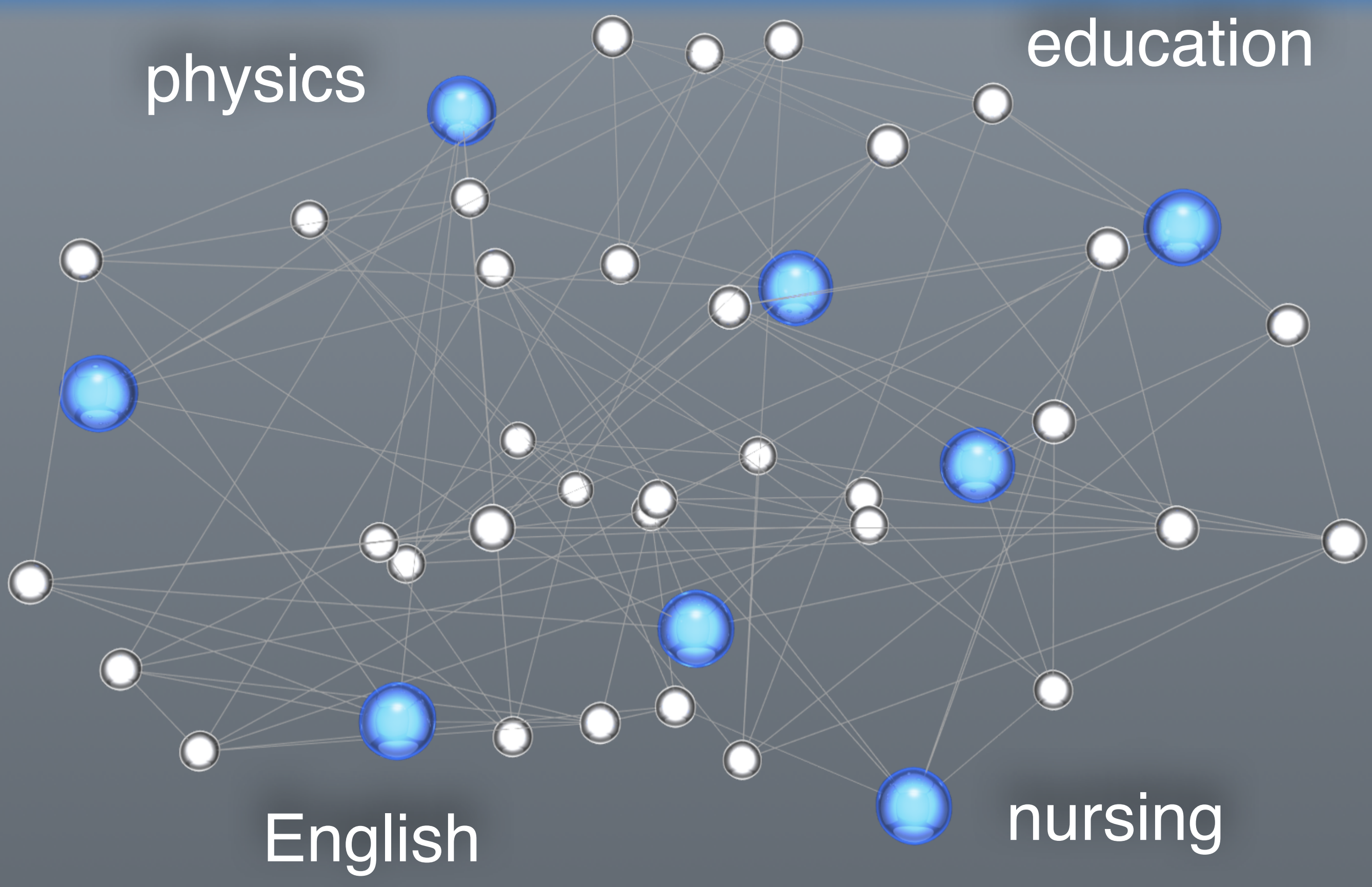




\section{Decentralized Organization}

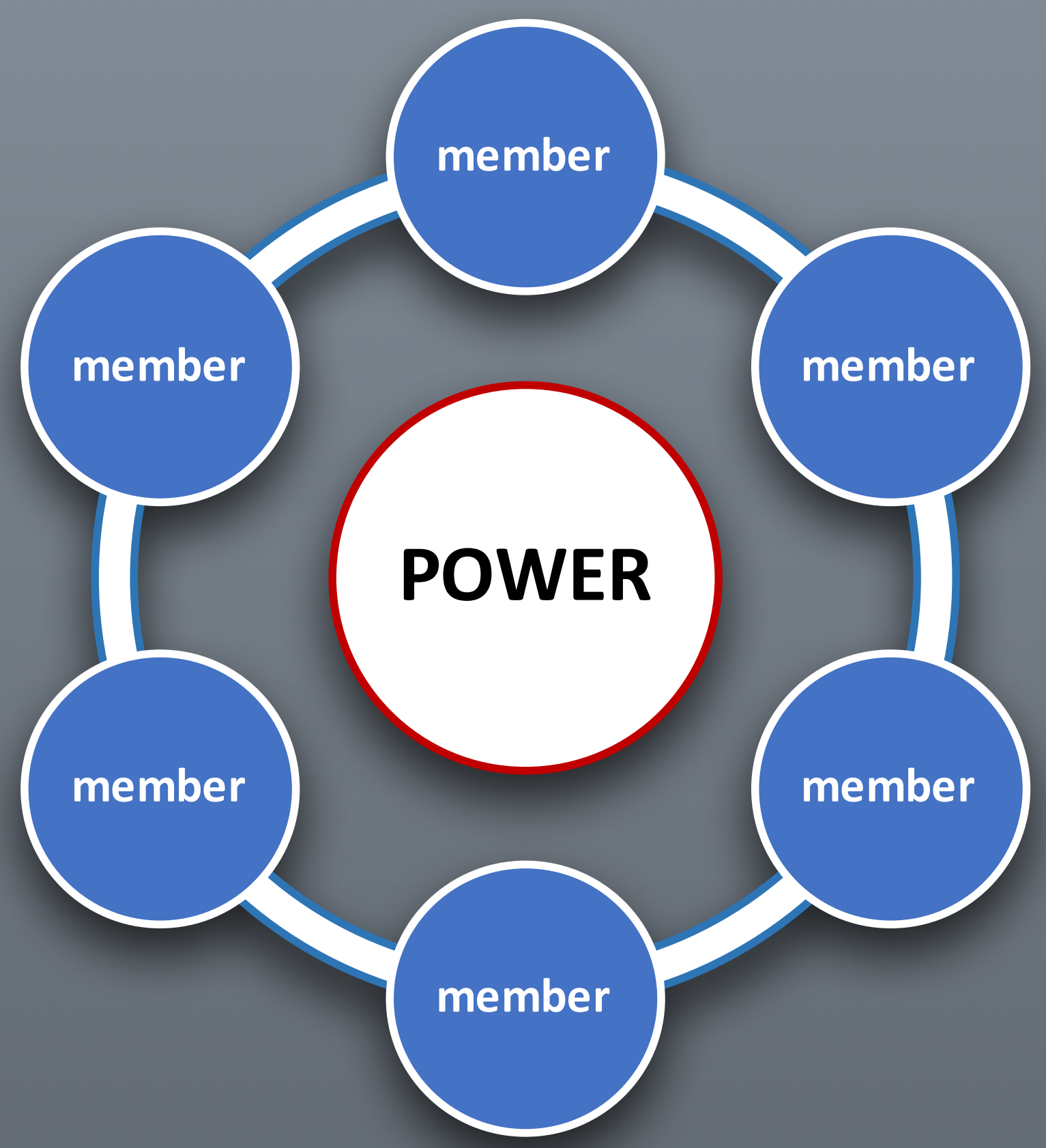




\section{Distributed Organization}

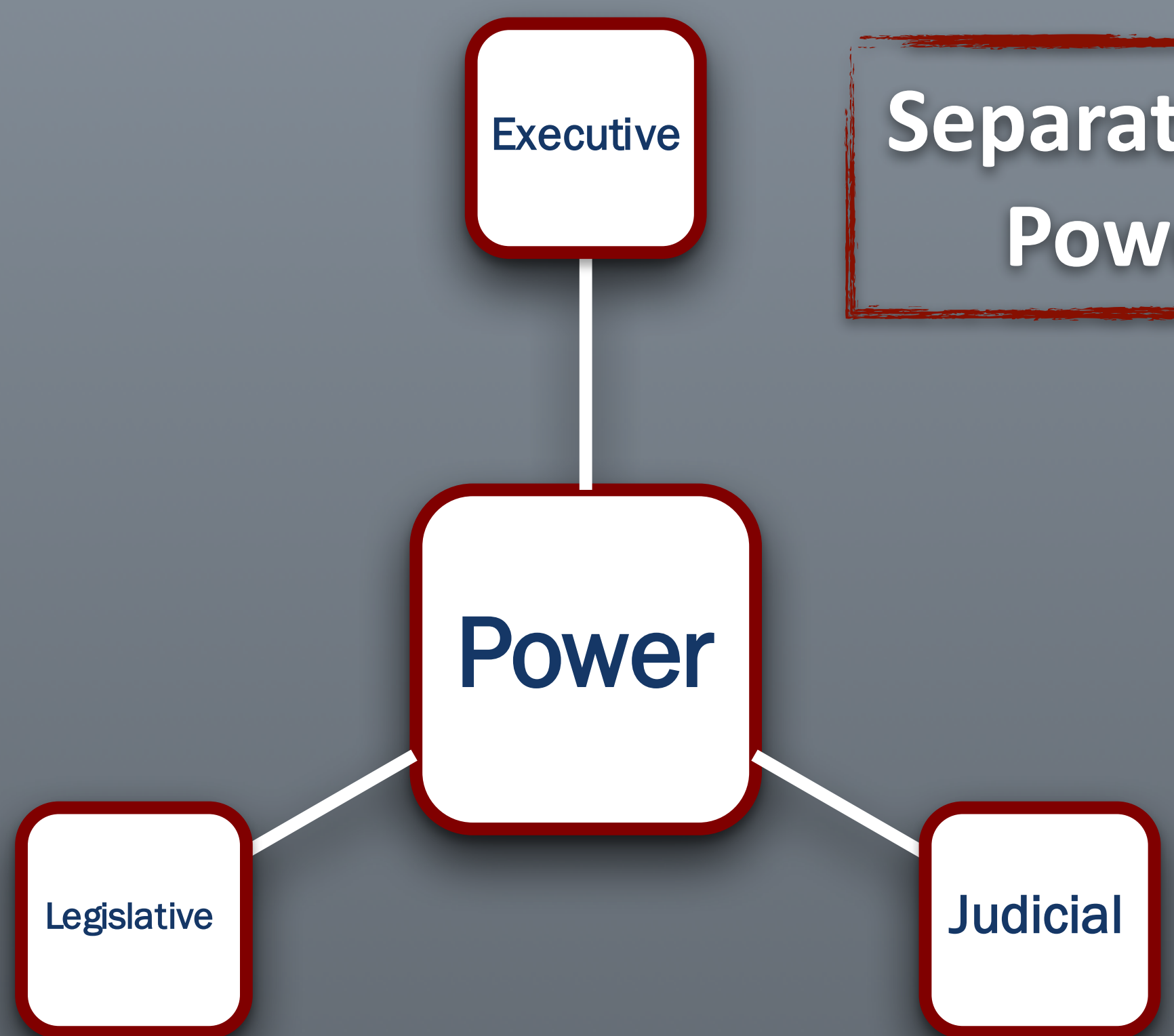




\section{Distributed Organization}

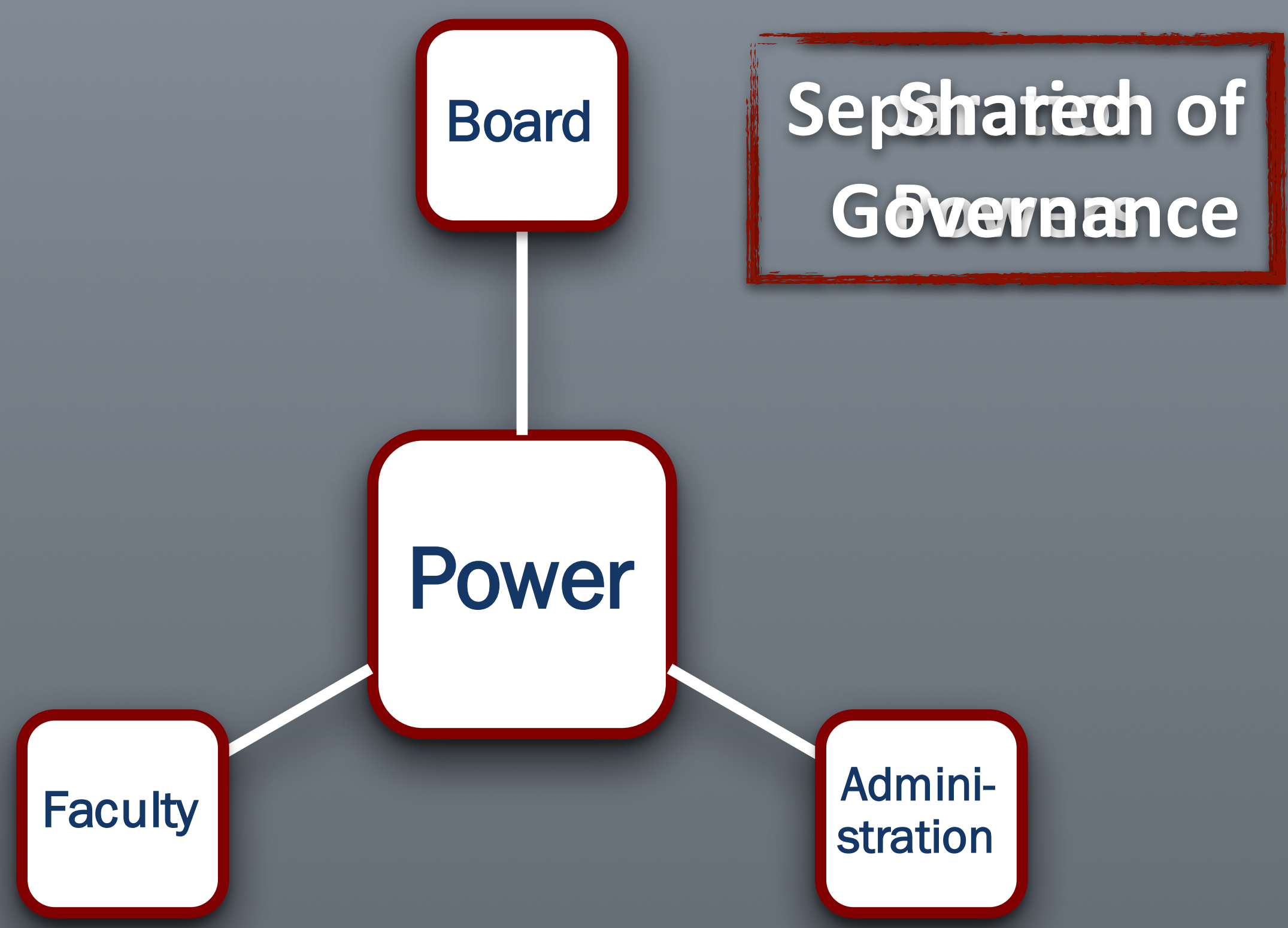




\section{Why Does This Matter?}

\section{Military Culture}

- strategy

- tactics

- targets

(1) win

- victory

- enemy

- team

- shock and awe

- take the offensive

- fog of war

- expediency

- tipping point corporate Culture

- Key Performance Indicators (KPIs)

- benchmarks

- SWOT analysis (strengths, weaknesses, opportunities, threats)

- Return On Investment (ROI)

- metrics

- entrepreneurial

- downsizing

- customers

- competition
Academic Culture

- collegiality

- academic freedom

- tenure

- critical or higher order thinking

- shared governance

- Bloom's Taxonomy

- active learning

- service learning

- flipped classroom

- multiple intelligences

- curriculum

- scaffolding 


\section{Strategic Planning}

\section{Military Culture}

- strategy

- tactics

- targets

- win

- victory

- enemy

- team

shock and awe

- take the offensive

- fog of war

- expediency

- tipping point

\section{corporate Culture}

-

Key Performance Indicators (KPIs)

- benchmarks

- SWOT analysis (strengths, weaknesses, opportunities, threats)

- Return On Investment (ROI)

- metrics

- entrepreneurial

- downsizing

- customers

- competition
Academic Culture

- collegiality

- academic freedom

- tenure

- critical or higher order thinking

- shared governance

- Bloom's Taxonomy

- active learning

- service learning

- flipped classroom

- multiple intelligences

- curriculum

- scaffolding 


\section{Strategic Planning}

Our leading current approach to producing change in higher education (strategic planning) originated in military, corporate, hierarchical cultures that don't necessarily operate like the matrix, decentralized, distributed culture of higher education. 


\section{Strategic Planning}

Many of its basic concepts and approaches ...

metrics

SWOT analysis

strategies

tactics

... don't harmonize well with the sociology of higher education. 


\section{Strategic Planning}

It's sort of an

invasive species

in higher

education.

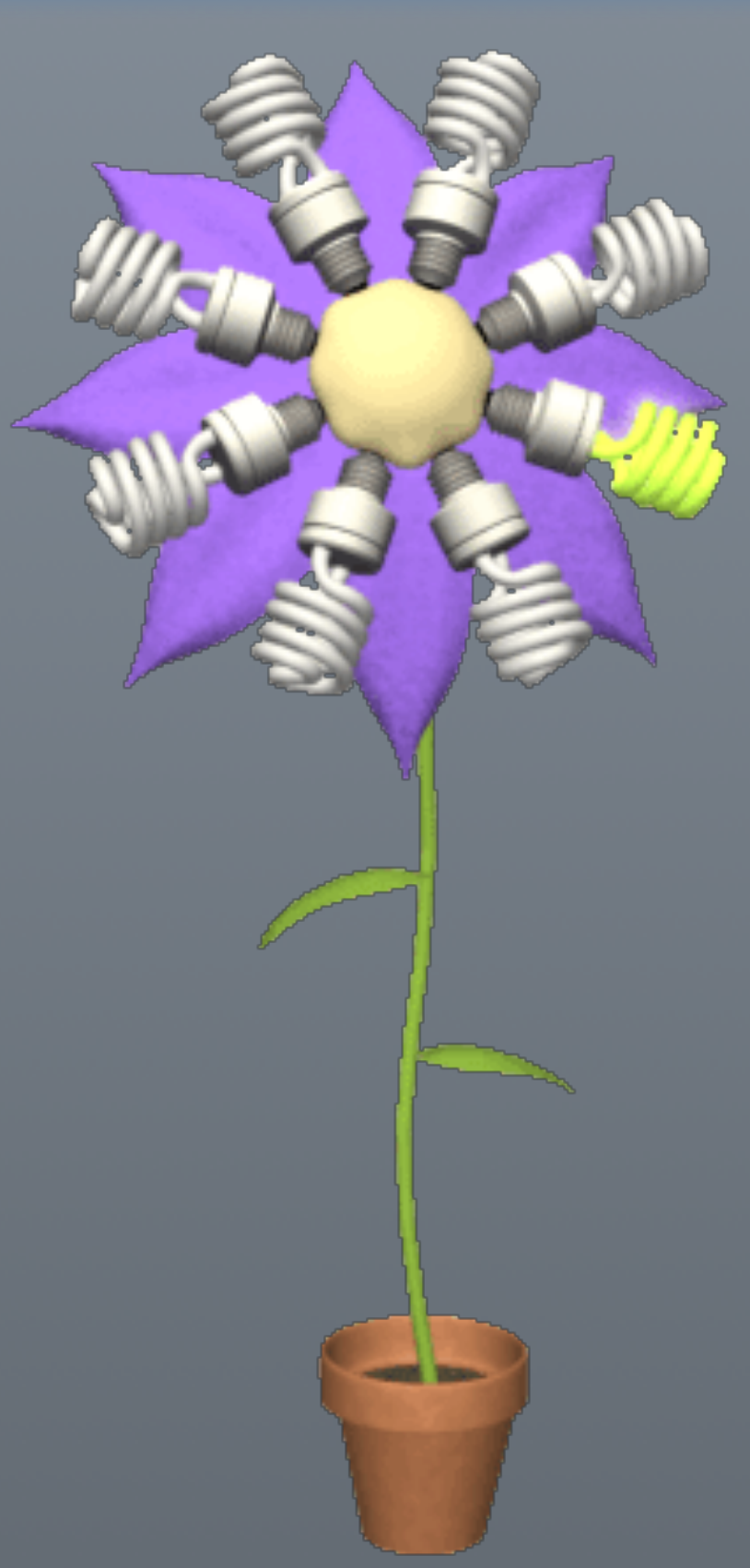




\section{What If ...?}

Academic Culture

What if we adopted an approach to change

that reflected values

and vocabulary closer

to this? What would it

look like?
- collegiality

- academic freedom

- tenure

- critical or higher order thinking

- shared governance

- Bloom's Taxonomy

- active learning

- service learning

- flipped classroom

- multiple intelligences

- curriculum

- scaffolding 


\section{Exercise \#4}

Let's discuss this

\section{Academic Culture}

- In small groups, take five minutes to talk about what a change mechanism appropriate to the culture and sociology of higher education would look like

- How could it be based on the values and vocabulary closer to the words on the right?

- Take five minutes for this discussion

- collegiality

- academic freedom

tenure

- critical or higher order thinking

- shared governance

- Bloom's Taxonomy

- active learning

- service learning

- flipped classroom

- multiple intelligences

- curriculum

- scaffolding 


\section{Exercise \#4}

We'll take five minutes for this exercise. 


\section{Exercise \#4}

Let's discuss this

\section{Academic Culture}

- In small groups, take five minutes to talk about what a change mechanism appropriate to the culture and sociology of higher education would look like

- How could it be based on the values and vocabulary closer to the words on the right?

- What did you decide?

- collegiality

- academic freedom

- tenure

- critical or higher order thinking

- shared governance

- Bloom's Taxonomy

- active learning

- service learning

- flipped classroom

- multiple intelligences

- curriculum

- scaffolding 


\section{Organic Academic Leadership}

When a flower doesn't bloom, you fix the environment in which

it grows, not the

flower.

-Alexander den Heijer 


\section{Organic Academic Leadership}

You don't change an institution or a program.

Y You build people.

And they change the world.

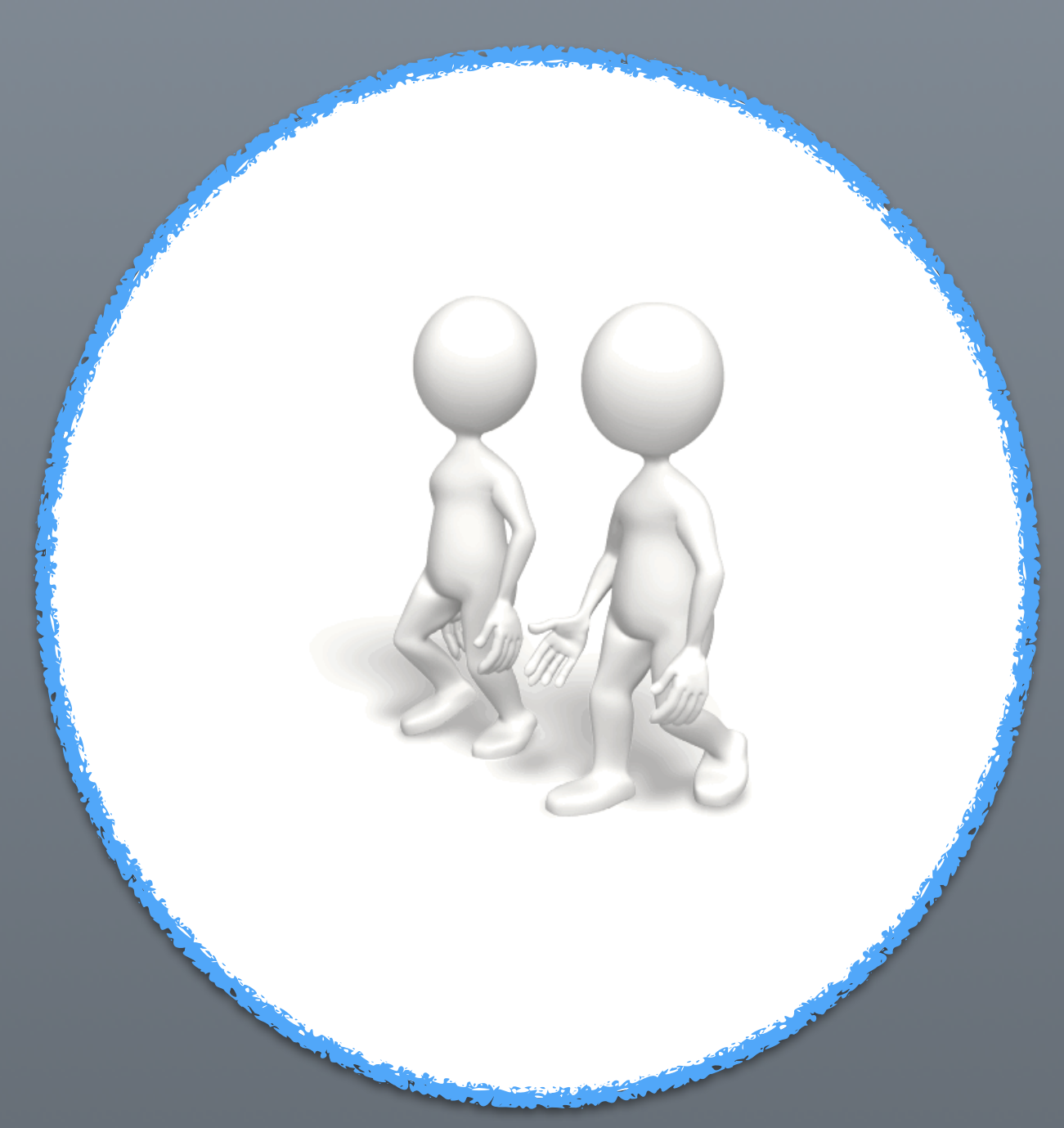


The Idea Is to Help People Become More Greative

- Orgonic Acodemic Leadership:

The idea that the academic leader's most important responsibility is developing people, not programs, strategies, or goals.

Creative Academic Leadership:

The idea that the academic leader's most important responsibility is help people become more creative, innovative, and forward-looking. 


\section{Greative Academic Leadership}

- Innovation is encouraged, recognized, and rewarded.

- Ideas are heard and seriously considered before being judged.

- As many people as possible are given the freedom to do their work in their own way.

- Most decisions don't have to be cleared through a person's supervisor. 


\section{Greative Academic Leadership}

- People feel comfortable talking with anyone in the organization (including the upper administration).

- People are appreciated for what they do.

- People are appreciated for who they are.

- Efforts are made to foster and develop creativity. 


\section{Greativity Blocks}

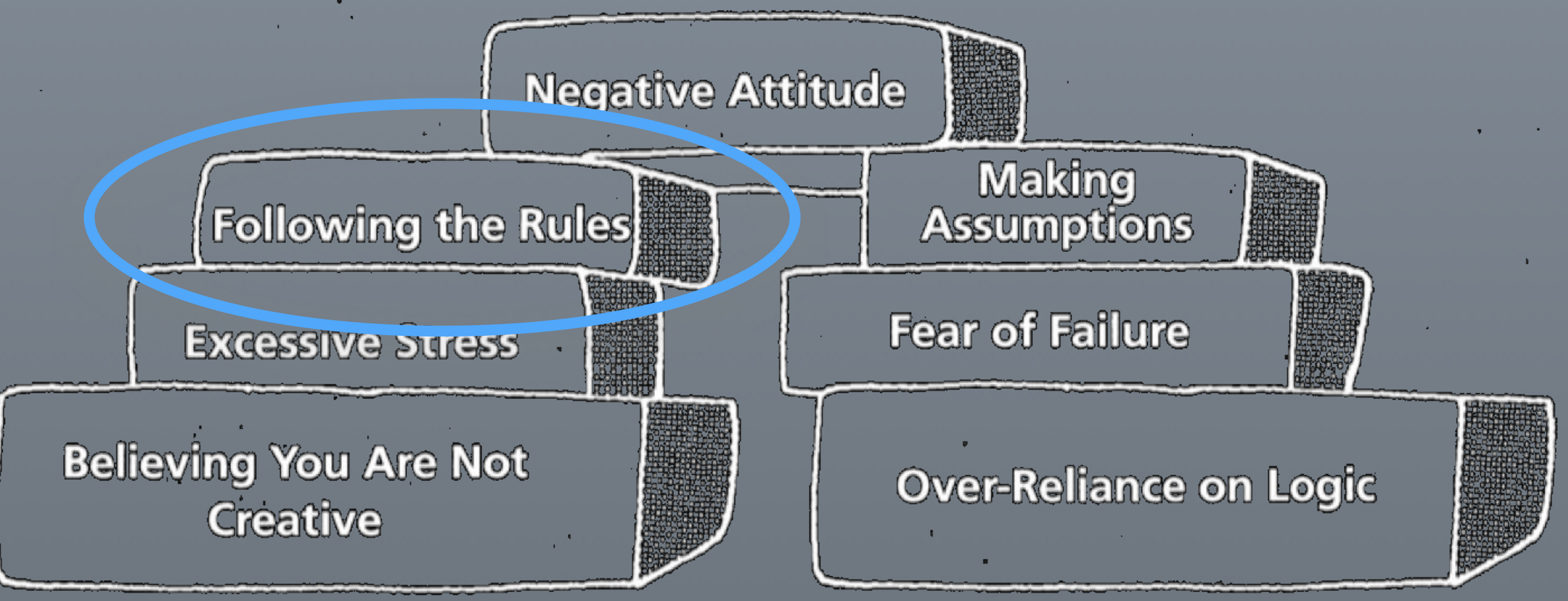




\section{Greativity Block Busters}

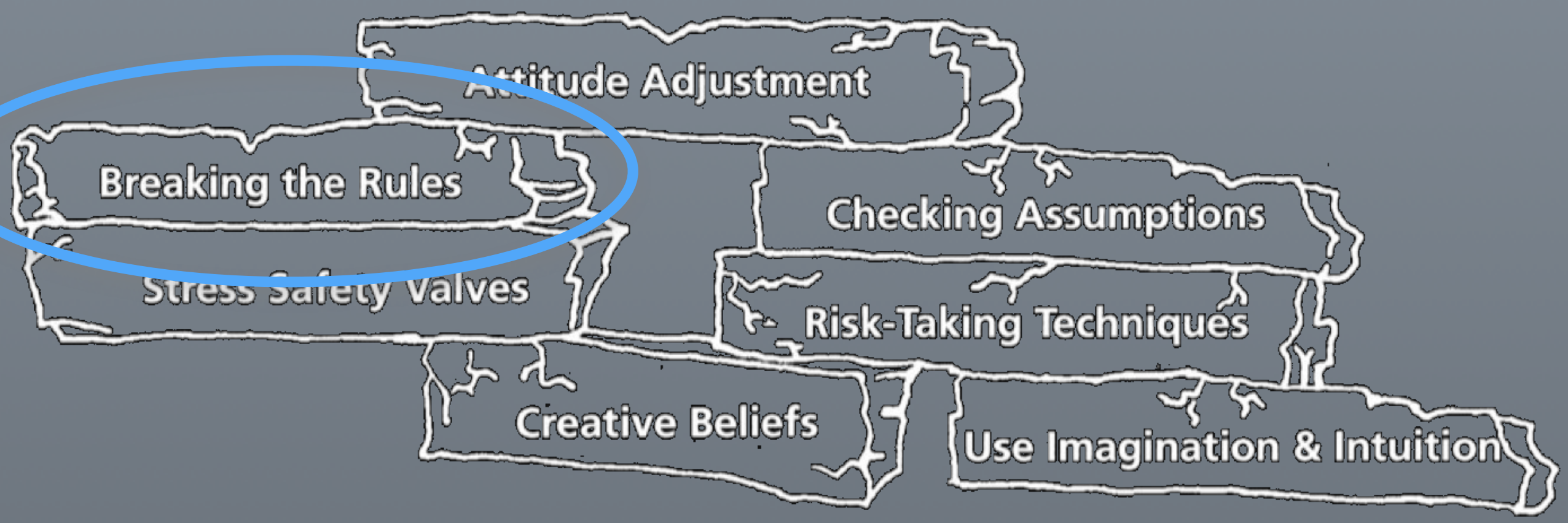




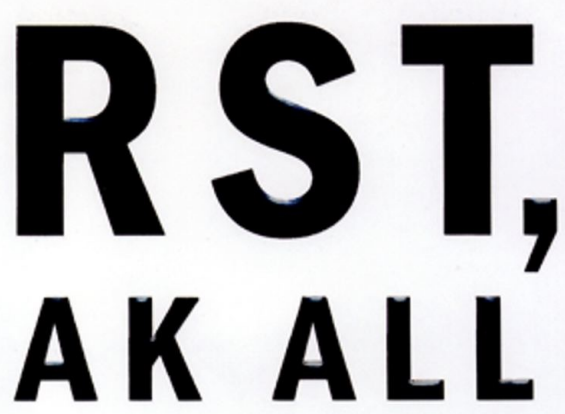
THE RULES WHAT THE WORLD'S GREATEST MANAGERS DO DIFFERENTLY BASED ON IN-DEPTH INTERVIEWS BY THE GALLUP ORGANIZATION OF OVER 80,000 MANAGERS IN OVER 400 COMPANIES-THE LARGEST STUDY OF ITS KIND EVER UNDERTAKEN MARCUS BUCKINGHAM \& CURT COFFMAN 


\section{First Break All the Rules}

- The best managers reject conventional wisdom.

- The best managers treat every employee as an individual.

- The best managers never try to fix weaknesses; instead they focus on strengths and talent.

- The best managers know they are on stage everyday. They know their people are watching every move they make.

- People leave their immediate managers, not the companies they work for. 


\section{First Break All the Rules}

- The best managers are those that build a work environment where the employees answer positively to the Gallup Organization's 12 Questions.

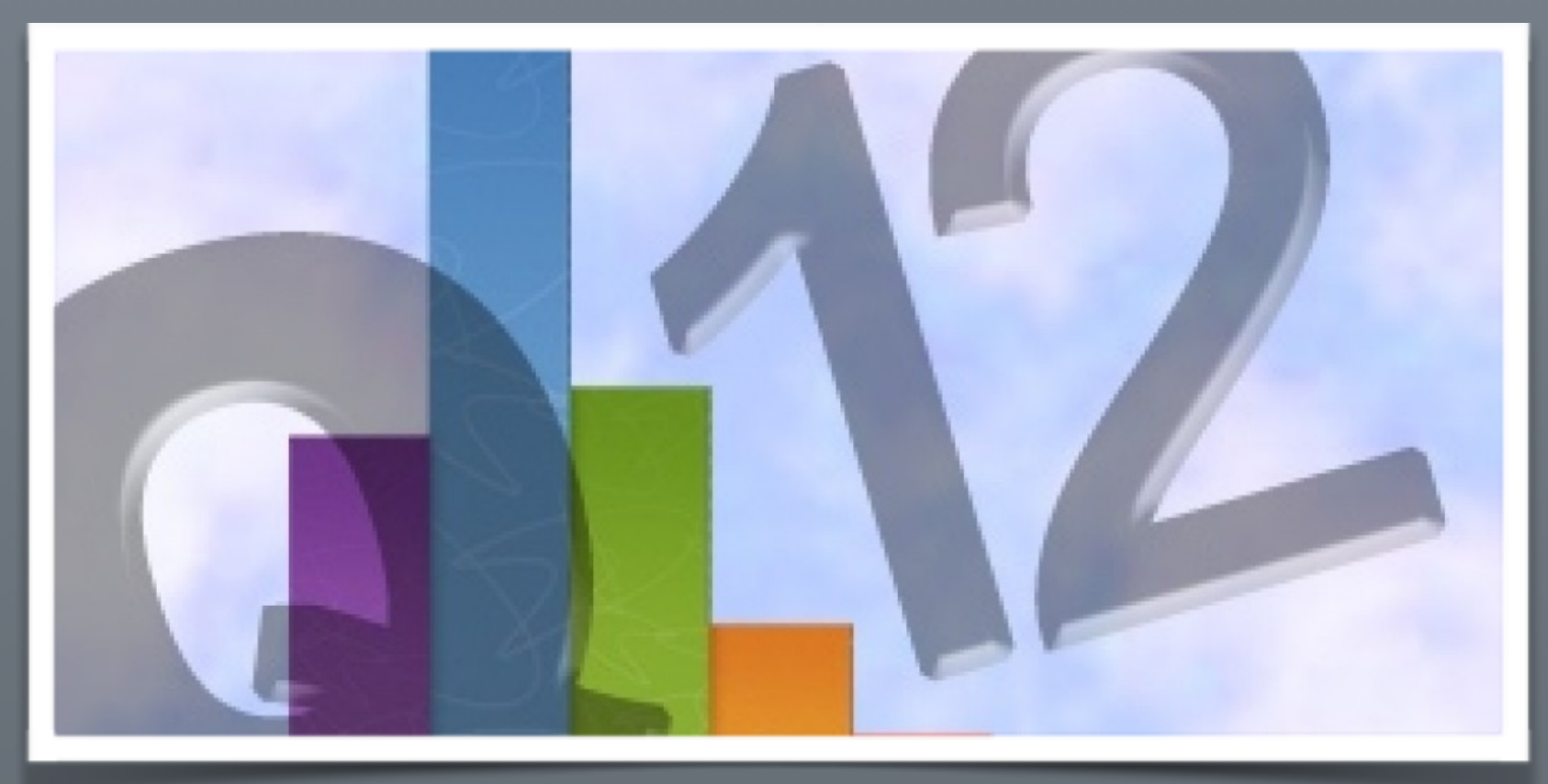




\section{Questions}

1. Do I know what is expected of me at work?

2. Do I have the materials \& equipment I need to do my work right?

3. At work, do I have the opportunity to do what I do best every day?

4. In the last 7 days, have I received recognition or praise for good work?

5. Does my supervisor or someone at work seem to care about me as a person?

6. Is there someone at work who encourages my development?

7. At work, do my opinions seem to count?

8. Does the purpose of my company make me feel like my work is important?

9. Are my co-workers committed to doing quality work?

10. Do I have a best friend at work?

11. In the last six months, have I talked with someone about my progress?

12. At work, have I had opportunities to learn and grow? 


\section{Risk Taking Techniques}

○ Ask "What If?" questions.

Decide what you can afford to lose.

- Take only one risk at a time.

- Develop back-up plans (i.e., scenario analysis).

Reward effort, not just

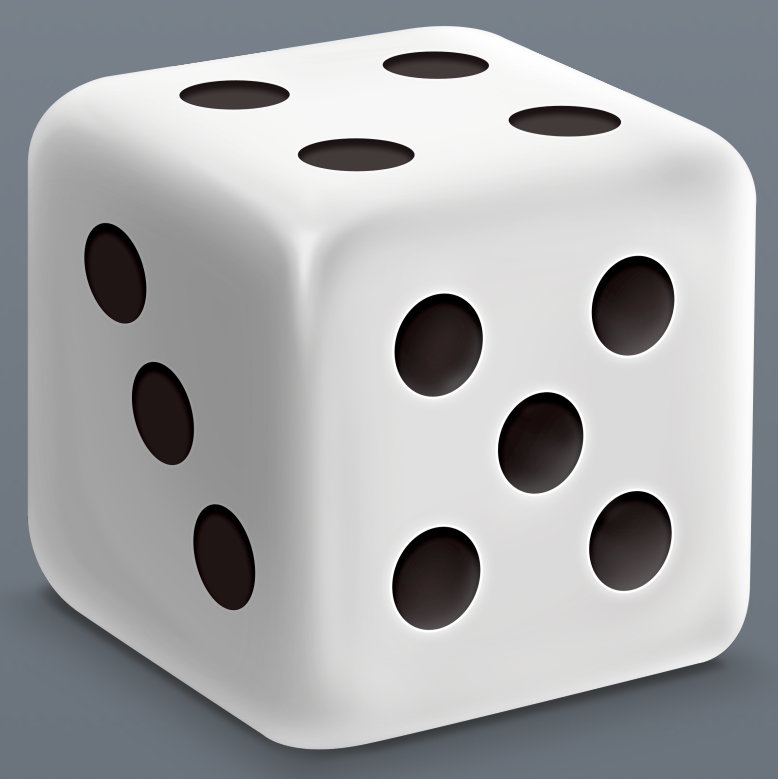
success. 


\section{Exercise \#5}

- Advising a college friend who's

now a department chair

- Read the case study and see if you can develop some good advice for

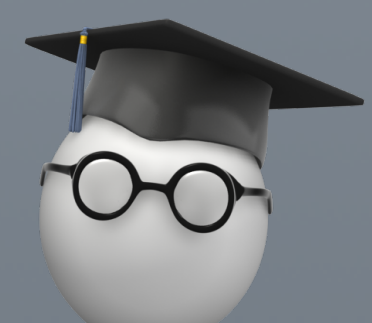
your friend

What seems to have gone wrong?

- How can your friend still turn things around?

- We'll take five minutes for this discussion 


\section{Exercise \#5}

We'll take five minutes for this exercise.

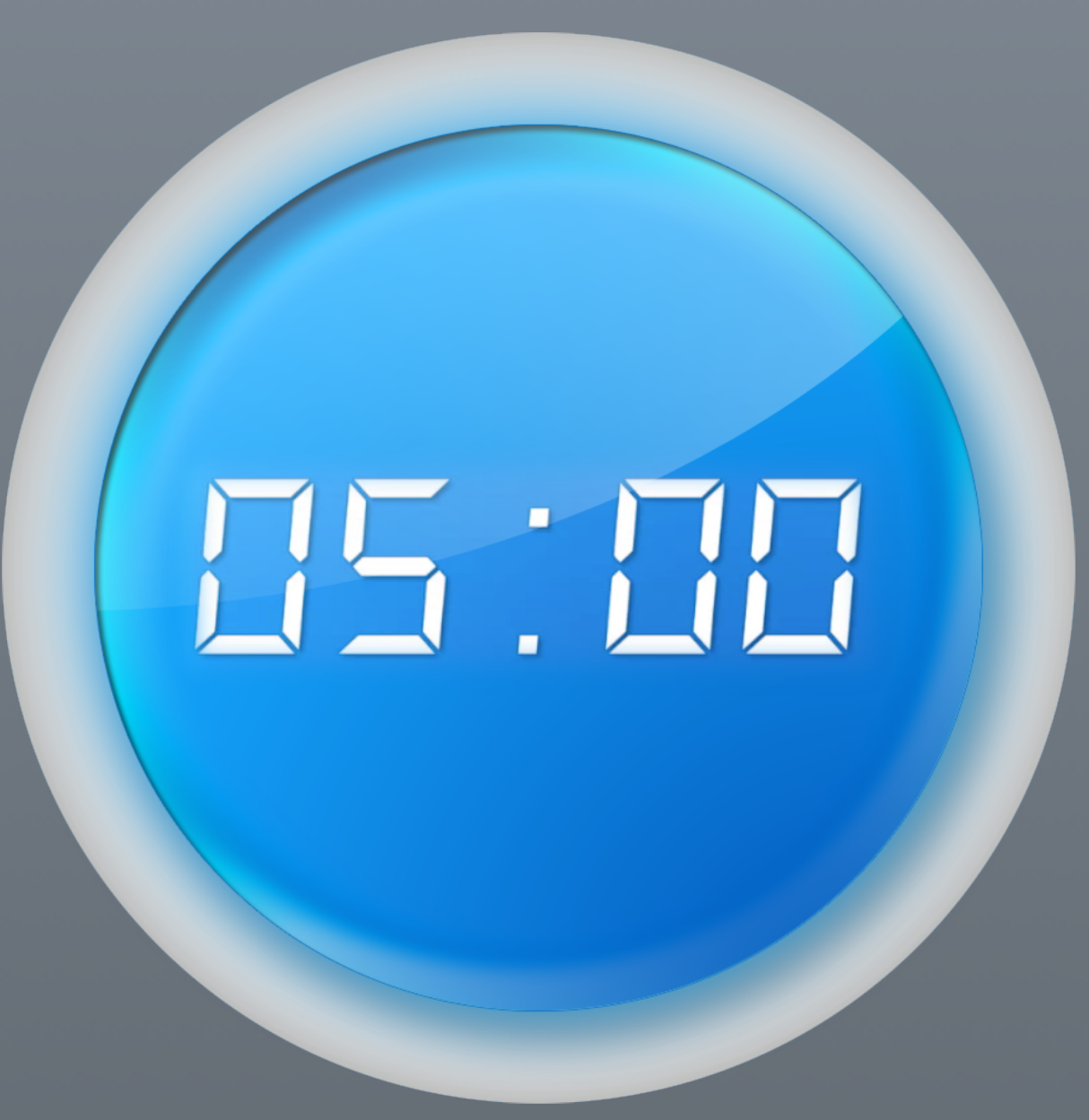




\section{Exercise \#5}

- Advising a college friend who's now a department chair

- Read the case study and see if you can develop some good advice for

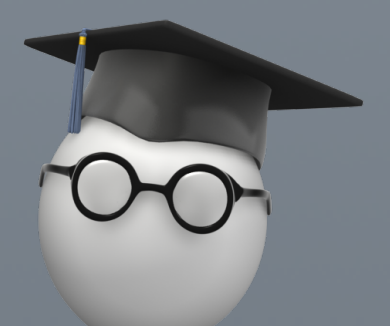
your friend

What seems to have gone wrong?

- How can your friend still turn things around?

- What did you recommend? 


\section{How Can We Communicate Better?}

- strategic planning

- metrics

- retention rates

- graduation rates

- space utilization

- cost per credit hour

- productivity

- efficiency

- mission-driven

- data-driven

- outcomes

- student-centered
- collegiality

- academic freedom

- tenure

- critical or higher order thinking

- shared governance

- Bloom's Taxonomy

- active learning

- service learning

- flipped classroom

- multiple intelligences

- curriculum

- scaffolding 


\section{Exercise \#6}

- Now let's apply the sociology of change to the three changes you identified on page 1 of the workbook

- Using the vocabulary and values that resonate with faculty members in higher education, write one compelling sentence about the benefit of each change as instructed in the workbook

- We'll take five minutes for this exercise

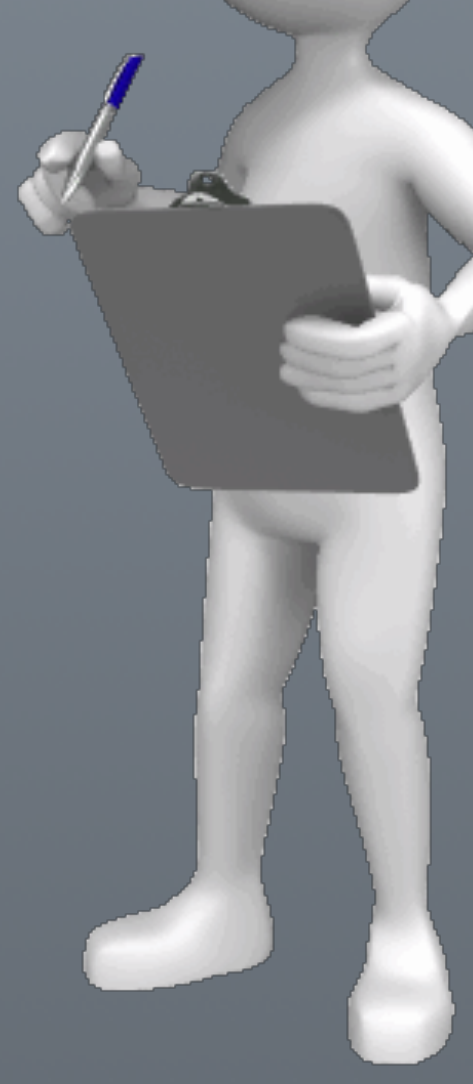




\section{Exercise \#6}

We'll take five minutes for this exercise.

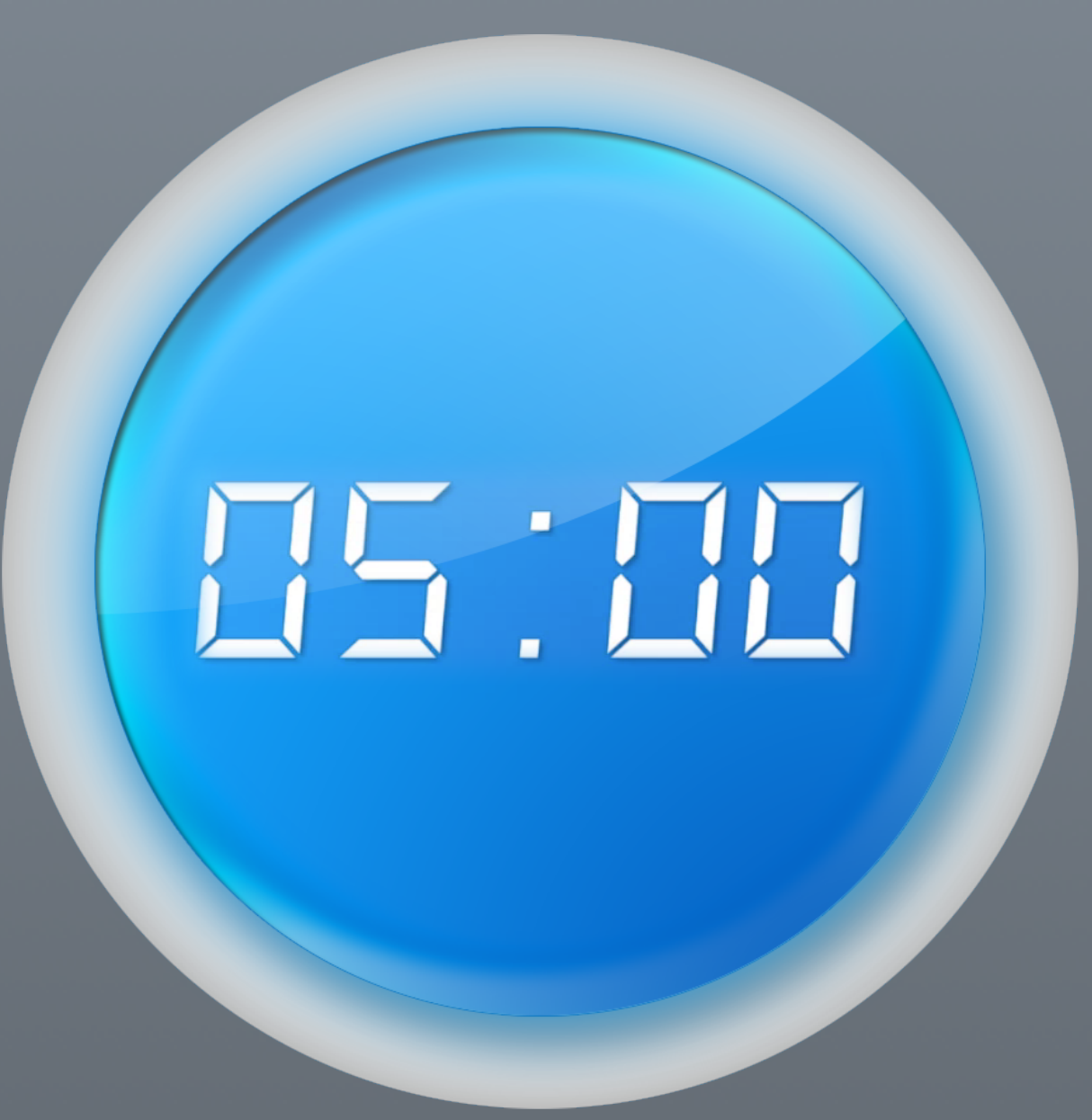




$$
\begin{gathered}
\text { The Philosophy of } \\
\text { Change }
\end{gathered}
$$
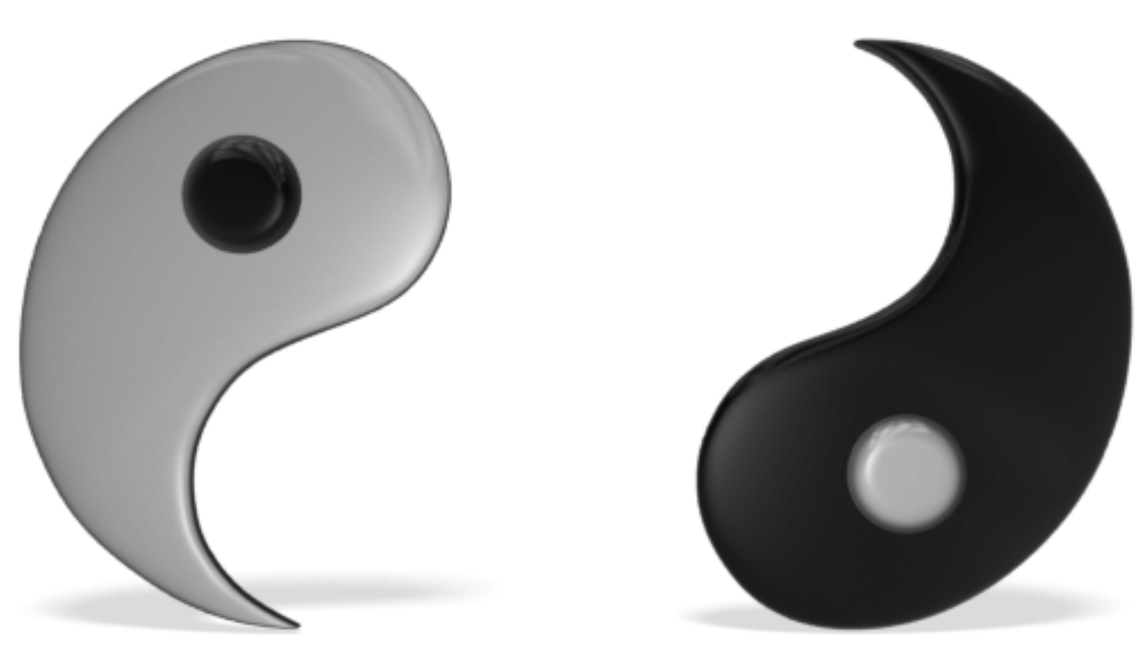


\section{Gommon Assumptions about Change}

1. The power of positive thinking can help promote positive change.

2. Large, complex problems usually require large, complex changes.

3. Change leaders may best be understood as catalysts for change.

4. The concept of SMART goals make change easier to implement and progress easier to assess.

5. If you get the sociology right, the psychology follows automatically. 


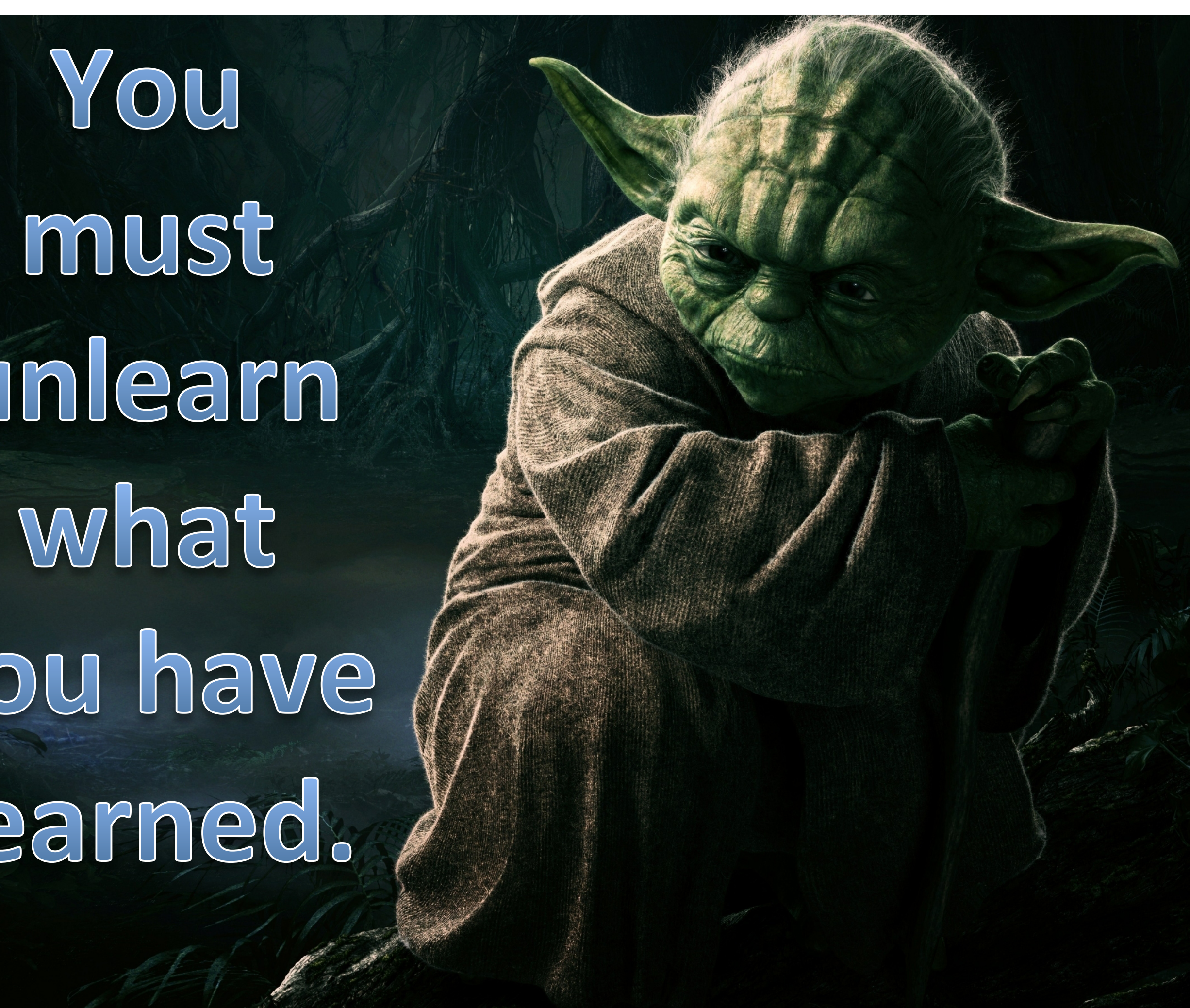




\section{Assumption \#1}

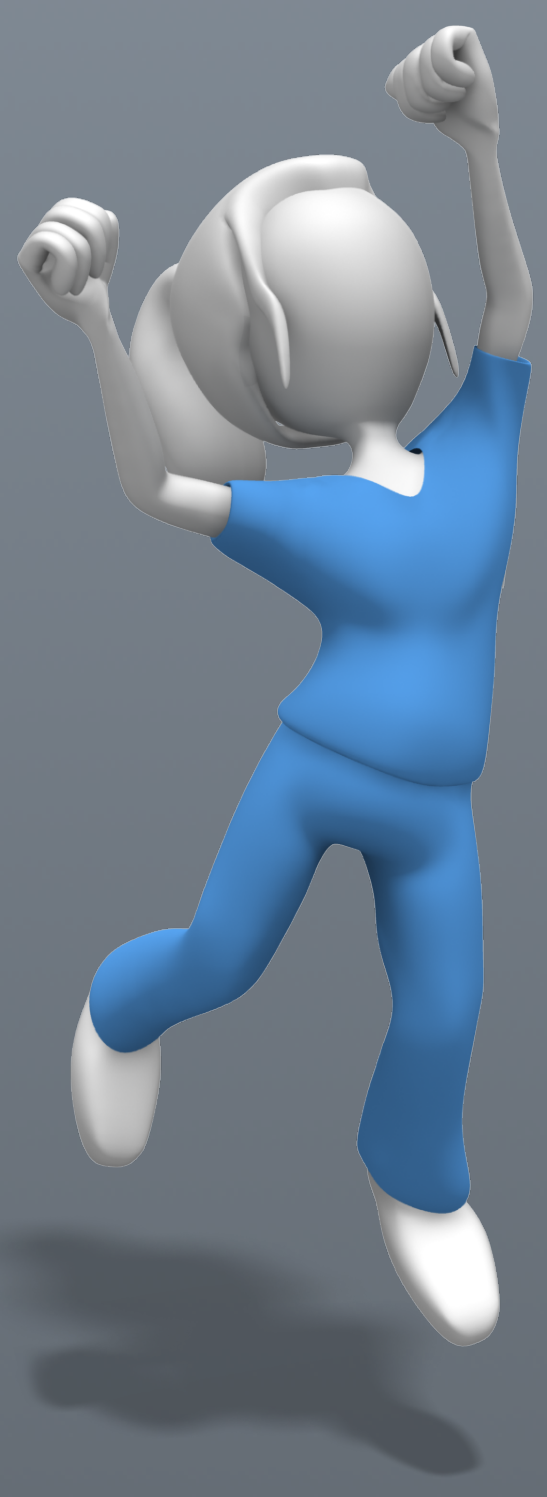

$$
\begin{aligned}
& \text { The power of } \\
& \text { positive thinking } \\
& \text { can help promote } \\
& \text { positive change. }
\end{aligned}
$$




\section{Positive Thinking}

\section{NORMAN VINCENT PEALE}

INTERMATIOKAL BESTSELLER More thas 5 million copies sold

POWER of

POSITIVE

THINKING
Formulate and stamp indelibly on your mind a mental picture of yourself as succeeding. Hold this picture tenaciously. Never permit it to fade. Your mind will seek to develop the picture ... Do not build up obstacles in your imagination. 


\section{Positive Thinking}

\section{The Law of Attraction}

When you want to attract something into your life, make sure your actions don't contradict your desires. ... Act as if you are receiving it. Do exactly what you would do if you were receiving it today, and take actions in your life to reflect that powerful expectation. Make room to receive your desires, and as you do, you are sending out that powerful signal of expectation.

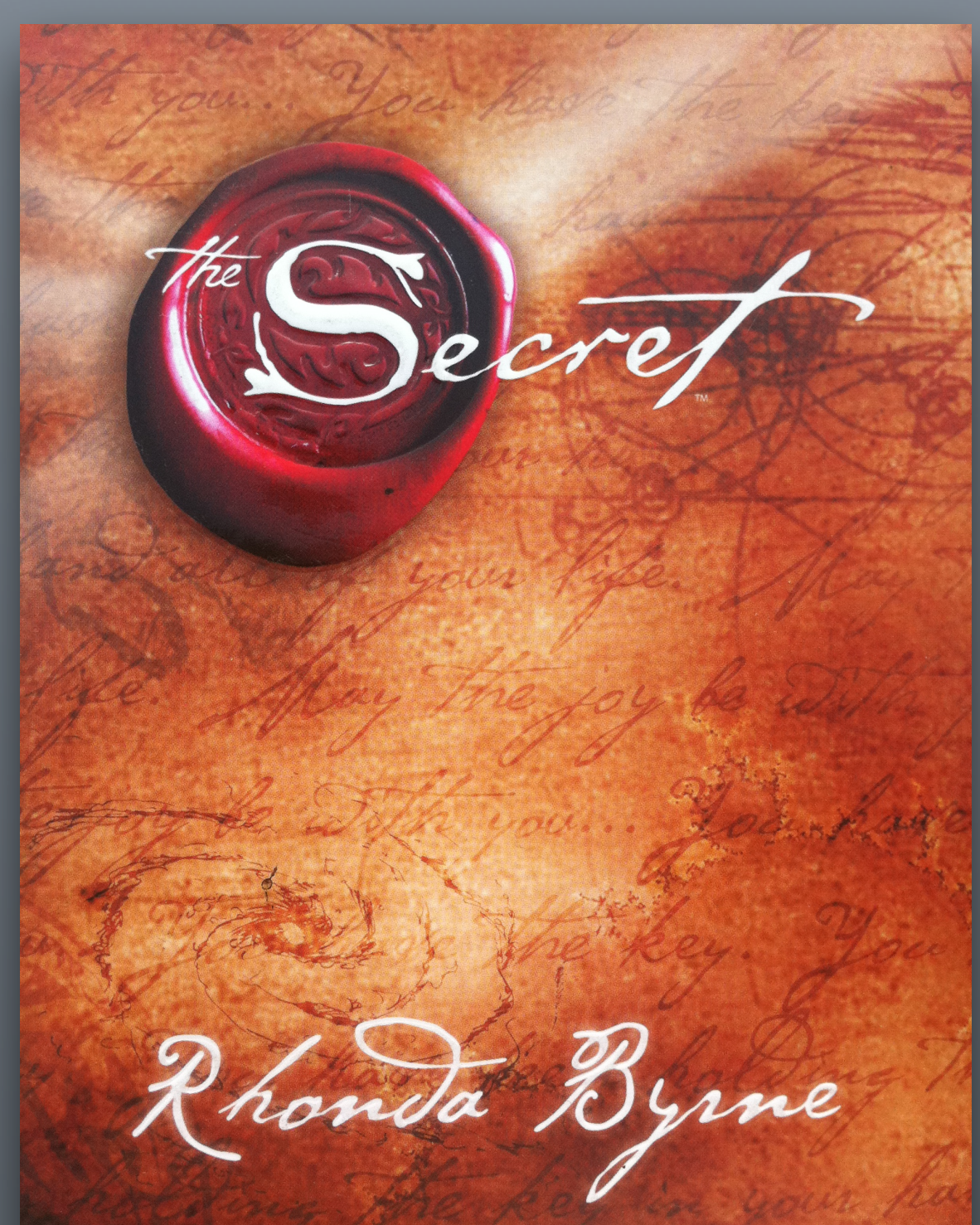




\section{Positive Thinking Does Have Benefits}

- Optimists are more likely to be hired than pessimists

- Optimists are more likely to get promoted than pessimists

- Optimists are recover from surgery and illnesses faster than pessimists

- Optimists are more likely to take direct action than pessimists

- Optimistic college students do better than pessimistic college students 


\section{But Positive Thinking Has Limits}

\section{It is ineffiective in leading positive change.}

Rethinking Positive

\section{Thinking}

INSIDE THE NEW SCIENCE

OF MOTIVATION

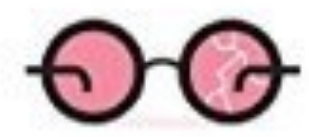

Gabriele Oettingen
"Positive fantasies, wishes, and dreams detached from an assessment of past experience didn't translate into motivation to act toward a more energized, engaged life. It translated into the opposite."

page 11 


\section{But Positive Thinking Has Limits}

\section{It is ineffective in leading positive change.}

Rethinking Positive Thinking

INSIDE THE NEW SCIENCE

OF MOTIVATION

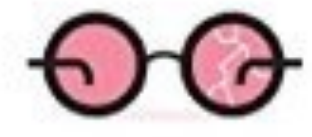

Gabriele Oettingen
Repeatedly in experiments that were conducted "positive thinking wasn't always helpful. Yes, sometimes it did help, but when it came in the form of a free-flowing dream - as so much positive thinking does

-it impeded people in the long term from moving ahead." 


\section{But Positive Thinking Has Limits}

\section{It is ineffective in leading positive change.}

Rethinking Positive Thinking

INSIDE THE NEW SCIENCE

OF MOTIVATION

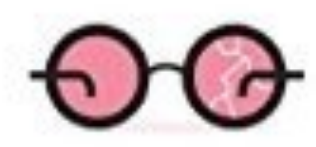

Gabriele Oettingen

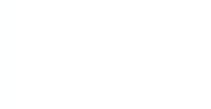

Positive thinking without an assessment of past experience usually doesn't improve anything. 


\section{Positive Thinking lsn't Positive Leadership}

"A book that every academic leader should read and put into practice." KIM CAMERON, associate dean of executive education. Ross School of Business, University of Michigan

Positive

Academic Leadership

How to STOP Putting Out Fires

and Start MAKING A DIFFERENCE

Jeffrey L. Buller
- Seeking positive results even in negative situations.

- Adopting positive defoult: assuming that people's motives are good unless proven otherwise.

- Preferring rewards to punishments. 


\section{So, If Positive Thinking Doesn't Work, What Does?}

Rethinking

\section{Positive}

Thinking

INSIDE THE NEW SCIENCE

OF MOTIVATION

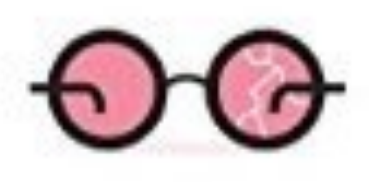

Gabriele Oettingen
"A book that every academic leader should read and put into practice." -KIM CAMERON, associate dean of executive education Ross School of Business. University of Michigan

\section{Positive}

Academic

Leadership

How to STOP Putting Out Fires

and Start MAKING A DIFFERENCE

Jeffrey L. Buller 


\section{Gabrielle Oettingen}

\section{from Rethinking Positive Thinking}

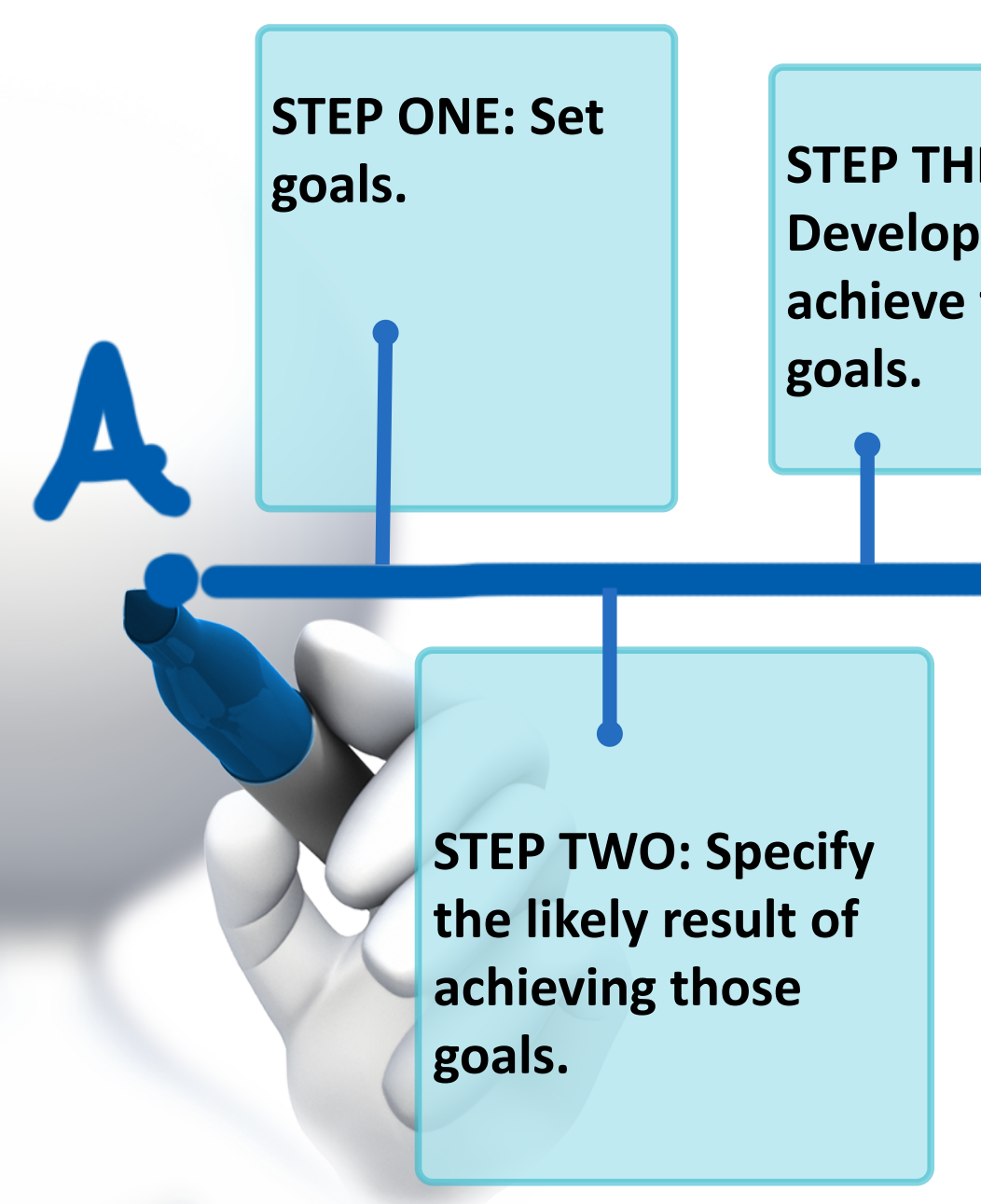

STEP FIVE: Develop a plan to overcome the potential obstacles identified in STEP FOUR. achieve those goals.
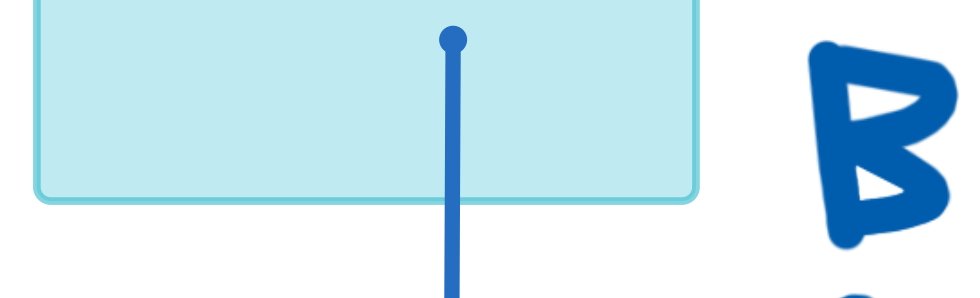

STEP FOUR: Identify the likely obstacles that may prevent you from achieving those
STEP SIX: Revise STEP THREE to include STEP FIVE. 


\section{Assumption \#2}

A large, complex problen is best

solved with a large complex soluntion.
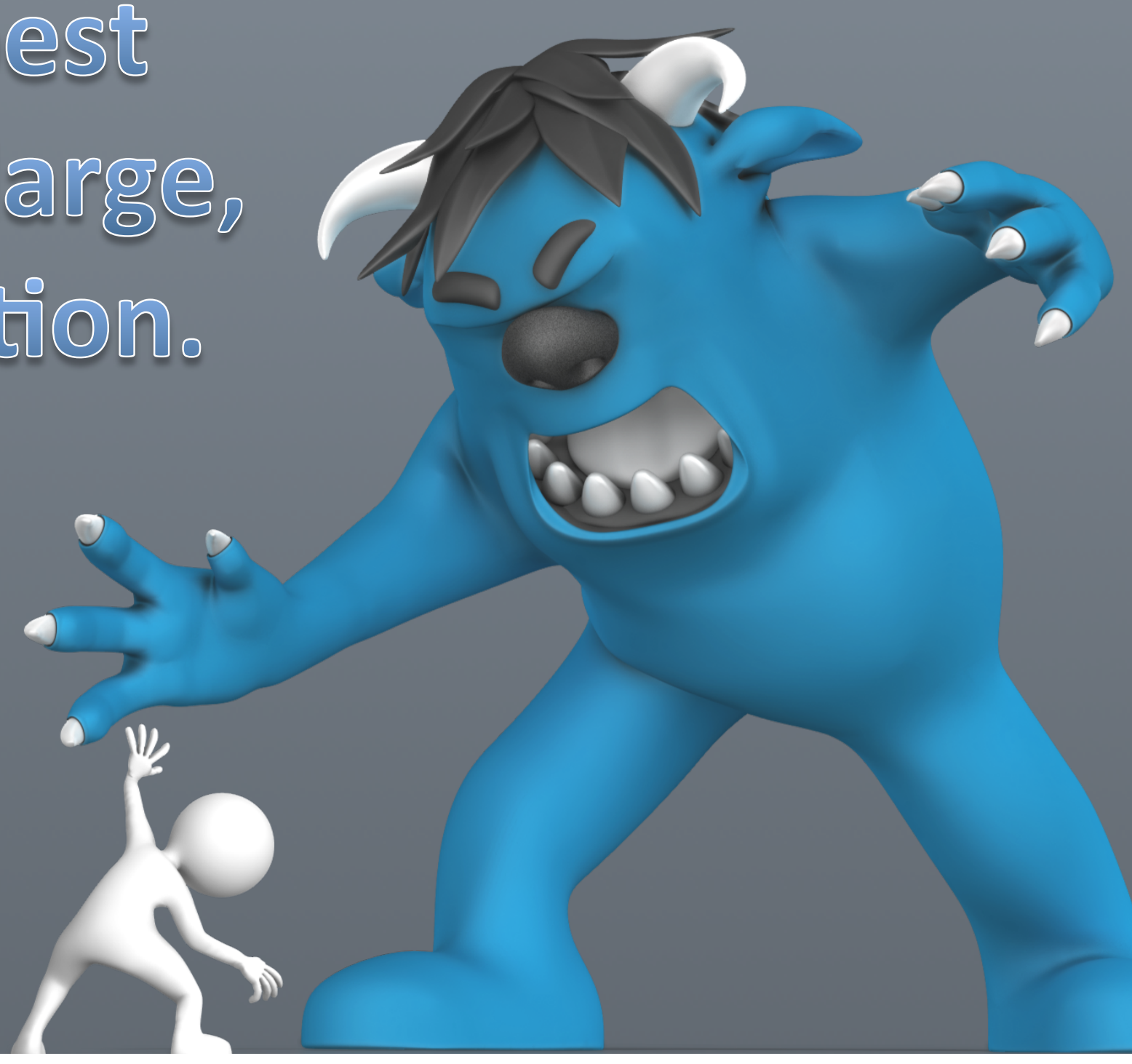


\section{Bacterial Infections}

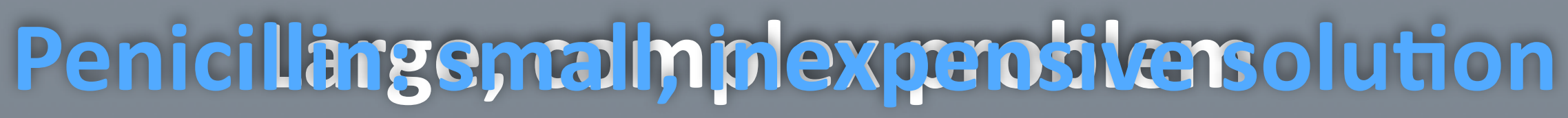




\section{The Muffin Conundrum}

- One morning, a faculty member's child gets his finger trapped in the hole of a muffin pan; it swells badly.

No one else is in the house.

No neighbors can be found.

Urgent Care is too far away. 


\section{The Muffin Conundrum}

- A hospital Emergency Room would take too long and be quite expensive.

The child needs to get to school.

- The faculty member needs to get to class.

- How can she solve this medical problem? 


\section{The Muffin Gonundrum}

- She decides that it can also be seen as a HARDWARE PROBLEM.

- They go to Home Depot where there are a lot of tools (maybe more than the emergency room).

- Staff in the tools department quickly and safely cut away the muffin pan.

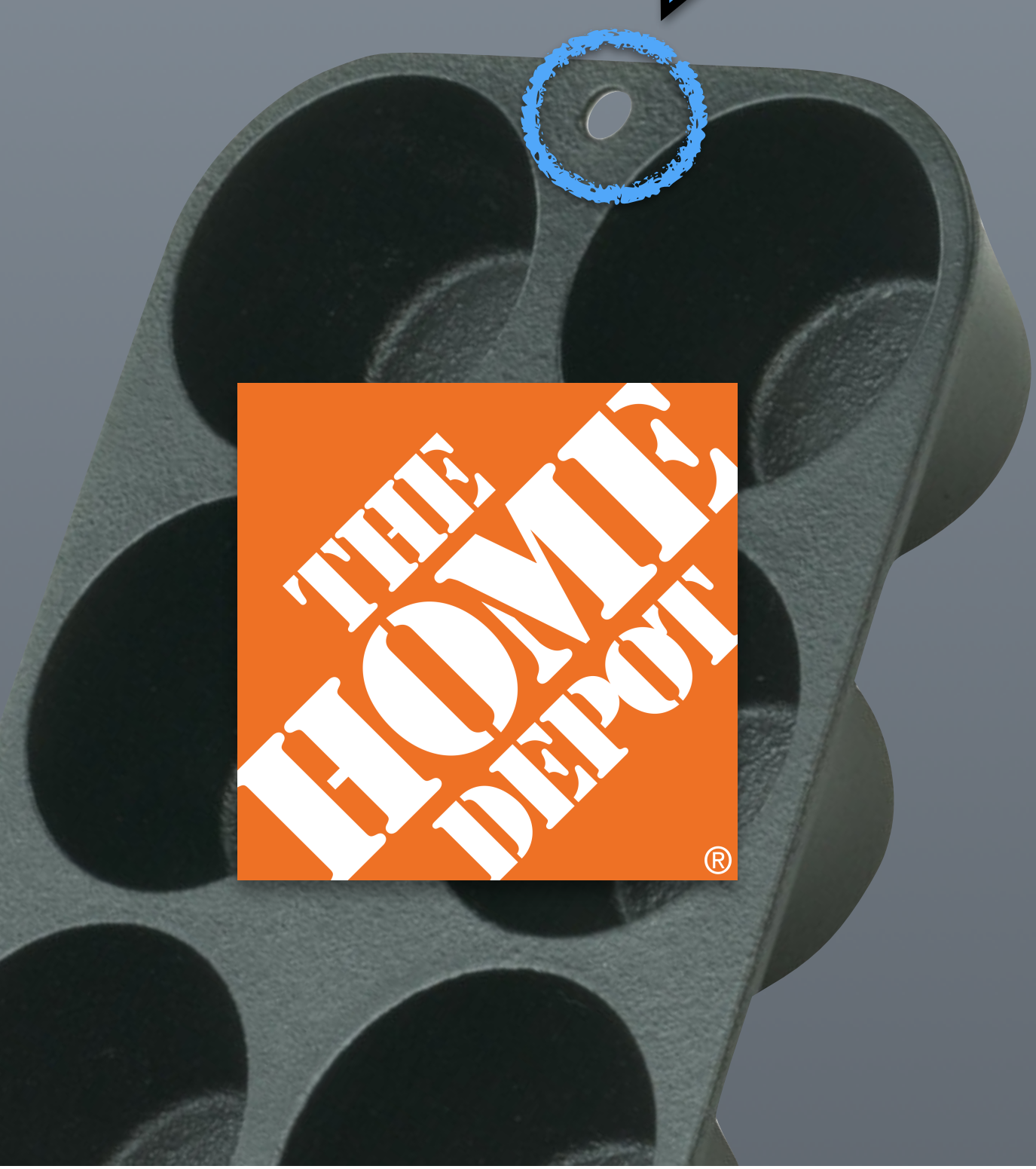




\section{The Muffin Gonundrum}

The child makes it to school on time.

- The faculty member makes it to class on time.

The cost: \$0.

- The complex problem was solved by a simple, direct solution.

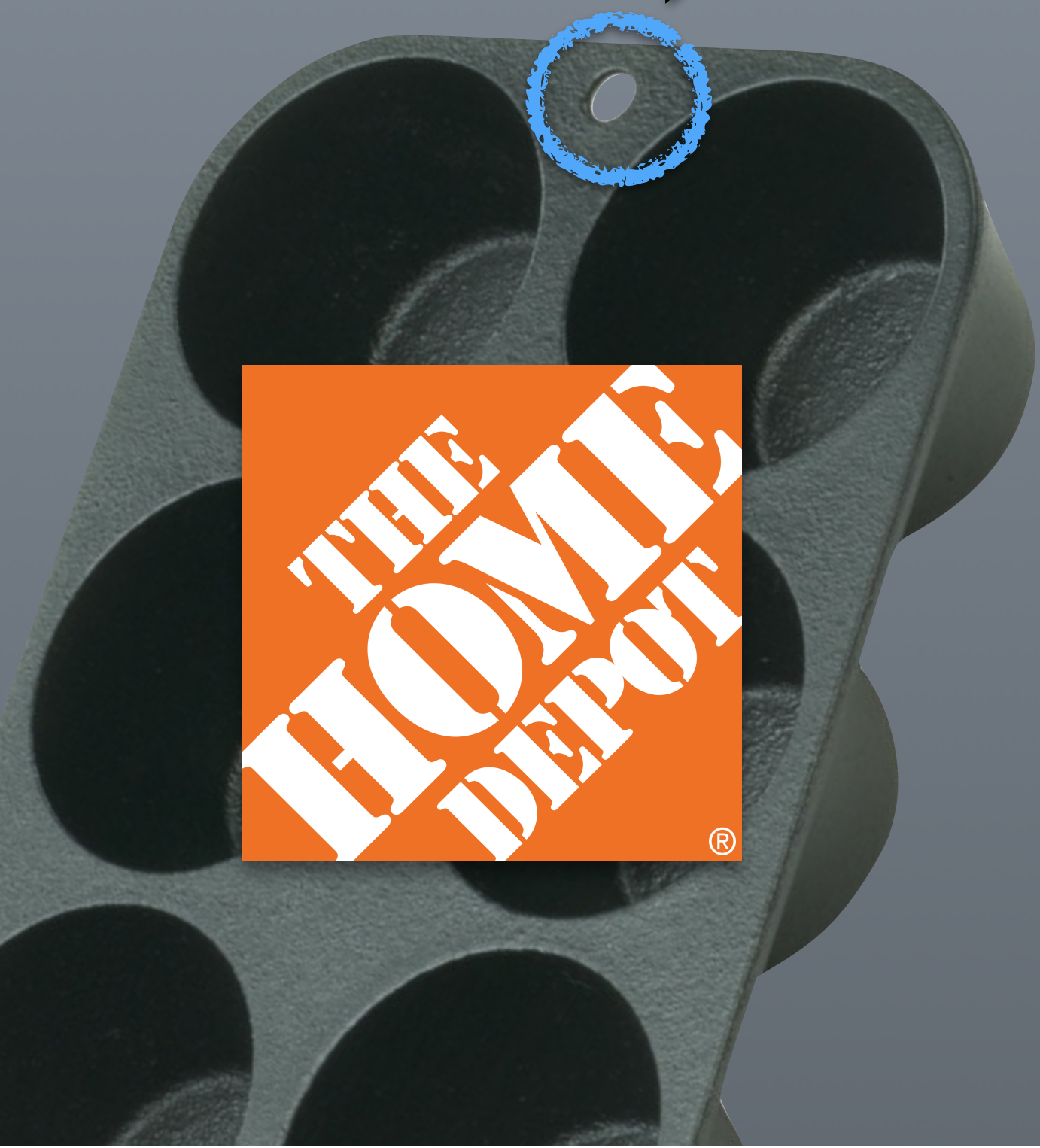




\section{The International Space Station}

- Power distributor broke down

- Metal shavings had built up, making it impossible to remove bolts

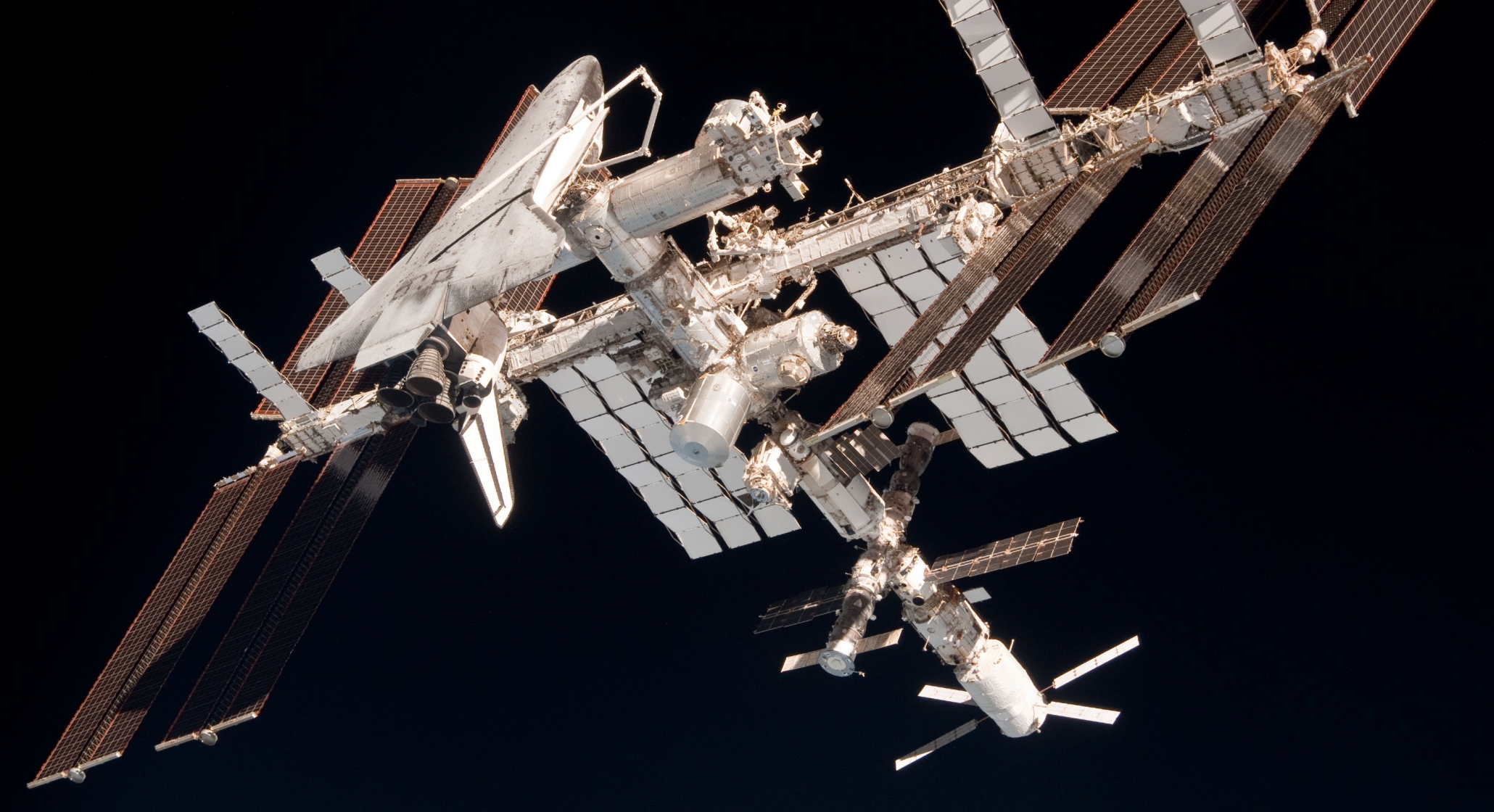




\section{The International Space Station}

- No tool small and firm enough to wipe away metal shavings

- Sending tool up on next resupply mission: too long

- Solution?
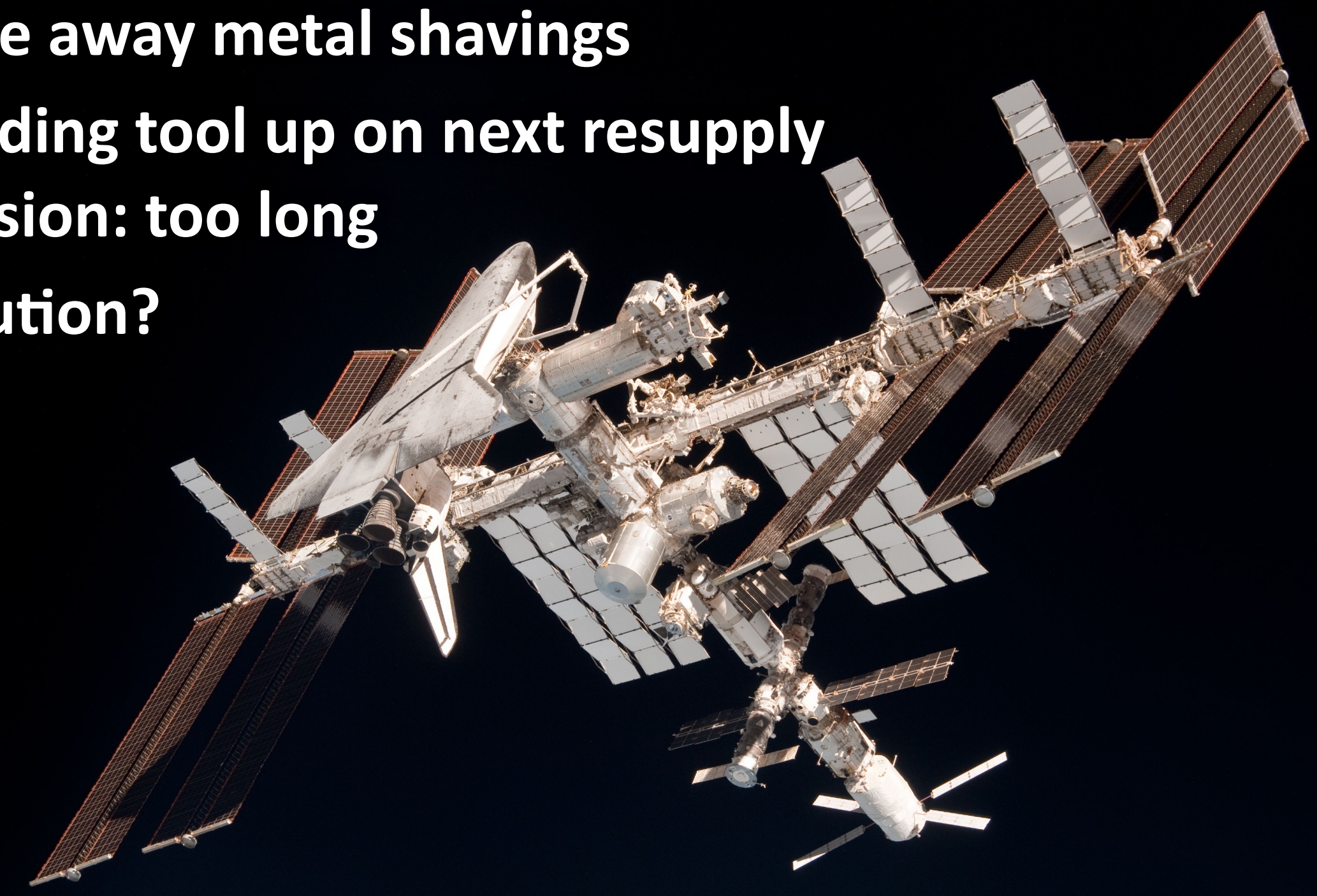


\section{The International Space Station}

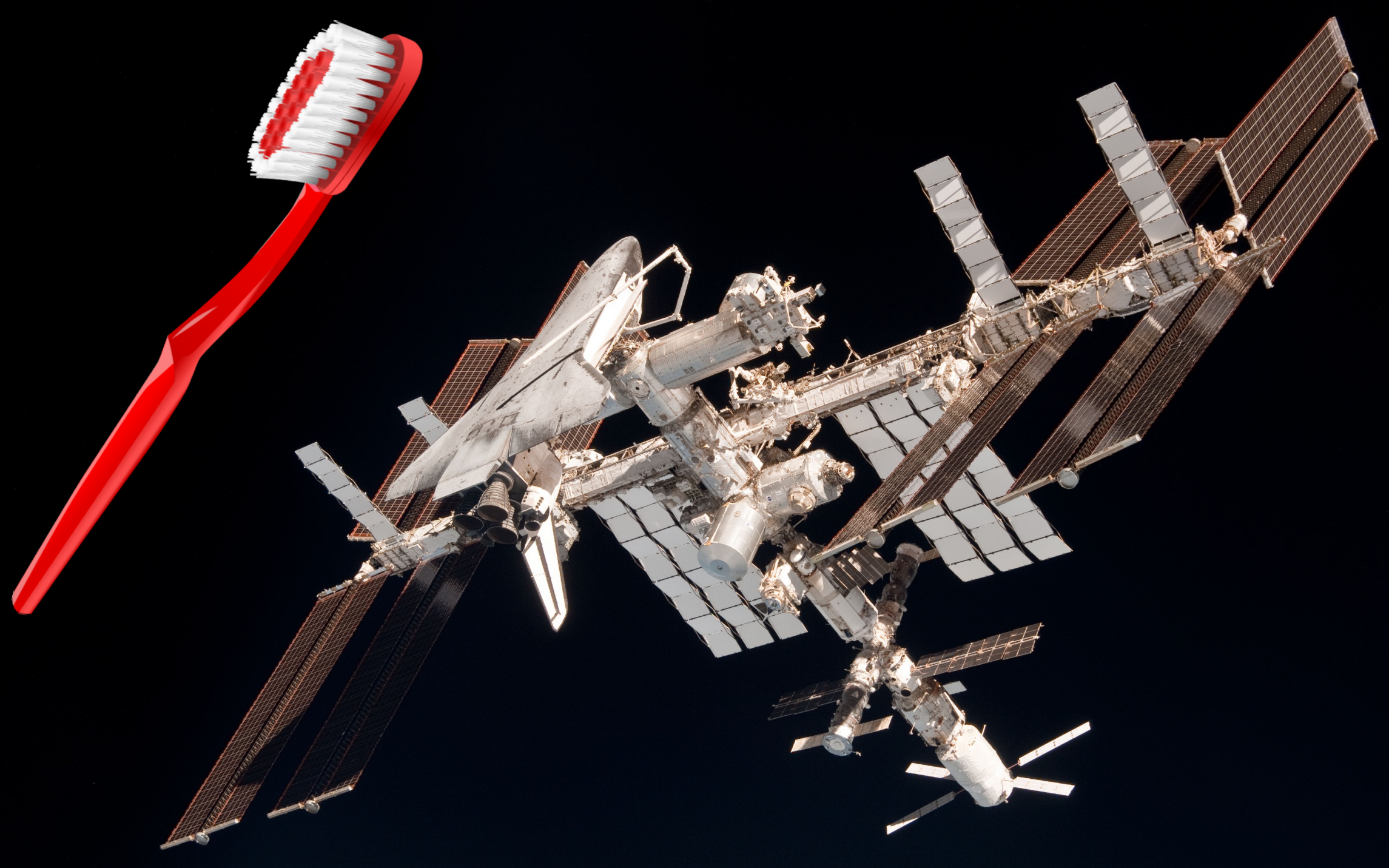




\section{Small Solutions}

\section{Shrink the Change}

- less obtrusive

- evokes less change aversion

- change becomes evolution, growth, natural development

- can be more cost effective

- requires creativity, innovation

- less overwhelming

\section{SWITCH (1)}

HOW TO CHANGE THINGS

WHEN CHANGE IS HARD

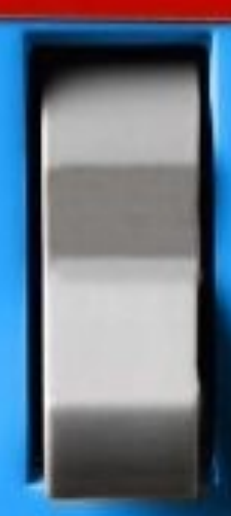

CHIP HEATH \& DAN HEATH THE BESTSELLING AUTHORS OF MADE TO STICK 


\section{Small Solutions}

\section{Shrink the Change}

- give up smoking for one week

- AA: one day at a time

- not "Top Ten Research Universities in the World" but "bring in additional $\$ 100,000$ in indirect costs that can support improving classrooms"

- circumvent red tape

\section{SWITCH (1)}

HOW TO CHANGE THINGS

WHEN CHANGE IS HARD

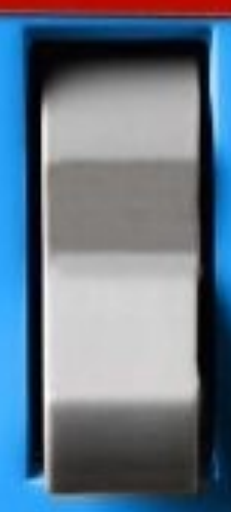

CHIP HEATH \& DAN HEATH MADE TO STICK 


\section{Small Solutions}

\section{Start the Trio Halfway There}

- silent phase of capital campaign: Who wants to give the first $\$ 100$ of a billion dollar campaign?

- car wash free after: a. 8 punches b. 10 punches but 2 free head start

- What would it take to get to the next step?

\section{SWITCH (1)}

HOW TO CHANGE THINGS

WHEN CHANGE IS HARD

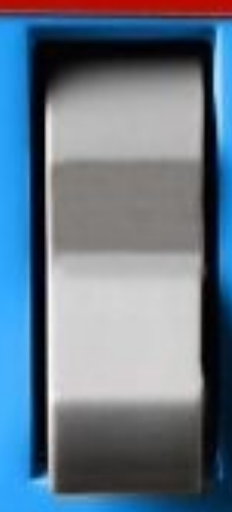

CHIP HEATH \& DAN HEATH MADE TO STICK 


\section{Assumption \#3}

Change leaders

may best be

un@ersto@@ as

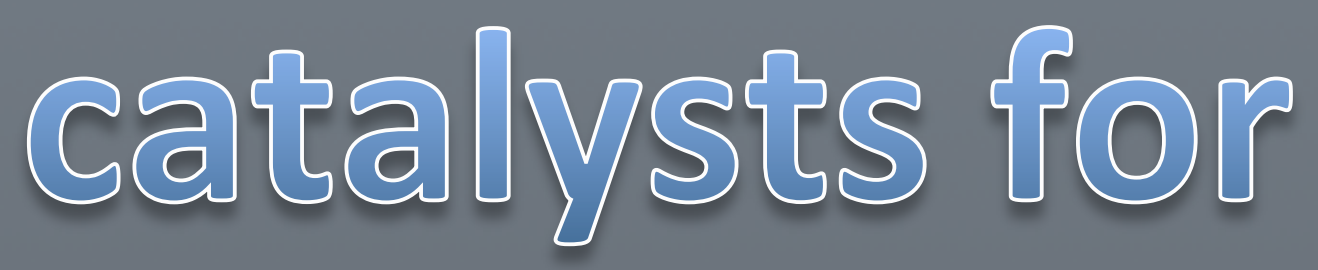

$$
\begin{aligned}
& \text { change. }
\end{aligned}
$$




\section{What Is a Catalyst?}

a substance that increases the rate of a chemical reaction without itself undergoing any permanent chemical change itself
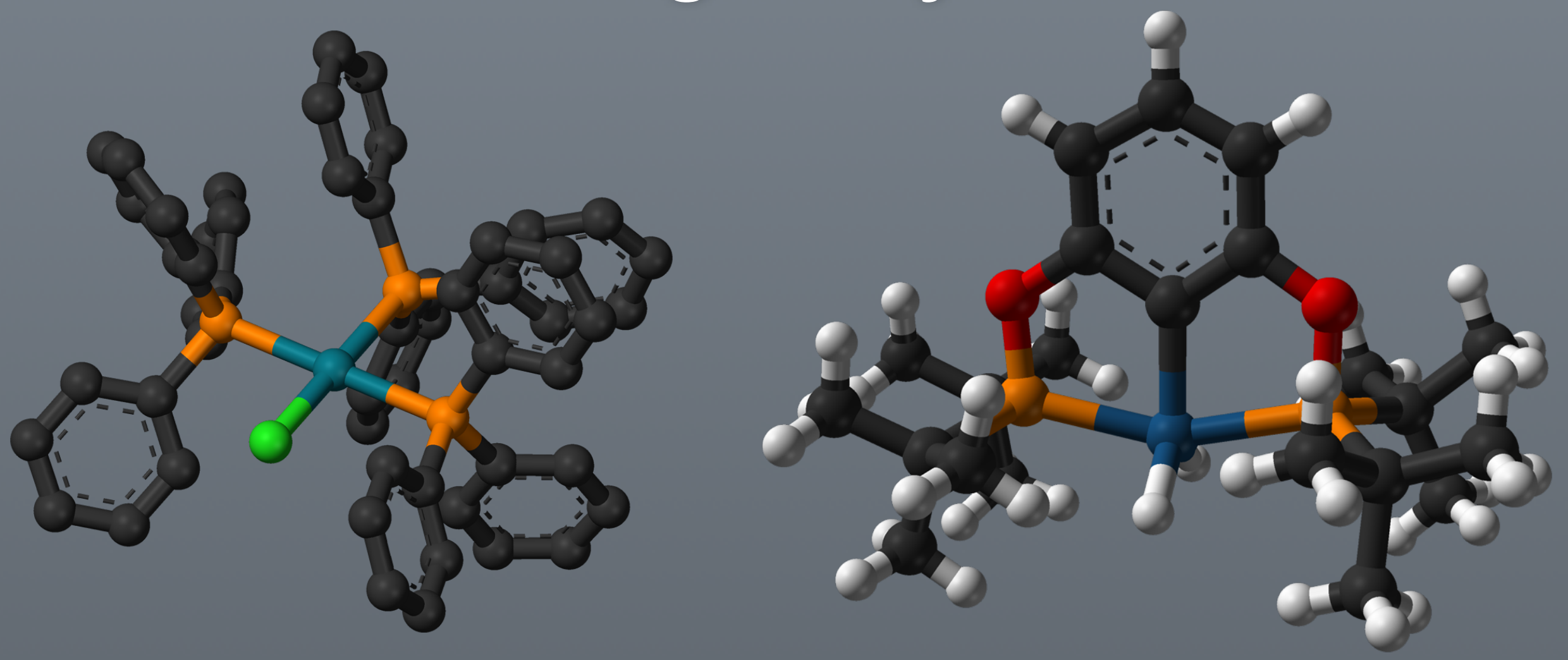


\section{What Is a Catalyst?}

a substance that increases the rate of a chemical reaction without itself undergoing any permanent chemical change itself
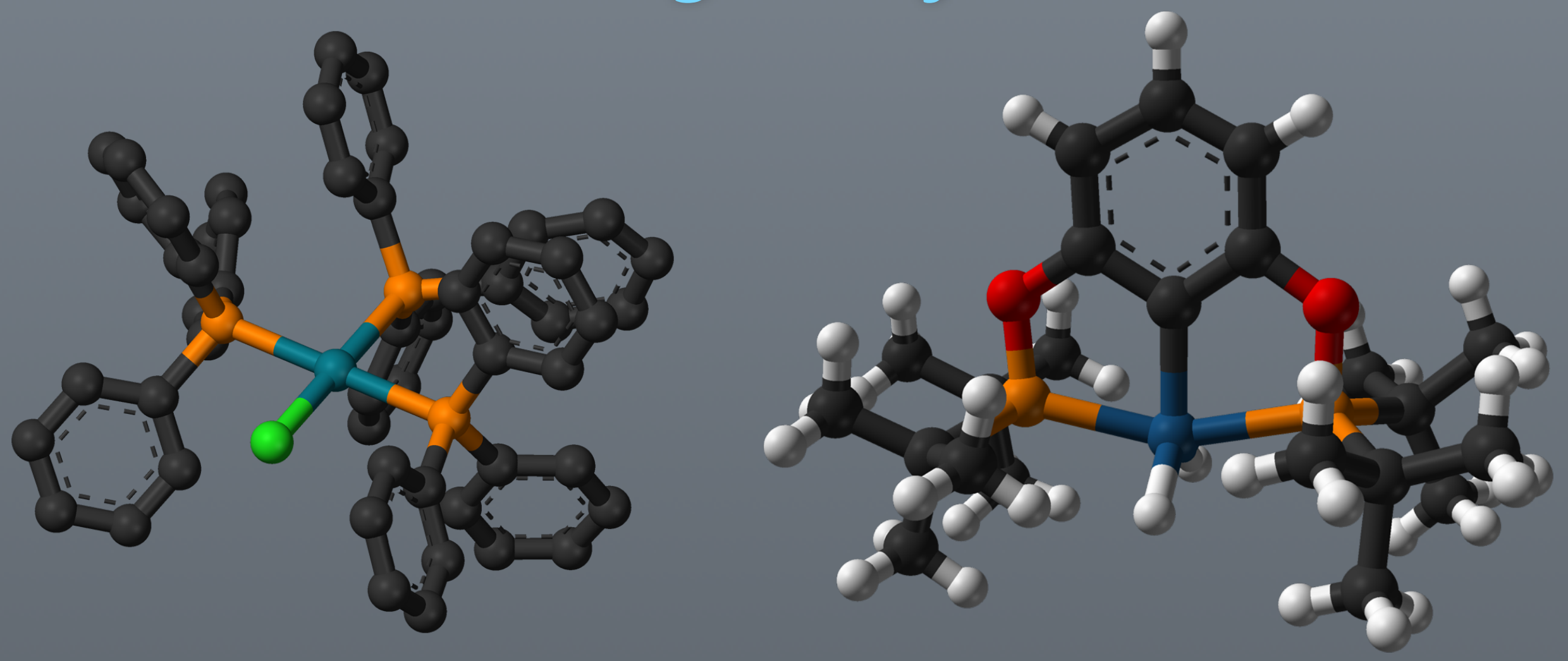


\section{The Reality}

You cannot produce

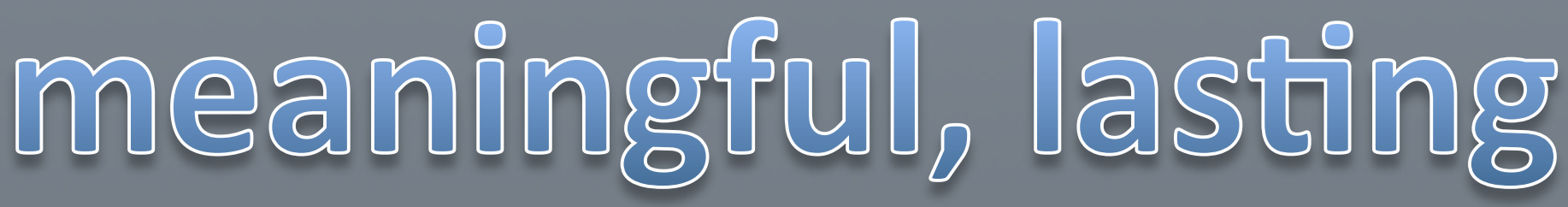

change withion a system without being change@ yourselis。 


\section{The Reality}

$$
\begin{gathered}
\text { There's no such thing as } \\
\text { a "change agento }
\end{gathered}
$$

What you actually are is

a "change reagent": a

component of the same reaction you are

$$
\text { producing. }
$$




\section{When You Change a System ...}

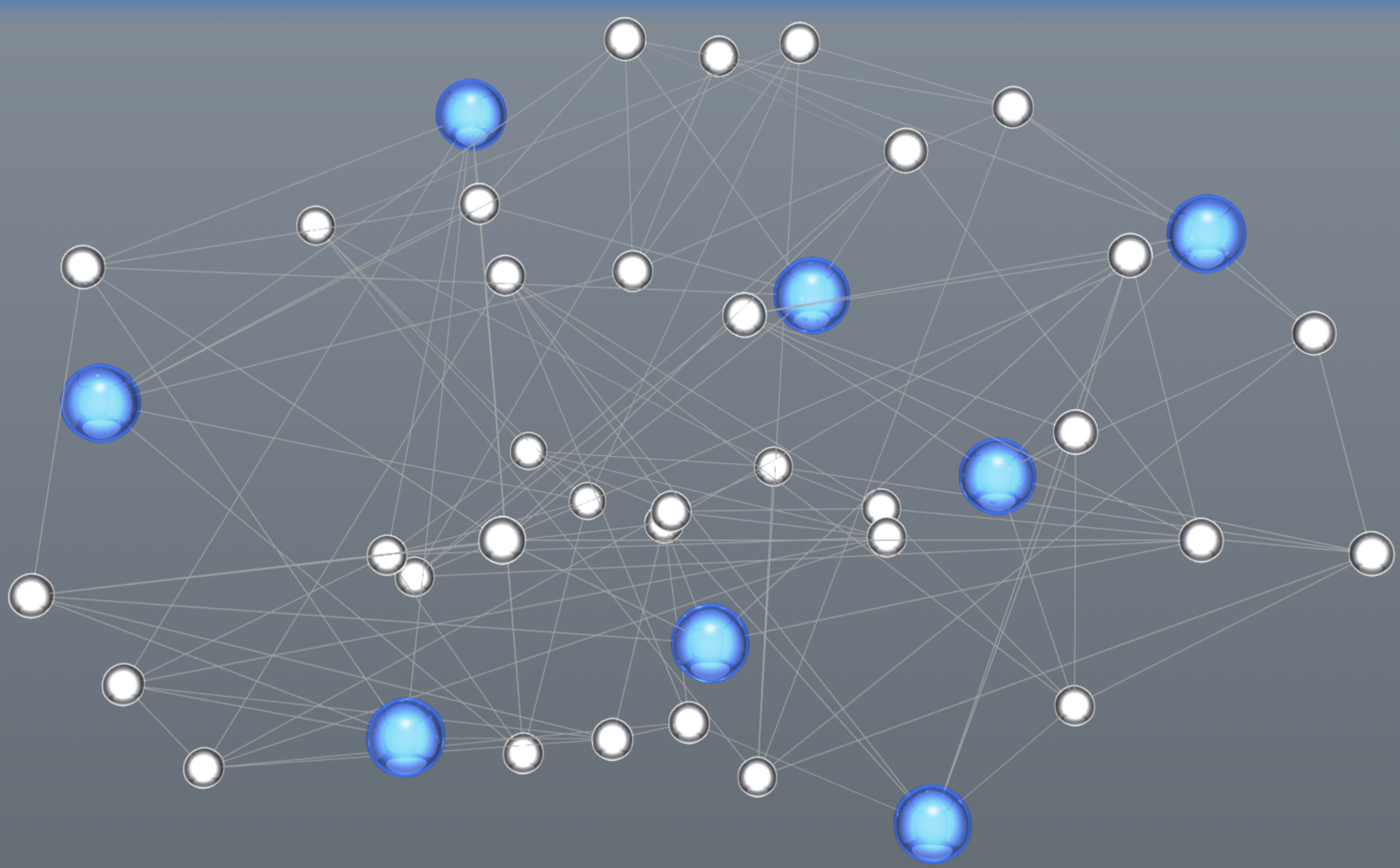




\section{... You're Part of That System}

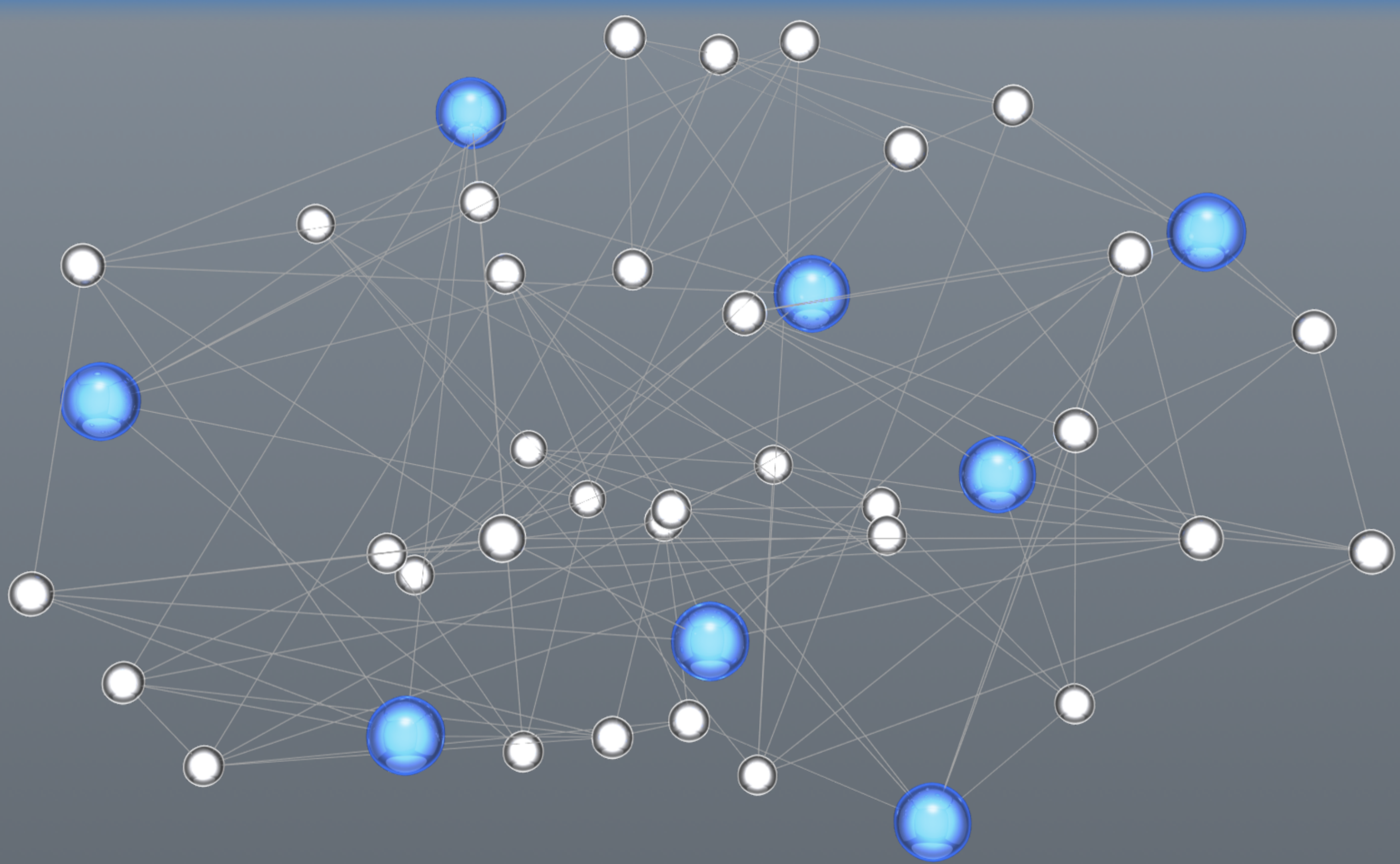




\section{And You'll End Up Being Changed}

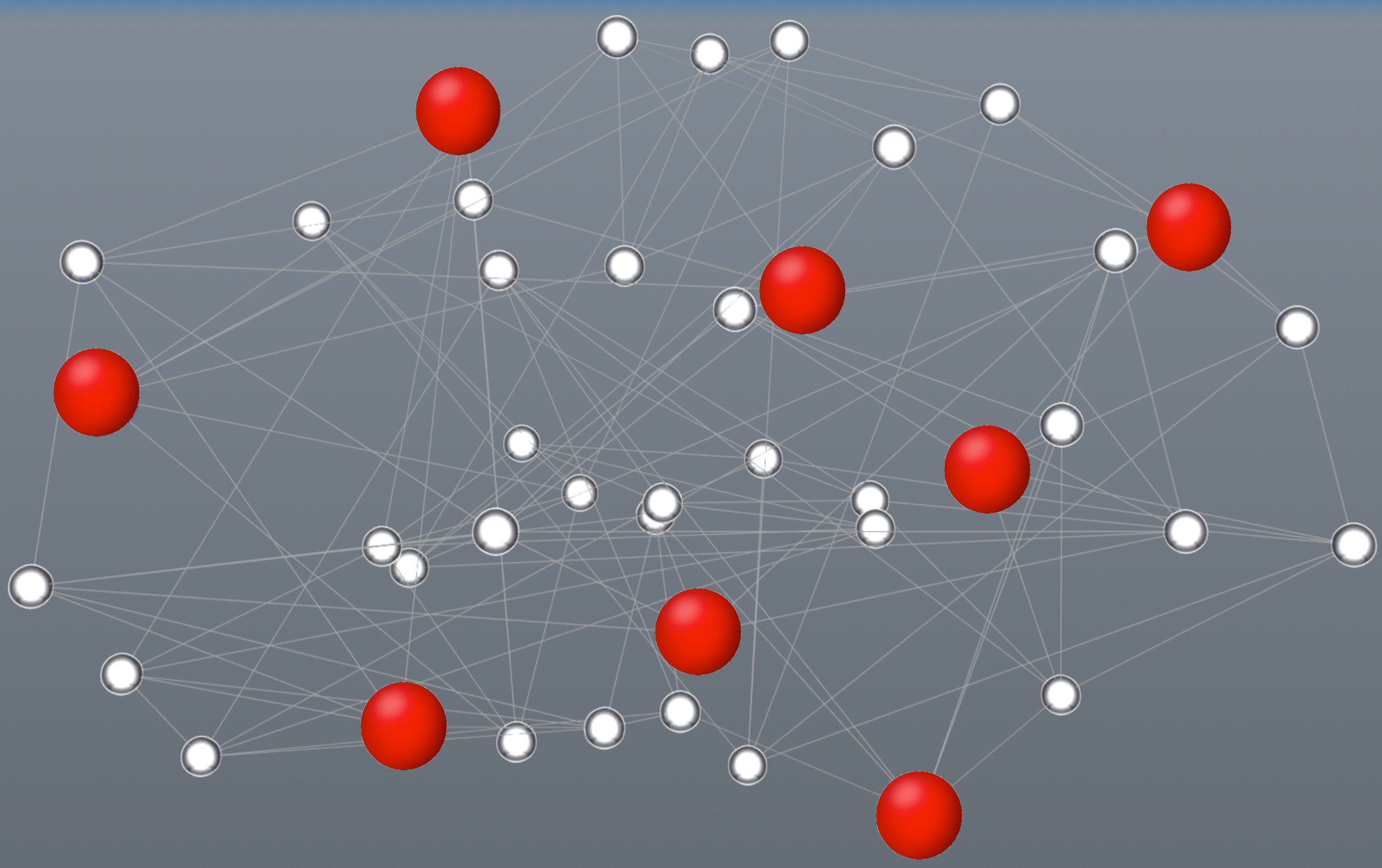




\section{Assumption \#4}

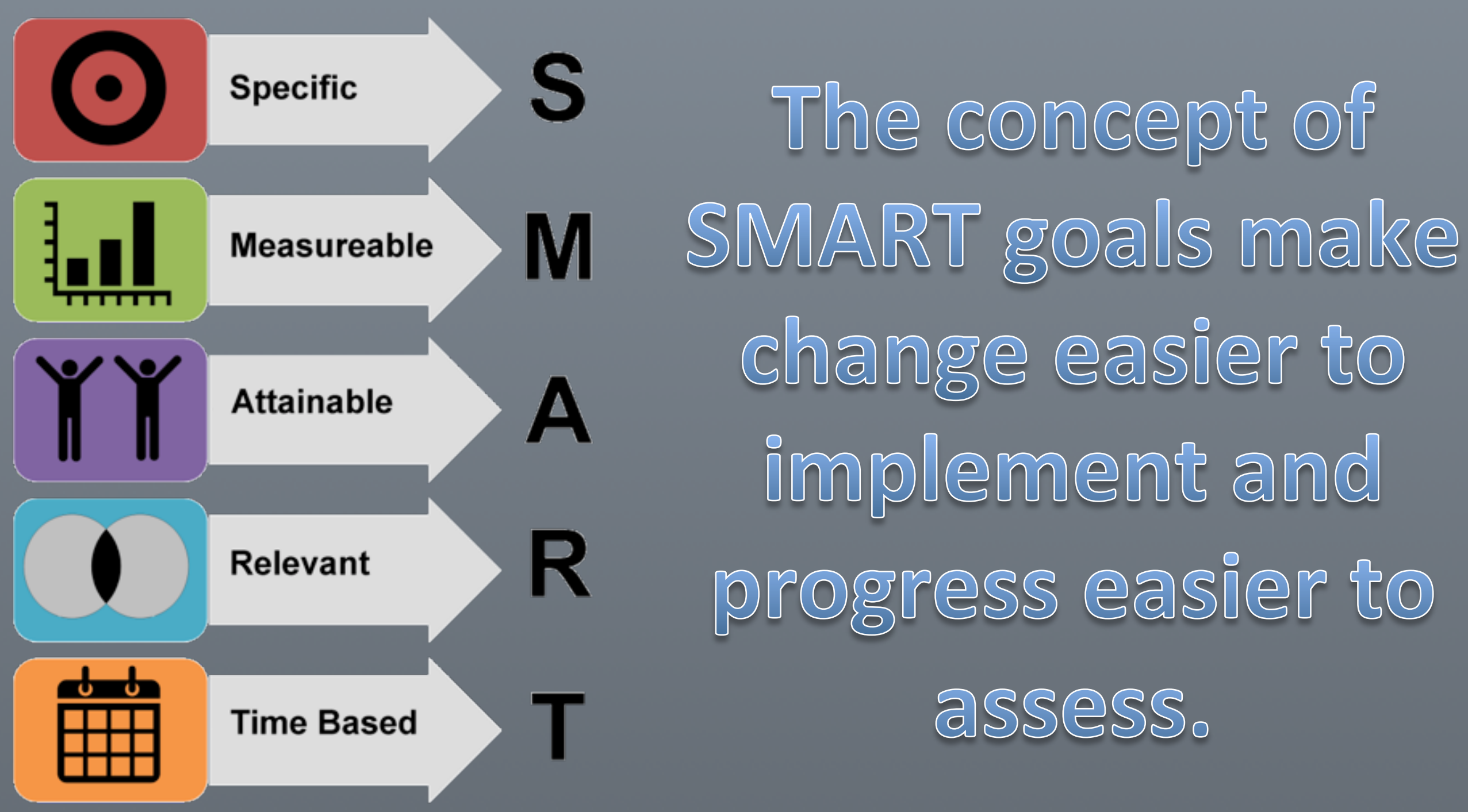




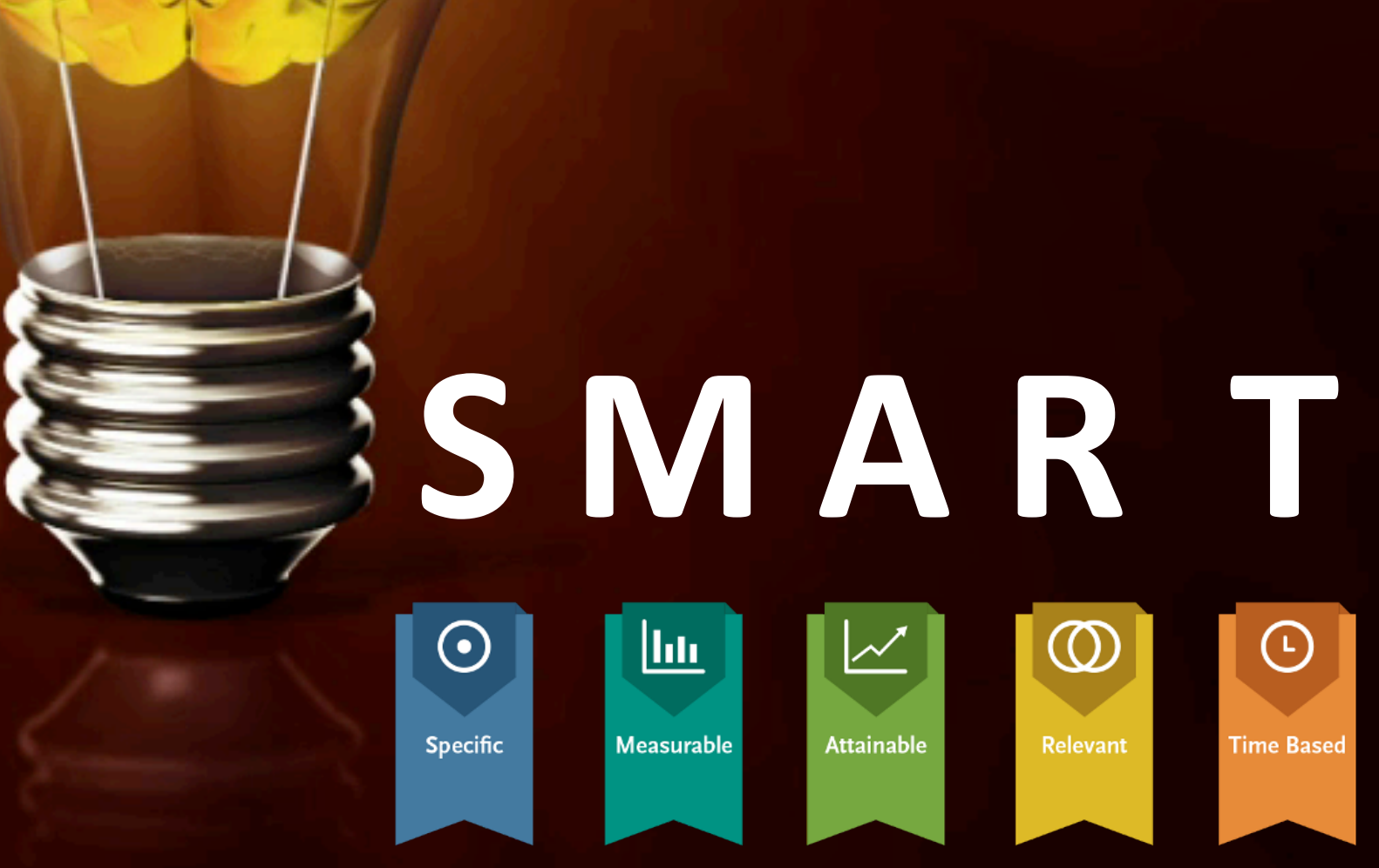




\section{The Problem with Smart Goals}

"The specificity of SMART goals is a great cure for the worst sins of goal setting - ambiguity and irrelevance ('We are going to delight our customers every day in every way!'). But SMART goals are better for steady-state situations than for change situations, because the assumptions underlying them are that the goals are worthwhile."

\section{SWITCH a}

HOW TO CHANGE THINGS

WHEN CHANGE IS HARD

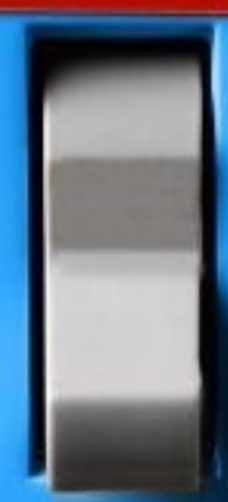

CHIP HEATH \& DAN HEATH THE BESTSELLING AUTHORS OF MADE TO STICK 


\section{The Problem with Smart Goals}

"The specificity of SMART goals is a great cure for the worst sins of goal setting - ambiguity and irrelevance ('We are going to delight our customers every day in every way!'). But SMART goals are better for steady-state situations than for change situations, because the assumptions underlying them are that the goals are worthwhile."

\section{SWITCH d}

HOW TO CHANGE THINGS

WHEN CHANGE IS HARD

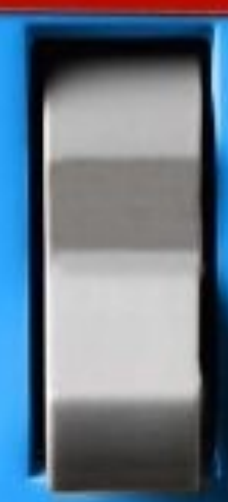

CHIP HEATH \& DAN HEATH THE BESTSELLING AUTHORS OF MADE TO STICK 


\section{The Problem with Smart Goals}

"SMART goals presume the emotion; they don't generate it. ... There are some people whose hearts are set aflutter by goals such as 'improving the liquidity ratio by 30 percent over the next 18 months.' They're called accountants."

-page 82

\section{SWITCH d.}

HOW TO CHANGE THINGS

WHEN CHANGE IS HARD

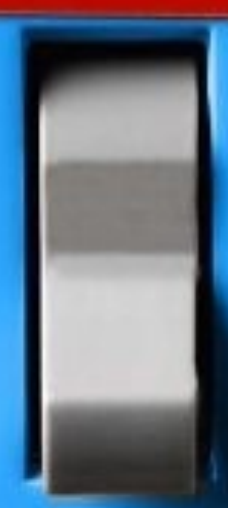

CHIP HEATH \& DAN HEATH MADE TO STICK 


\section{The Problem with Smart Goals}

SMART goals engage the rider.
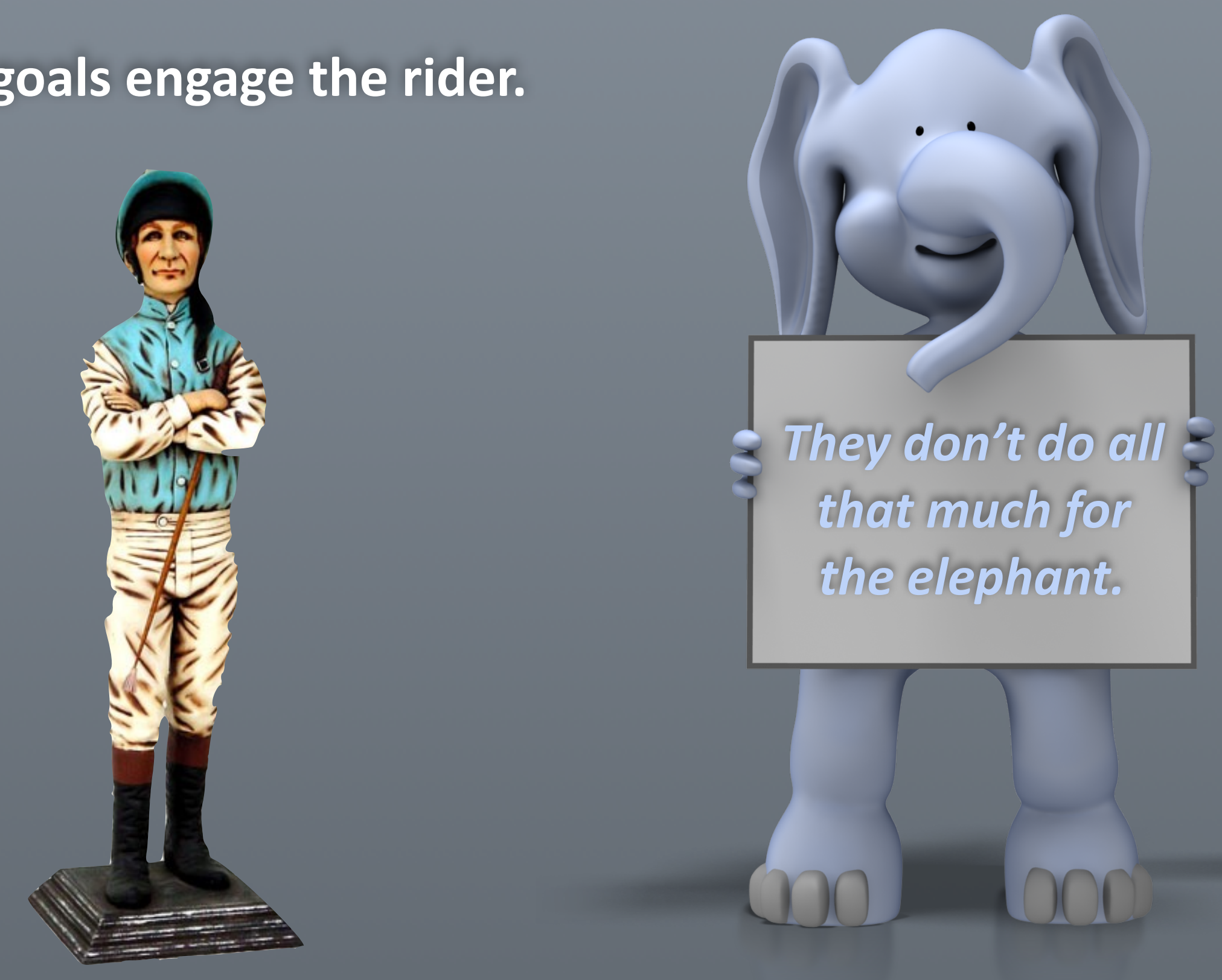


\section{Elephants Are Excited by the Vision}

- Riders need to know the SMART next step

- As well as the ultimate destination

- Effective change leadership involves engaging both our rational and emotional sides simultaneously 


\section{Long-Term Dream and Short-Term Practicality}

EMOTIONAL $\rightarrow$ : : : $:$ :

"Oh, I hope we're going somewhere fun! 


\section{Assumption \#5}

$$
\begin{aligned}
& \text { th vou get the } \\
& \text { sociology right } \\
& \text { the psyshology } \\
& \text { iollows. }
\end{aligned}
$$




\section{Assumption \#5}

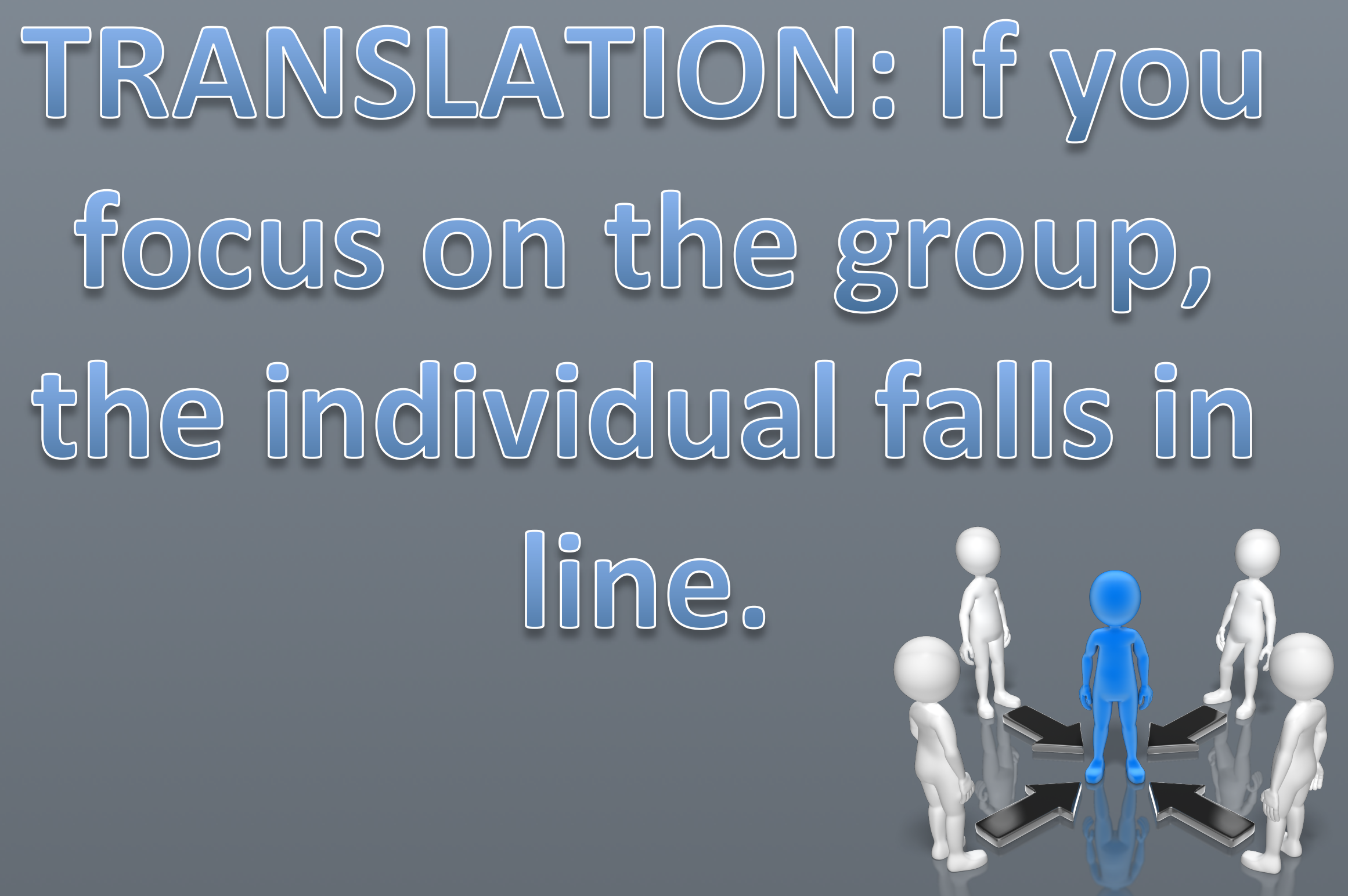




\section{Groups Are Made of Individuals}

- Change leadership often requires a lot of one-on-one conversations

- It is like coaching: motivating individuals to achieve a team result

- Effective change leadership requires understanding that not everyone shares the same philosophy of change

- It adheres to a philosophy that the psychology and sociology of change are both equally important

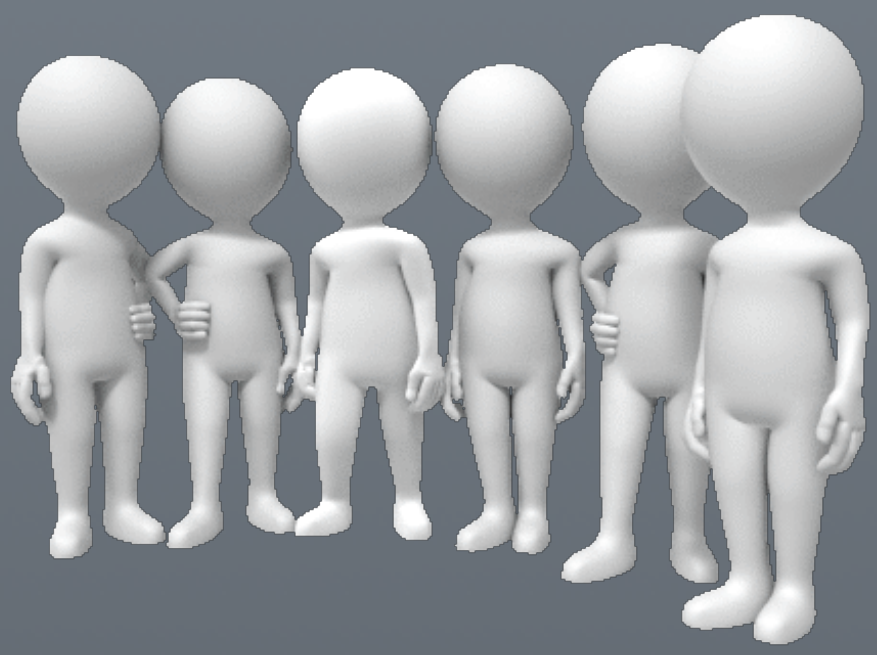




\section{Exercise \#7}

- Look back at the three changes you identified on page one.

- See if you made any of the five common assumptions about them.

If you did, how does re-evaluating that assumption help you with the change?

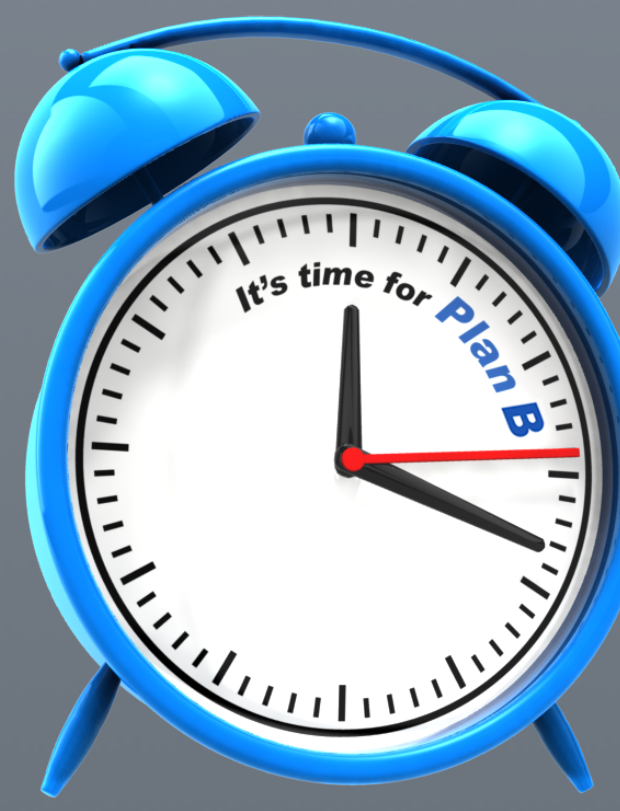

- If not, what's one thing you can do next week to make progress on each change? 


\section{Exercise \#7}

We'll take five minutes for this exercise. 


\section{Summing Up}

- Change is often difficult because we don't perceive the extent to which different people view change differently

- Change is often difficult when we don't understand the unique culture in which the change occurs

- Change becomes even more difficult when we approach it with false assumptions

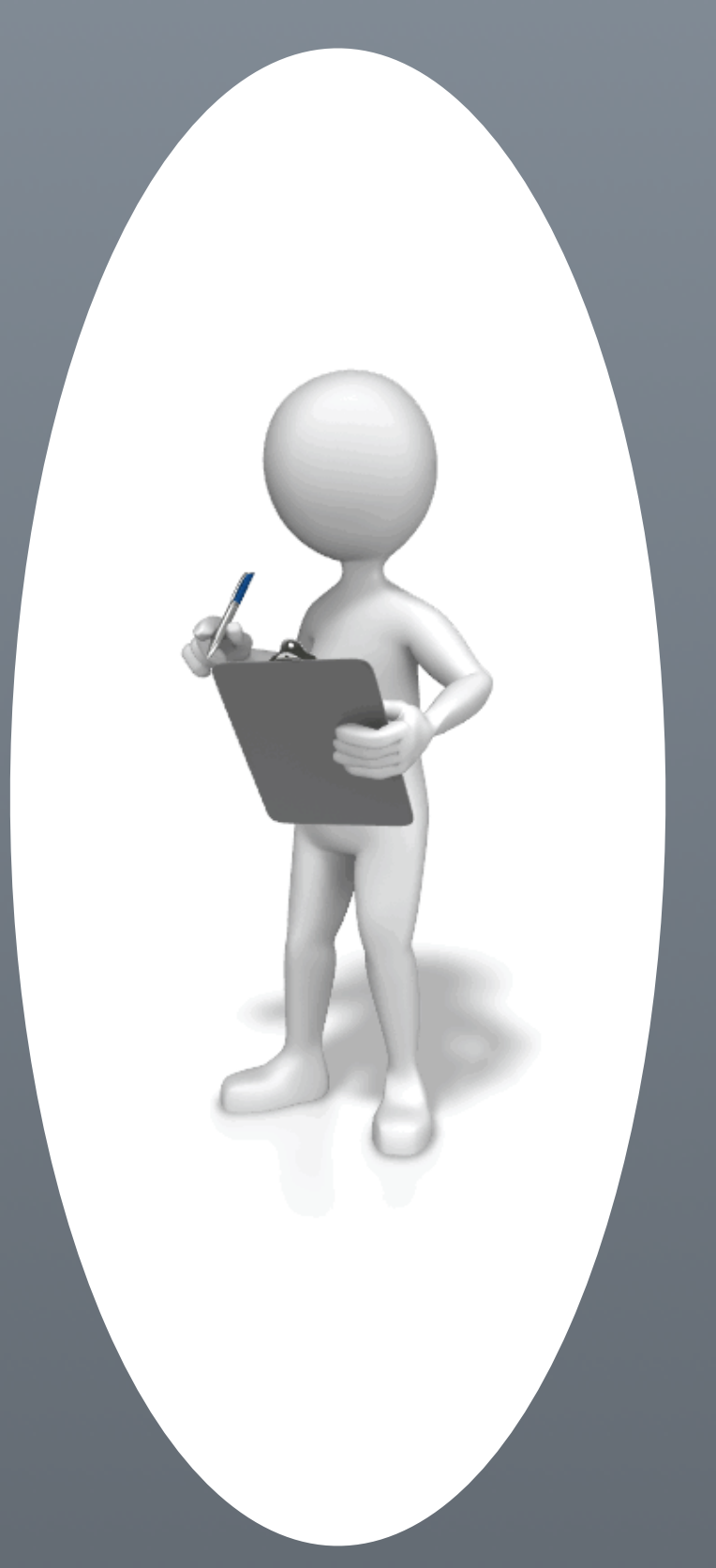




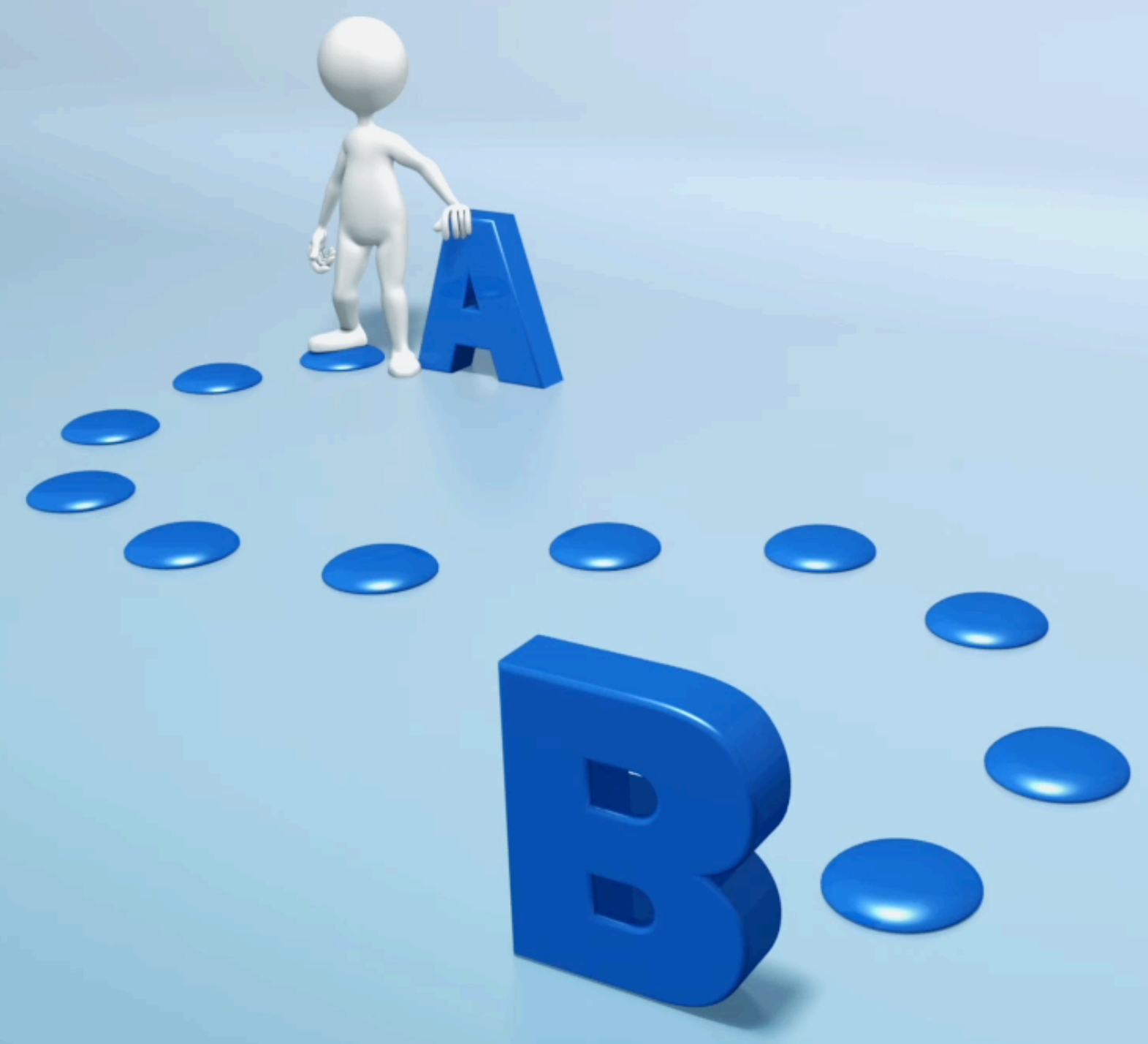

Change Leadership in Higher Education A Workshop for Academic Leaders 


\section{Questions? Comments?}
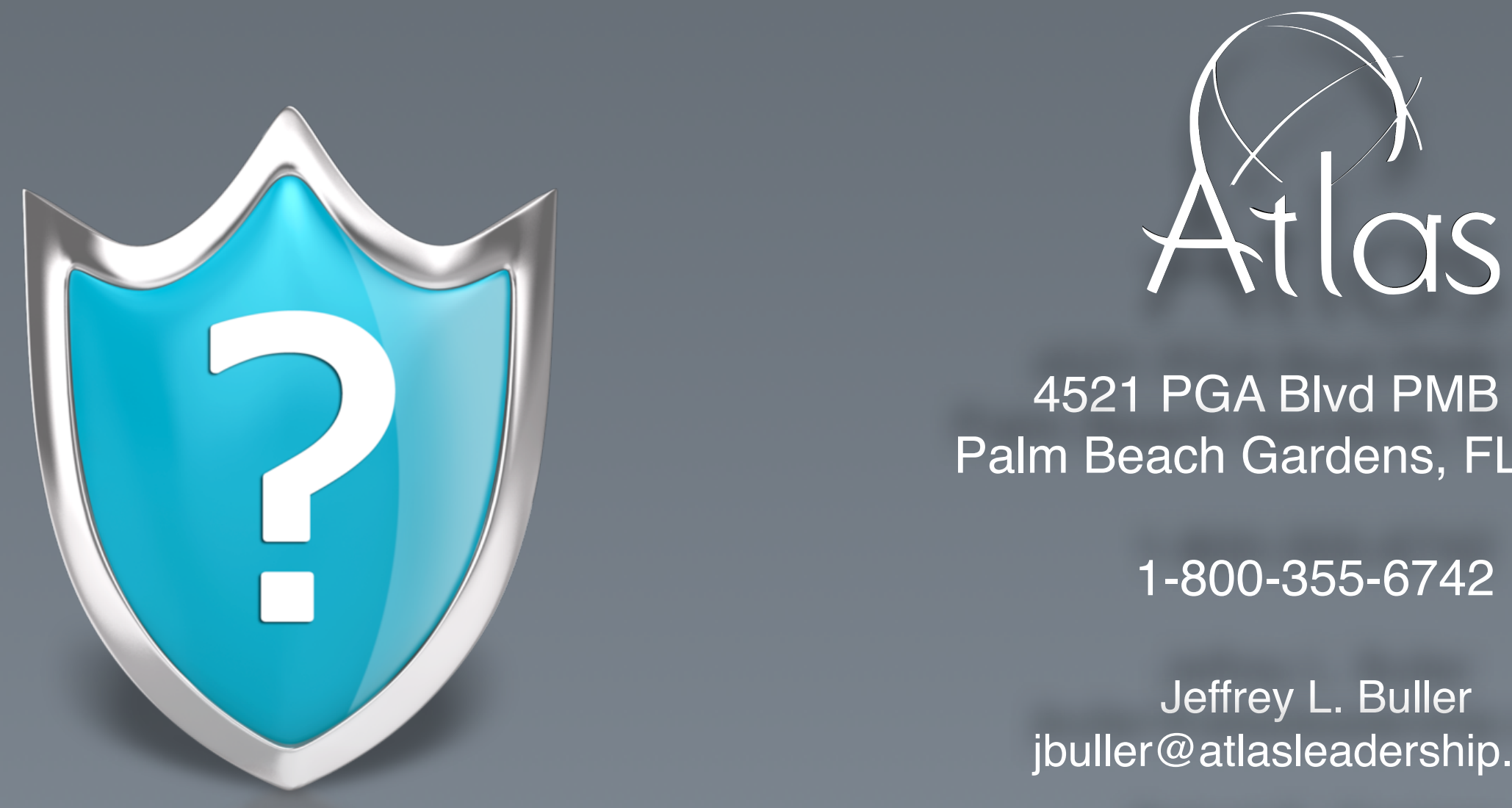

4521 PGA Blvd PMB 186 Palm Beach Gardens, FL 33418

1-800-355-6742

Jeffrey L. Buller

jbuller@atlasleadership.com

Robert E. Cipriano

rcipriano@atlasleadership.com

www.atlasleadership.com

questions@atlasleadership.com sales@atlasleadership.com 